Universidade de São Paulo

Escola Superior de Agricultura "Luiz de Queiroz"

\title{
A influência da paisagem na provisão do serviço de polinização por insetos no girassol
}

\author{
Carina Aparecida de Souza Silva
}

Tese apresentada para obtenção do título de Doutora em Ciências. Áreas de concentração: Entomologia

Piracicaba

2019 
Carina Aparecida de Souza Silva

Licenciado em Ciências Biológicas

A influência da paisagem na provisão do serviço de polinização por insetos no girassol versão revisada de acordo com a resolução CoPGr 6018 de 2011

Orientador:

Prof. Dr. WESLEY AUGUSTO CONDE GODOY

Co-orientadora:

Dra. DENISE DE ARAUJO ALVES

Tese apresentada para obtenção do título de Doutora em Ciências. Áreas de concentração: Entomologia

\section{Piracicaba}




\section{Dados Internacionais de Catalogação na Publicação DIVISÃO DE BIBLIOTECA - DIBD/ESALQ/USP}

Silva, Carina Aparecida de Souza

A influência da paisagem na provisão do serviço de polinização por insetos no girassol / Carina Aparecida de Souza Silva. - - versão revisada de acordo com a resolução CoPGr 6018 de 2011 - - Piracicaba, 2019.

$87 \mathrm{p}$.

Tese (Doutorado) - - USP / Escola Superior de Agricultura "Luiz de Queiroz".

1. Cobertura florestal 2. Heterogeneidade espacial 3. Mata Atlântica 4. Serviços ecossistêmicos 5. Biodiversidade 6. Produtividade I. Título 
Aos meus pais Valdivo e Rosmary, meus irmãos Camila e Renan, meus sobrinhos Heitor, Letícia e Beatriz, e meu noivo Carlos Roberto pelo carinho, incentivo, apoio e paciência durante esses anos de formação profissional, e principalmente, pessoal. 


\section{AGRADECIMENTOS}

Agradeço primeiramente a Deus, que sempre me deu força, sabedoria e discernimento para vencer todos os obstáculos até aqui. Agradeço também a Maria mãe de Jesus, a quem eu sempre pedi e ganhei a intercessão nos momentos mais difíceis. Gratidão pela sua luz, Senhor!

Aos meus pais Valdivo e Rosmary, meus irmãos Camila e Renan, além dos meus sobrinhos Heitor, Letícia e Beatriz. Agradeço a eles por todo o amor, carinho, incentivo, paciência e por me ensinarem a importância de uma família. Amo vocês!

A todos os meus familiares, meus avós Alvenise, Manoel Barreto, Lourdes e Moacir (in memoriam). Aos tios, tias, primos e primas, que muitas vezes sem saber o que eu fazia, me deram todo o apoio e incentivo.

Aos donos das áreas rurais na região da Cantareira-Mantiqueira onde o estudo foi realizado, pelas autorizações, informações, receptividade e confiança.

Ao meu orientador Prof. Dr. Wesley A. C. Godoy, a quem eu tive a honra de conhecer e trabalhar durante esses quatros anos. Obrigada pela atenção, paciência, ensinamentos e sugestões prestadas no decorrer deste trabalho.

À minha co-orientadora Dra. Denise de A. Alves, que foi a primeira pessoa a acreditar na minha capacidade de realizar um trabalho tão bonito e complexo. Obrigada por ter aceitado me orientar e permitir que eu fizesse parte do grupo do laboratório das "abelhas".

Ao Prof. Dr. Milton C. Ribeiro pelo suporte provido pelo projeto temático, pelas colaborações e ensinamentos ao longo desses quatro anos. Obrigada por ter me ensinado o que é “ecologia de paisagem”!

Ao Prof. Dr. Eduardo A. B. Almeida pela identificação das abelhas e ao Dr. Léo C. da Rocha-Filho pela identificação das abelhas da tribo Euglossini.

Ao Dr. Bruno Malaquias e ao Dr. Rafael Moral pela ajuda nas análises estatísticas. Também agradeço pela amizade que construímos ao longo desses quatro anos e pelos ensinamentos. Gratidão!

Agradeço a todos do Laboratório de Ecologia e Entomologia Florestal, do Laboratório de Manejo Integrado de Pragas e do Laboratório de Ecologia Molecular de Artrópodes pela convivência e colaboração.

Aos técnicos do Departamento de Entomologia (LEA) da ESALQ/USP, Chico, Carlinhos, Willian e o Dino, meu amigo e companheiro de prosa. Obrigada pelos cafezinhos!

Agradeço a todos do LEEC, em especial ao Rafael Souza (Urucum) e a Paula Montagnana.

Ao meu parceiro de campo Carlinhos (Fernando) do Departamento de Ecologia da UNESP-RC. Ao pessoal da Guaimbê jardinagem, especialmente o Marquinhos, o Bruno e o 
Gustavo. Também sou grata a todas as pessoas que participaram do campo comigo como a Bruna Almeida, Bruno Lavrini, Caroline, Mariana Leite, Vagner e outros tantos que colaboraram para que esse trabalho fosse realizado. Agradeço a Rafaela Tadei pela ajuda na montagem dos insetos coletados. Muito obrigada pela ajuda e disponibilidade de todos!

Aos meus amigos de doutorado da Pós-graduação em Entomologia da ESALQ/USP. Em especial, quero agradecer imensamente a Cynthia Jacob e sua família pela ajuda no decorrer do projeto, amizade, companheirismo e acolhimento. Também agradeço, a Marcela Barbosa e ao Roberto Gaioski, pois foram as primeiras pessoas que conheci no doutorado e que foram fundamentais nessa etapa da minha vida. Vou levar vocês comigo para sempre!

Aos meus queridos amigos de vida Mariana, Suelen, Elisangela (Danda), Letícia Mariano, Silvia Rafaela, Ana Flávia Boeni, Paulo Liduário, Maria Estela, Elaine Silva-Zacarin, Giuliano, Danielle, Renata Cuba, que mesmo longe sempre apoiaram e incentivaram em todos os momentos. Amo vocês!

Às amigas do apartamento 41 e do dia-a-dia Marina, Carol e Elaine.

Aos meus amigos Aloisio, Valéria, Carol, Val, Marcela, Lúcio, Camila, Kátia e tantos outros que me receberam de braços abertos e mostraram a verdadeira essência da igreja e do amor de Cristo. Gratidão!

Ao meu amigo, companheiro, noivo e futuro esposo Beto, que sempre esteve ao meu lado, assim como a sua família, em especial a Dona Lurdes e o Seu Caxi. Agradeço pela ajuda ao realizar os experimentos, cultivando os girassóis e indo para o campo comigo. Mas agradeço, principalmente, pelo apoio, incentivo, amor, carinho e atenção. Obrigada pelo bem que me faz!

À Coordenação de Aperfeiçoamento de Pessoal de Nível Superior (CAPES) e ao Programa de Pós-Graduação em Entomologia da ESALQ/USP pela concessão da bolsa e oportunidade. Agradeço também a A.B.E.L.H.A. e a FAPESP (2013/50421-2) pelo suporte e apoio financeiro dados ao projeto. 
"Até aqui me ajudou o Senhor" I Samuel 7:12 


\section{SUMÁRIO}

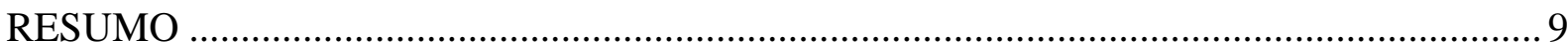

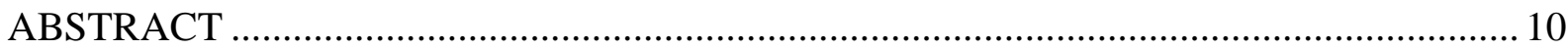

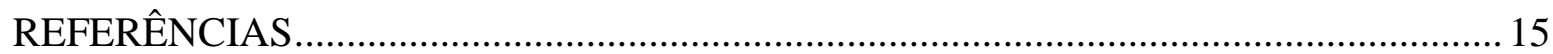

2. POLINIZAÇÃO POR ABELHAS AUMENTA A QUALIDADE DO ÓLEO DE

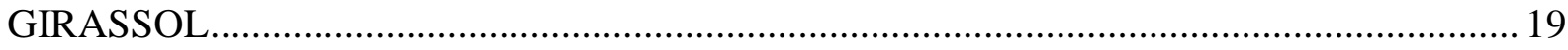

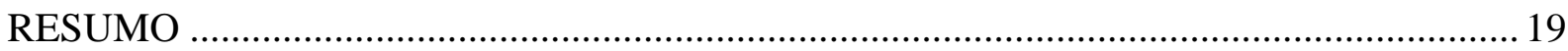

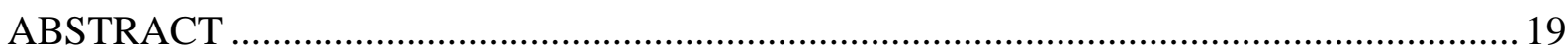

2.1. INTRODUÇÃ

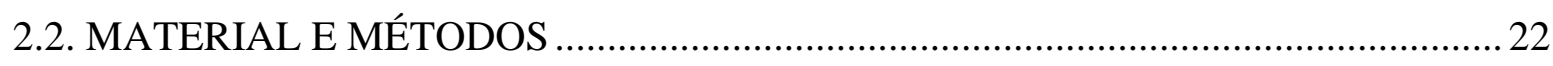

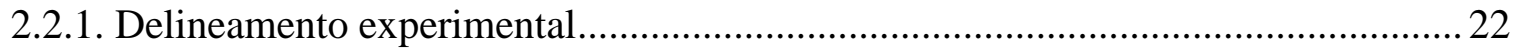

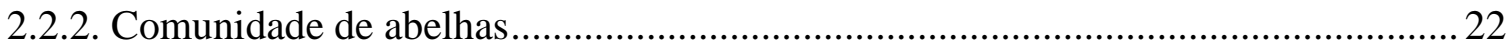

2.2.3. Qualidade dos aquênios e valor de mercado ....................................................... 23

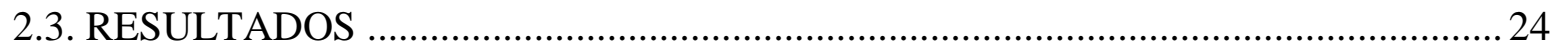

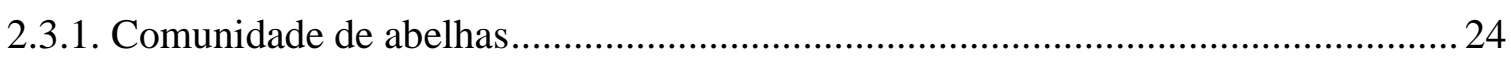

2.3.2. Qualidade dos aquênios e valor de mercado ....................................................... 26

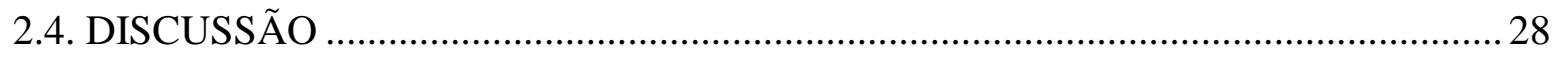

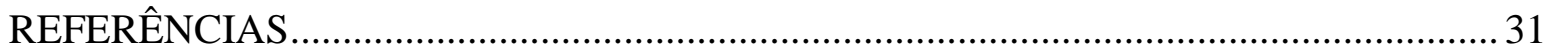

3. EFEITOS DA COBERTURA FLORESTAL E DA HETEROGENEIDADE ESPACIAL NA

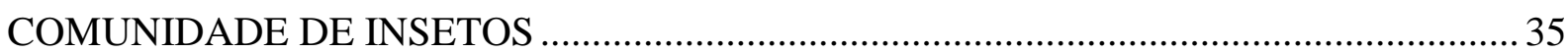

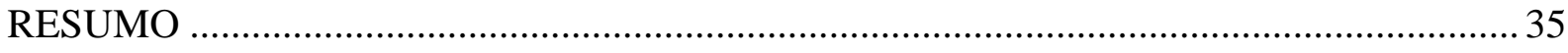

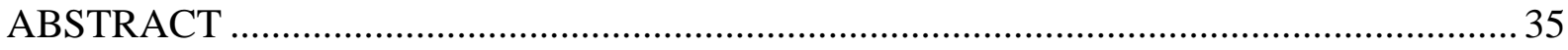

3.1. INTRODUÇÃ

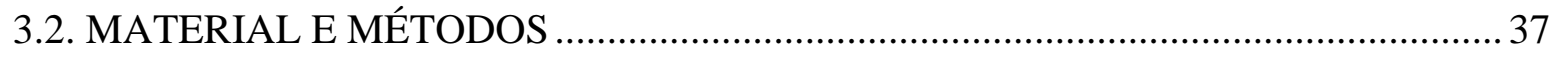

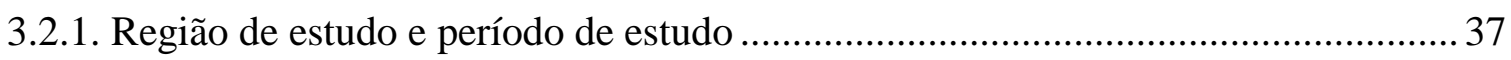

3.2.2. Seleção das paisagens e Métricas de paisagem ...................................................... 38

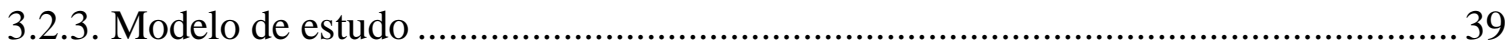

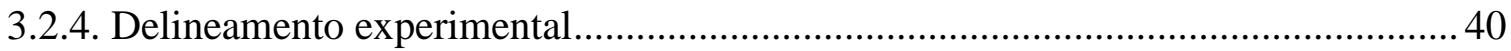

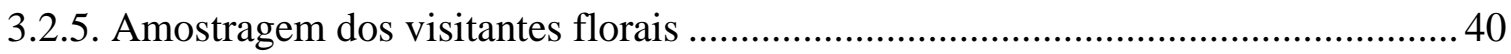

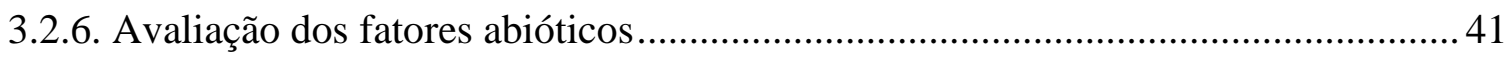

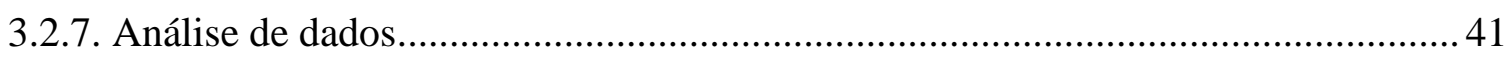

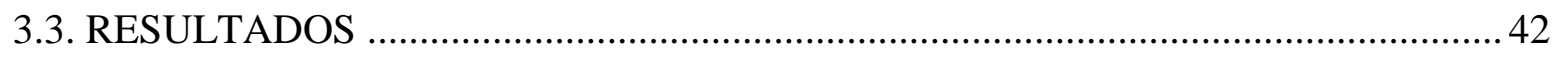

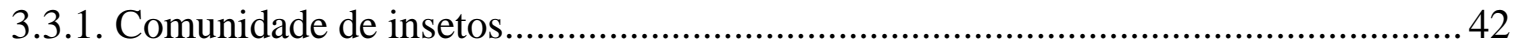

3.3.2. Efeitos da paisagem na comunidade de insetos ..................................................... 43 


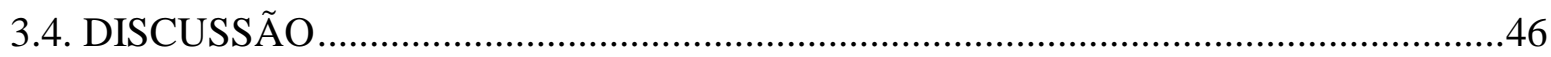

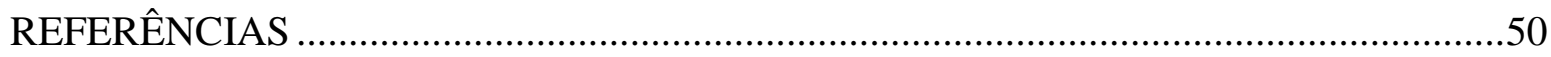

4. A INFLUÊNCIA DA PAISAGEM NOS VISITANTES FLORAIS E SEUS EFEITOS NA PRODUTIVIDADE DE SEMENTES E DE ÓLEO DE GIRASSOL ...................................59

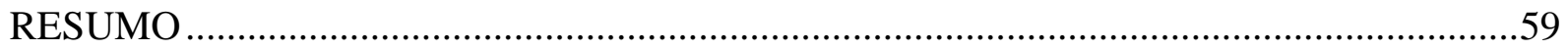

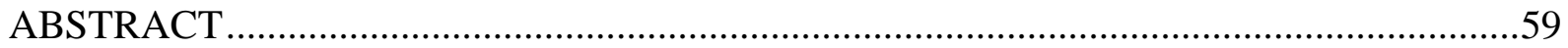

4.1. INTRODUÇÃA

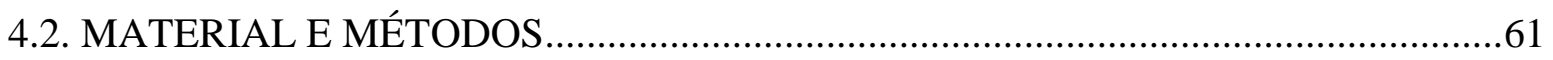

4.2.1. Área de estudo e seleção das unidades amostrais ................................................61

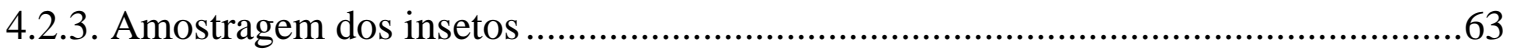

4.2.4. Quantidade e qualidade de aquênios e valor nutricional do óleo de girassol ..........63

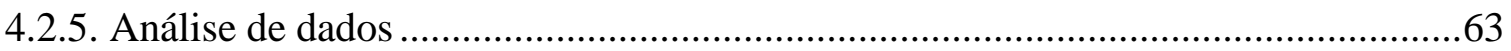

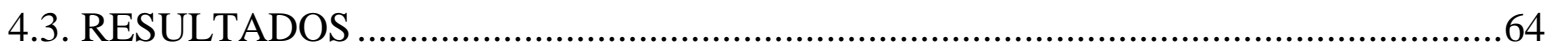

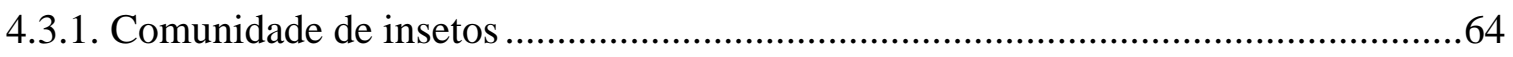

4.3.2. Paisagem e serviço de polinização ............................................................................64

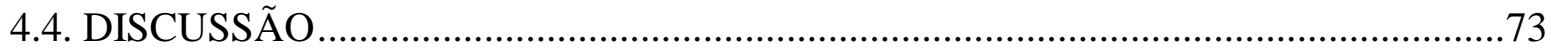

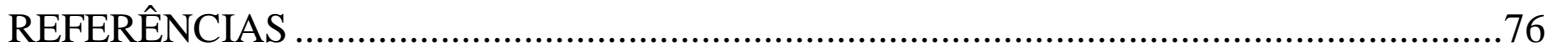

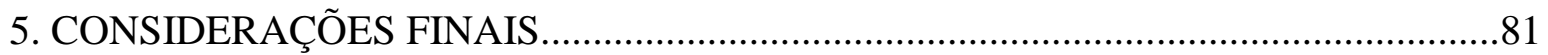

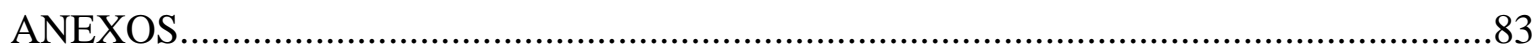




\section{RESUMO}

\section{A influência da paisagem na provisão do serviço de polinização por insetos no girassol}

As populações de insetos e os serviços ecossistêmicos realizados por esses organismos estão ameaçados por ações antrópicas, devido à conversão de habitats naturais em paisagens agriculturáveis extensa e/ou urbanizadas. Essas modificações geradas nas paisagens naturais criaram novos cenários e aumentou os desafios de investigar como o arranjo espacial do uso do solo pode afetar os processos ecológicos. Apesar do aumento do número de estudos com esse foco, ainda são escassas as avaliações na região tropical que analisam os efeitos das mudanças da paisagem sobre os polinizadores e a seus serviços. Assim, a fim de prover mais dados que possam contribuir para o entendimento das questões acima, este estudo foi estruturado em três capítulos com os seguintes objetivos: (1) investigar o papel das abelhas na produção de sementes e qualidade do óleo do girassol; (2) avaliar os efeitos de diferentes proporções da heterogeneidade espacial e de cobertura florestal na comunidade de insetos que visitam o girassol, e; (3) avaliar a provisão do serviço de polinização nessa cultura. Para isso, o primeiro capítulo foi realizado na Escola Superior de Agricultura "Luiz de Queiroz" - ESALQ/USP, Piracicaba, e os experimentos dos capítulos subsequentes foram conduzidos em 12 paisagens com gradiente de heterogeneidade espacial e cobertura florestal de Mata Atlântica, no Corredor Cantareira-Mantiqueira, Estado de São Paulo, Brasil. Este estudo mostrou a visitação de abelhas em girassóis híbridos aumentou o peso dos aquênios em $91 \%$, os níveis de vitamina $\mathrm{E}$ em $45 \%$ e os ácidos graxos insaturados em 0,3\%, quando comparados a flores isoladas desses polinizadores. Além disso, estimou-se que, devido aos serviços de polinização fornecidos pelas abelhas, o produtor praticamente duplica o valor de venda dos aquênios por hectare de área cultivada. Em relação aos experimentos conduzidos nas 12 paisagens da Mata Atlântica, foram amostrados 2.181 indivíduos de 130 espécies de insetos, pertencentes a 40 famílias de seis ordens. As abelhas foram os visitantes florais mais abundantes $(77,2 \%)$ e com maior riqueza $(36,9 \%)$ dentre os visitantes florais. Apis mellifera dominou a comunidade de insetos visitantes, seguida por Trigona spinipes. Essas espécies são consideradas “super-generalistas" quanto às suas preferências florais e importantes polinizadores em áreas degradadas, já que suas populações se mantêm em paisagens mais simplificadas e desfavoráveis a outros polinizadores. Isso pode explicar a relação negativa entre a proporção de floresta e a riqueza de insetos que visitaram os girassóis. A heterogeneidade espacial não teve efeito significativo nos índices de diversidade. No entanto, é necessário cuidado ao interpretar esses dados e levar em consideração a qualidade dos habitats naturais da paisagem circundantes aos girassóis e os traços comportamentais e ecológicos de cada espécie amostrada. Neste estudo, ficou evidente que, apesar de A. mellifera contribuir para o incremento da produtividade do girassol, o serviço de polinização realizado por outros insetos foi mais eficiente e efetivo, uma vez que influenciou positivamente no aumento do número e peso dos aquênios por capítulo, na quantidade de óleo extraído das sementes e no nível de gamatocoferol contido no óleo. Além disso, houve também a diminuição no teor de ácidos graxos saturados. Como seu consumo aumenta a concentração de colesterol no sangue humano, a melhora da composição nutricional do óleo de girassol foi auxiliada pela ação de polinizadores. Assim, este estudo destacou o importante papel dos polinizadores para a segurança alimentar humana e a relação entre características da paisagem e o serviço de polinização, fornecendo dados básicos úteis para estratégias políticas que podem auxiliar na proteção dos polinizadores.

Palavras-chave: Cobertura florestal, Heterogeneidade espacial, Mata Atlântica, Serviços ecossistêmicos, Biodiversidade, Produtividade 


\section{ABSTRACT \\ The influence of landscape on the provision of insect pollination service in sunflower}

Insect populations and ecosystem services performed by these organisms are threatened by anthropogenic actions, such as the conversion of natural habitats into extensive agricultural and/or urbanized areas. These changes in natural landscapes have created new scenarios and increased the challenges of investigating the effect of spatial arrangement of land use in ecological processes. Despite the increasing number of studies focusing on this topic, evaluations in tropical region that analyze the effects of landscape changes on pollinators and their provision of pollination services are still scarce. Thus, in order to provide more data that address the aforementioned issues, this study was structured into three chapters, with the following aims: (1) to investigate the role of bees in seed production and sunflower oil quality; (2) to evaluate the effects of spatial heterogeneity and forest cover on sunflower-visiting insect community, and; (3) to evaluate the provision of pollination service in sunflowers. To achieve these goals, the experiments were carried out at the "Luiz de Queiroz" College of Agriculture - ESALQ/USP, Piracicaba, and in 12 landscapes across gradients of spatial heterogeneity and Atlantic Rainforest cover, in the Cantareira-Mantiqueira Corridor region, São Paulo State, Brazil. This study showed that bee visitation in hybrid sunflowers increased the achenes weight by $91 \%$, the levels of vitamin E by $45 \%$ and unsaturated fatty acids by $0.3 \%$. Furthermore, it was estimated that due to the pollination services provided by the bees, the grower of the sunflower hybrid used in this study doubles the sales value of achenes per hectare of cultivated area. In relation to the experiments conducted in the 12 Atlantic Rainforest landscapes, 2,181 individuals belonging to 130 insect species of 40 families (six orders) were sampled. Bees were the most abundant $(77.2 \%)$ and the richest $(36.9 \%)$ sunflower visitors. Apis mellifera dominated sunflower-visitor communities, followed by Trigona spinipes. These species are traditionally considered "super generalists" in relation to their floral preferences and important pollinators in degraded areas, since their populations remain in simplified landscapes that are unsuitable to other pollinators. It could explain the negative relationship between the forest proportion and the richness of sunflower-visiting insect community. Spatial heterogeneity had no significant effect on the diversity indexes. However, it is necessary to interpret these data with caution and to take in account the quality of the natural habitats surrounding the sunflowers and the behavioral and ecological traits of each insect species. Although $A$. mellifera contributed to increase sunflower productivity, the pollination services performed by other insect taxa were more efficient and effective, as they contributed to increase the number and weight of achenes per sunflower head, the quantity of oil extracted from seeds and the gamma-tocopherol oil concentration. In addition, there was a decrease in levels of saturated fatty acids. Since their consumption increases the concentration of cholesterol in human blood, the pollinators had an important role in the improvement of the nutritional composition of sunflower oil. Thus, this study highlighted the important role of pollinators for human food security and the relationship between surrounding landscapes and pollination service, providing useful baseline figures to policy strategies that can help to safeguard pollinators.

Keywords: Forest cover, Spatial heterogeneity, Atlantic rainforest, Ecosystem services, Biodiversity, Productivity 


\section{INTRODUÇÃO GERAL}

O rápido crescimento da população humana tem aumentado significativamente os desafios para atender às elevadas demandas na produção de alimento e bicombustíveis, acarretando transformações nos ambientes terrestres (Garibaldi et al., 2011). A população mundial já ultrapassou os sete bilhões de habitantes e estima-se que em 30 anos chegará a quase 10 bilhões (UN, 2017). Para suprir a demanda por recursos, advinda do crescimento populacional humano expressivo, o uso do solo provavelmente tem sido o fator que mais atua nas modificações de áreas naturais, em decorrência da expansão de áreas agrícolas e urbanas (Crawford, 1997; Satterthwaite et al., 2010). Diante disso, nos últimos 50 anos houve um aumento de cerca $30 \%$ de área cultivada e de $60 \%$ de produção agrícola (FAO, 2010). Dentre os serviços ecossistêmicos diretamente ligados à agricultura está a polinização (Costanza et al., 1997), um processo fundamental para a produção de alimento e segurança alimentar (IPBES, 2016; Potts et al., 2016; Burkle et al., 2017), contribuindo para o bem-estar, a saúde e os valores socioculturais humanos (Potts et al., 2016; Hill et al., 2019).

Cerca de $90 \%$ das plantas com flores são dependentes de animais, especialmente os insetos, para a transferência de grãos de pólen em quantidade suficiente para a fertilização dos óvulos e a consequente formação de frutos e sementes (Ollerton et al., 2011). Das 107 culturas agrícolas importantes mundialmente e usadas diretamente na alimentação humana, mais de 75\% se beneficiam da ação desses polinizadores (Klein et al., 2007). Esse benefício é refletido na produção de frutos maiores, mais pesados e vistosos, com maior número de sementes (Klein et al., 2007; Potts et al., 2016), maior teor de micronutrientes (Eilers et al., 2011; Smith et al., 2015), agregando maior valor de mercado e traduzindo em lucro direto ao agricultor (Potts et $a l ., 2016)$. O valor global da polinização biótica foi estimado em US\$ 235-577 bilhões anuais (Potts et al., 2016) - o que contribui com 35\% da produção agrícola global (Klein et al., 2007).

Os polinizadores bióticos são em sua maioria insetos, sendo considerados os agentes mais eficientes e efetivos na reprodução sexuada de uma ampla variedade de espécies vegetais (Kearns et al., 1998; Klein et al., 2007). Entretanto, as populações de insetos polinizadores estão sendo ameaçadas por ações antrópicas em todo o mundo (Potts et al., 2016). Dentre diversos fatores, a conversão do solo para a agricultura intensiva e/ou urbanização e as mudanças climáticas estão entre as principais causas para o declínio dessas populações (González-Varo et al., 2013; Janzen \& Hallwachs, 2019). Estes fatores são particularmente importantes nas regiões tropicais (Newbold et al., 2014), uma vez que mais de 100 milhões de hectares de floresta foram perdidos a partir da década 80 (IPBES, 2019) e estima-se a destruição 
de $2.101 \mathrm{~km}^{2}$ ao ano (Hansen et al., 2013). Essa perda da cobertura vegetal original, que chega a armazenar cerca de 340 bilhões de toneladas de carbono (Gibbs et al., 2007), também altera o clima (Magnago et al., 2015).

A perda de florestas tropicais está diretamente associada à alta expansão de terras agriculturáveis, uma vez que somente a atividade pecuária na América Latina ocupa cerca de 42 milhões de hectares (IPBES, 2019). Dentre os países americanos, o Brasil se destaca, pois é o segundo maior fornecedor mundial de alimento e produtos agrícolas (OCDE/FAO, 2015) e o quinto país em área cultivada, somando mais de 60 milhões de hectares (MAPA, 2017). Cerca de 60\% das culturas agrícolas brasileiras de importância econômica - para alimentação humana, pecuária, biocombustível, vestuário - dependem, em algum grau, de polinizadores, em especial das abelhas. O valor total do serviço de polinização foi estimado em US\$ 12 bilhões, contribuindo com cerca de $30 \%$ do valor anual da produção agrícola nacional (Giannini et al., 2015).

Dentre as culturas brasileiras que se beneficia economicamente com os serviços realizados pelos polinizadores está o girassol (Helianthus annuus, Asteraceae), cuja polinização equivaleu a $65 \%$ do valor total de sua produção, estimado em US\$ 40,8 milhões (Giannini et $a l ., 2015)$. Essa espécie vegetal é muito atrativa aos insetos, uma vez que suas flores produzem muito pólen e néctar (Parker, 1981), e possui alta dependência da polinização cruzada, uma vez que suas flores são protândricas e passam por dicotomia temporal, na qual o grão de pólen é liberado antes dos estigmas estarem receptivos (Free, 1993). Assim, mesmo os híbridos de girassol mais modernos, com altos níveis de autocompatibilidade, se beneficiam da ação dos polinizadores (Parker, 1981; Degrandi-Hoffman \& Chambers, 2006; Bartual et al., 2018), tanto em relação ao aumento no peso de sementes (Silva et al., 2018) e do teor de óleo (Parker, 1981; Bartual et al., 2018), quanto nos níveis de componentes nutricionais (Silva et al., 2018).

Embora o Brasil não seja um dos maiores produtores de girassol, o país possui atualmente 95,5 mil hectares de área cultivada com produção de 149.000 toneladas (CONAB, 2019), utilizado na sucessão e rotação de culturas e nutrição animal. Mas a partir de 2004, o girassol teve maior destaque no cenário agrícola brasileiro, quando foi inserido no Programa Nacional de Produção e Uso do Biodiesel (PNPB), que visa a produção e o mercado de biocombustível, a inclusão social na cadeia produtiva e o menor impacto do meio ambiente (BRASIL, 2004). Além do biodiesel, o óleo extraído das sementes do girassol se destaca no mercado mundial, devido ao seu alto valor nutricional, pois é rico em tocoferóis e tocotrienóis (mais representado 
pela vitamina E), fitoesteróis e ácidos graxos (FAO/WHO, 2015), que podem auxiliar na prevenção de doenças cardiovasculares (Mathur et al., 2015).

Diante dessa crescente demanda por alimentos mais saudáveis, em especial os óleos, se faz necessário o melhoramento genético de cultivares girassol ou estratégias de campo que maximizem a qualidade do seu óleo. Além do girassol, outras culturas de importância agrícola também se beneficiam com a polinização entomófila em relação a teores nutricionais, como a canola (Brassica napus: Bommarco et al., 2013; Bartomeus et al., 2014), amêndoas (Prunus dulcis: Brittain et al., 2014), morango (Fragaria x ananassa: Klatt et al., 2014), feijão (Vicia faba) e trigo sarraceno (Fagopyrum esculentum) (Bartomeus et al., 2014). No entanto, a maioria desses estudos foi realizada em regiões de clima temperado. Dessa forma, é premente a necessidade de avaliações em cultivos na região tropical, uma vez que a polinização biótica influencia em $70 \%$ na produtividade de frutas e sementes de culturas nos trópicos (Roubik, 1995).

Em 39 sistemas de cultivo em diferentes biomas com heterogeneidade de habitats (tipos de culturas mistas, presença de sebes e tiras de flores), a abundância de polinizadores foi $76 \%$ maior em comparação a campos de monocultura (Kennedy et al., 2013), uma vez que ambientes mais heterogêneos disponibilizam mais fontes de recurso e, consequentemente, maior variedade de interações entre plantas e visitantes florais (Moreira et al., 2015). No Brasil, alguns estudos evidenciaram incremento na provisão do serviço de polinização por insetos em diversas culturas agrícolas próximas a habitats naturais (De Marco \& Coelho, 2004; Freitas et al., 2014; Witter et al., 2015; Saturni et al., 2016; Campbell et al., 2018; Hipólito et al., 2018), uma vez que esses ambientes são essenciais para a manutenção da diversidade de polinizadores, fornecendo locais adequados para nidificação (cavidades arbóreas, bambus, substratos no solo), reprodução, proteção contra inimigos e obtenção de alimentos (flores que ofertem pólen e/ou néctar) (Roubik, 1989; Viana et al., 2012; Wratten et al., 2012).

Por ser um hotspot de biodiversidade, que suporta alto número de espécies e altas taxas de endemismo, inclusive de polinizadores (Boscolo et al., 2017; Nery et al. 2018), a Mata Atlântica constitui importante modelo para este estudo (Myers et al., 2000; Joly et al., 2014). No entanto, restam apenas $16 \%$ de sua cobertura original, incluindo pequenos fragmentos isolados e florestas secundárias em fases iniciais e intermediárias de desenvolvimento (Ribeiro et al., 2009). Nos Estados de São Paulo e Minas Gerais, a expansão agropecuária, mais especificamente a produção de eucalipto para a produção de papel e celulose, colaborou para a redução desse ecossistema (Joly et al., 2014). 
Diante do exposto, o objetivo deste estudo foi fornecer informações sobre a comunidade de insetos que visitam as flores do girassol, bem como avaliar o serviço de polinização prestado por eles. Para isso, três capítulos foram estruturados e são brevemente introduzidos nesta seção.

\section{Capítulo 1}

Objetivo: Investigar o papel das abelhas na produtividade do girassol, em relação à produção de sementes e à qualidade nutricional do óleo.

Hipótese: Flores expostas à visita de abelhas produzem maior número de sementes, mais pesadas, com maior quantidade de óleo e teores de vitamina $\mathrm{E}$ e ácidos graxos do que as flores em que os visitantes florais são excluídos.

\section{Capítulo 2}

Objetivo: Avaliar os efeitos da cobertura florestal e heterogeneidade espacial na comunidade de insetos que visitam o girassol na Mata Atlântica.

Hipótese: Áreas mais heterogêneas e com maior cobertura florestal exibirão maior riqueza, abundância e diversidade de insetos que visitam as flores do girassol do que em áreas com baixa heterogeneidade e cobertura florestal.
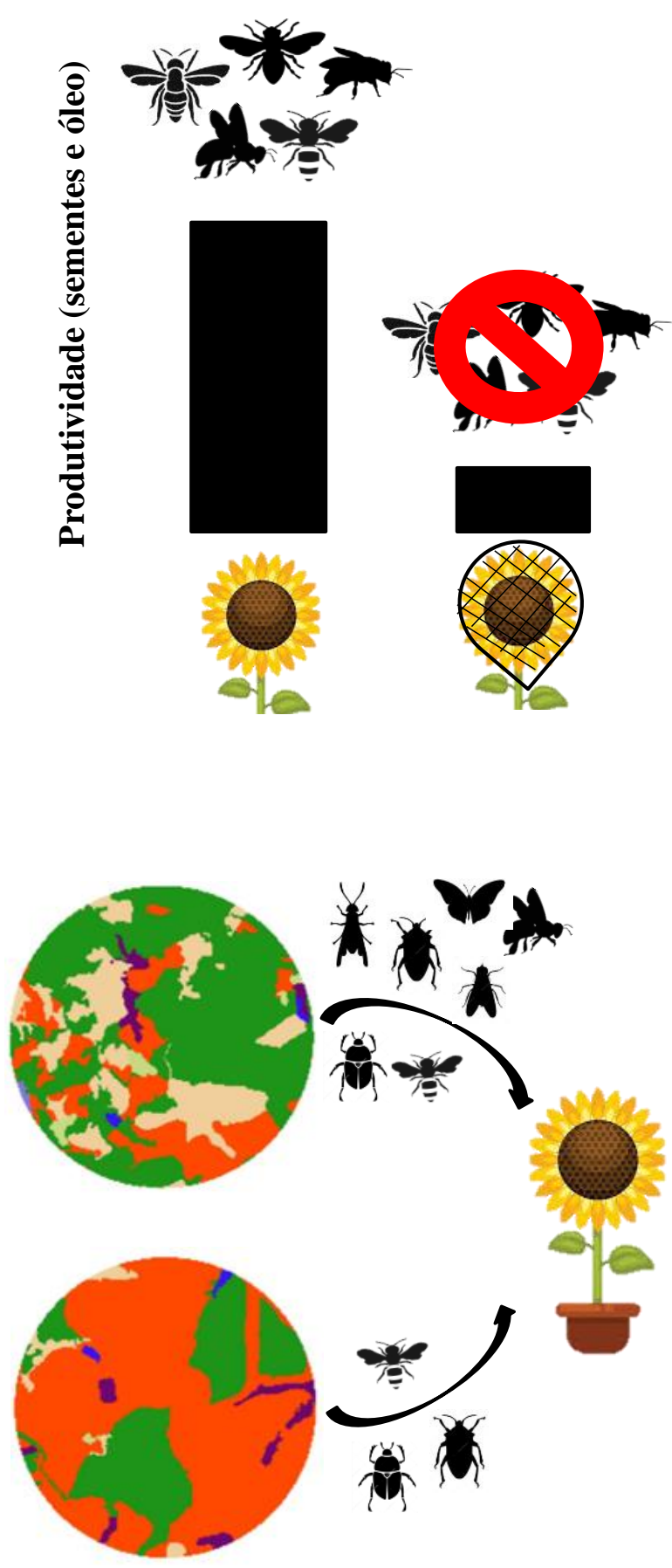


\section{Capítulo 3}

Objetivo: Avaliar a influência da paisagem na provisão do serviço de polinização do girassol por insetos.

Hipótese: Em áreas com maior riqueza e abundância de visitantes florais, maiores serão a quantidade de sementes produzidas e a qualidade do óleo extraído.
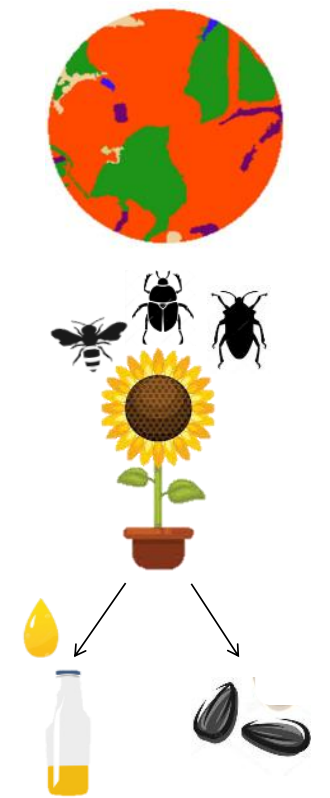
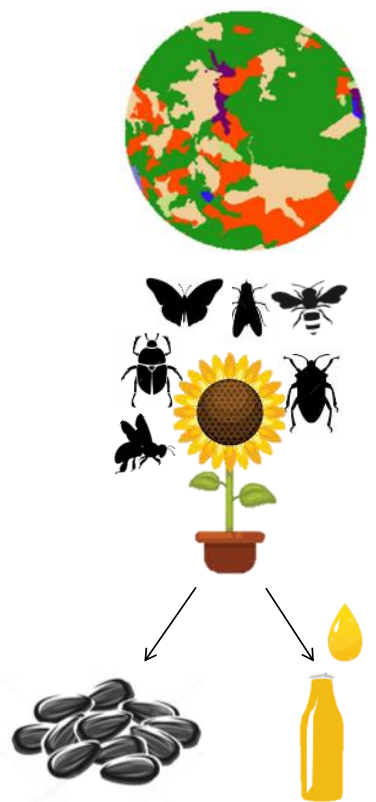

\section{REFERÊNCIAS}

Bartomeus I, Potts SG, Steffan-Dewenter I, Vaissière BE, Woyciechowski M, Krewenka KM, Tscheulin T, Roberts SPM, Szentgyörgyi H, Westphal C, Bommarco R, 2014 Contribution of insect pollinators to crop yield and quality varies with agricultural intensification. PeerJ 2: e328.

Bartual AM, Bocci G, Marini S, Moonen AC, 2018. Local and landscape factors affect sunflower pollination in a Mediterranean agroecosystem. PLoS ONE 13: e0203990.

Brittain C, Kremen C, Garber A, Klein AM, 2014. Pollination and Plant Resources Change the Nutritional Quality of Almonds for Human Health. PLoS ONE 9: e90082.

Bommarco R, Marini L, Vaissière BE, 2012. Insect pollination enhances seed yield, quality, and market value in oilseed rape. Oecologia 169: 1025-1032.

BRASIL, 2004. Ministério do Desenvolvimento Agrário. Programa Nacional de Produção e Uso do Biodiesel (PNPB): inclusão social e desenvolvimento territorial. http://www.mda.gov.br/sitemda/sites/sitemda/files/user_arquivos_64/Biodiesel_Book_fin al_Low_Completo.pdf (accessed 10/03/2019)

Burkle LA, Delphia CM, O'Neill KM, 2017. A dual role for farmlands: food security and pollinator conservation. Journal of Ecology 105: 890-899.

CONAB, 2019. Acompanhamento da safra brasileira de grãos 2018/19 (levantamento mensal $4^{\mathbf{0}}, \mathbf{5}^{\mathbf{0}}, \mathbf{6}^{\mathbf{0}}$ e $\mathbf{7}^{\mathbf{0}}$ ). https://www.conab.gov.br/info-agro/safras/graos/boletim-da-safrade-graos (accessed 23/04/2019).

Costanza R, d'Arge R, de Groot R, Farber S, Grasso M, Hannon B, Limburg K, Naeem S, ONeill RV, Paruelo J, Raskin RG, Sutton PL, van den Belt M, 1997. The value of the world's ecosystem services and natural capital. Nature 387: 253-260.

Crawford IM, 1997. Agricultural and food marketing management. Food and Agriculture Organization of The United Nations (FAO), Roma. 
De Marco P, Coelho FM, 2004. Services performed by the ecosystem: forest remnants influence agricultural cultures' pollination and production. Biodiversity and Conservation 13: 1245-1255.

Eilers EJ, Kremen C, Greenleaf SS, Garber AK, Klein A-M, 2011. Contribution of pollinatormediated crops to nutrients in the human food supply. PLoS ONE 6: e21363.

Free JB, 1993. Insect pollination of crops. Academic Press, London.

Freitas BM, Pacheco Filho AJ, Andrade PB, Lemos CQ, Rocha EE, Pereira NO, Bezerra AD, Nogueira DS, Alencar RL, Rocha RF, 2014. Forest remnants enhance wild pollinator visits to cashew flowers and mitigate pollination deficit in NE Brazil. Journal of Pollination Ecology 12: 22-30.

Giannini TC, Cordeiro GD, Freitas BM, Saraiva AM, Imperatriz-Fonseca VL, 2015. The dependence of crops for pollinators and the economic value of pollination in Brazil. Journal of Economic Entomology 108: 849-857.

Gibbs HK, Brown S, Niles JO, Foley JA, 2007. Monitoring and estimating tropical forest carbon stocks: making REDD a reality. Environmental Research Letters 2: 045023.

González-Varo JP, Biesmeijer JC, Bommarco R, Potts SG, Schweiger O, Smith HG, SteffanDewenter I, Szentgyörgyi H, Woyciechowski M, Vilà M, 2013. Combined effects of global change pressures on animal-mediated pollination. Trends in Ecology \& Evolution 28: 524-530.

Hansen MC, Potapov PV, Moore R, Hancher M, Turubanova S, Tyukavina A, Thau D, Stehman S, Goetz S, Loveland TR, 2013. High-resolution global maps of 21st-century forest cover change. Science 342: 850-853.

Hill R, et al., 2019. Biocultural approaches to pollinator conservation. Nature Sustainability 2: 214-222.

Hipólito J, Boscolo D, Viana BF, 2018. Landscape and crop management strategies to conserve pollination services and increase yields in tropical coffee farms. Agriculture, Ecosystems \& Environment 256: 218-225.

IPBES, 2016. The assessment report of the Intergovernmental Science-Policy Platform on Biodiversity and Ecosystem Services on pollinators, pollination and food production. IPBES. http://www.ipbes.net/ (accessed 26 April 2018).

IPBES, 2019. Media Release: Nature's Dangerous Decline 'Unprecedented'; Species Extinction Rates 'Accelerating'. IPBES. https://www.ipbes.net/news/Media-ReleaseGlobal-Assessment (accessed 08 may 2019).

Janzen DH, Hallwachs W, 2019. Perspective: Where might be many tropical insects? Biological Conservation 233: 102-108.

Joly CA, Metzger JP, Tabarelli M, 2014. Experiences from the Brazilian Atlantic Forest: ecological findings and conservation initiatives. New Phytologist 204: 459-473.

Kearns CA, Inouye DW, Waser NM, 1998. Endangered mutualisms: The conservation of plantpollinator interactions. Annual Review of Ecology and Systematics 29: 83-112.

Klatt BK, Holzschuh A, Westphal C, Cloug Y, Smit I, Pawelzik E, 2014. Bee pollination improves crop quality, shelf life and commercial value. Proceedings of the Royal Society B 281: 20132440 . 
Klein AM, Vaissière BE, Cane JH, Steffan-Dewenter I, Cunningham SA, Kremen C, Tscharntke T, 2007. Importance of pollinators in changing landscapes for world crops. Proceedings of the Royal Society B 274: 303-313.

Hansen MC, Potapov PV, Moore R, Hancher M, Turubanova SA, Tyukavina A, Thau D, Stehman SV, Goetz SJ, Loveland TR, Kommareddy A, Egorov A, Chini L, Justice CO, Townshend JRG (2013). High-Resolution Global Maps of 21st-Century Forest Cover Change. Science 342: 850-853.

Magnago LFS, Magrach A, Laurance WF, Martins SV, Meira-Neto AA, Simonelli M, Edwards DP (2015) Would protecting tropical forest fragments provide carbon and biodiversity cobenefits under REDD+? Global Change Biology 9: 3455-3468.

MAPA, 2017. Lavouras são apenas 7,6\% do Brasil, segundo a NASA. MAPA. http://www.agricultura.gov.br/noticias/dados-da-nasa-demonstram-que-apenas-7-6-daarea-do-brasil-e-ocupada-por-lavouras (accessed 9 may 2019).

Mathur P, Ding Z, Saldeen T, Mehta JL, 2015. Tocopherols in the prevention and treatment of atherosclerosis and related cardiovascular disease. Clinical Cardiology 38: 570-576.

Myers N, Mittermeier R, Mittermeier C, da Fonseca G, Kent J, 2000. Biodiversity hotspots for conservation priorities. Nature 403: 853-858.

Newbold T, Hudson LN, Phillips HR, Hill SL, Contu S, Lysenko I, Blandon A, Butchart SH, Booth HL, Day J, 2014. A global model of the response of tropical and sub-tropical forest biodiversity to anthropogenic pressures. Proceedings of the Royal Society B: Biological Sciences 281: 20141371.

OECD-FAO, 2015. Agricultural Perspectivas Agrícolas 2015-2024. OECD-FAO. http://www.fao.org/3/a-i4761o.pdf (accessed 08 may 2019).

Ollerton J, Winfree R, Tarrant S, 2011. How many flowering plants are pollinated by animals? Oikos 120: 321-326.

Potts SG, Imperatriz-Fonseca VL, Ngo HT, Aizen MA, Biesmeijer JC, Breeze TD, Dicks LV, Garibaldi LA, Hill R, Settele J, Vanbergen AJ, 2016. Safeguarding pollinators and their values to human well-being. Nature 540: 220-229.

Ribeiro MC, Metzger JP, Martensen AC, Ponzoni FJ, Hirota MM, 2009. The Brazilian Atlantic Forest: How much is left, and how is the remaining forest distributed? Implications for conservation. Biological Conservation 142: 1141-1153.

Ricketts TH, 2004. Tropical forest fragments enhance pollinator activity in nearby coffee crops. Conservation Biology 18: 1262-1271.

Roubik DW, 1995. Pollination of cultivated plants in the tropics. Agricultural Services Bulletin. FAO, Roma.

Satterthwaite D, McGranahan G, Tacoli C, 2010. Urbanization and its implications for food and farming. Philosophical transactions of the Royal Society of London. Series B, Biological sciences 365: 2809-2820.

Saturni FT, Jaffé R, Metzger JP, 2016. Landscape structure influences bee community and coffee pollination at different spatial scales. Agriculture, Ecosystems \& Environment 235: $1-12$.

Silva CA, Godoy WA, Jacob CR, Thomas G, Câmara GM, Alves DA, 2018. Bee pollination highly improves oil quality in sunflower. Sociobiology 65: 583-590. 
Smith MR, Singh GM, Mozaffarian D, Myers SS, 2015. Effects of decreases of animal pollinators on human nutrition and global health: a modelling analysis. The Lancet 386: 1964-1972.

Steffan-Dewenter I, Munzenberg U, Burger C, Thies C, Tscharntke T, 2002. Scale-dependent effects of landscape context on three pollinator guilds. Ecology 83: 1421-1432.

UN, 2017. World Population Prospects: The 2017 Revision, Key Findings and Advance Tables. In: Department of Economic and Social Affairs, P.D. (Ed.). United Nations, New York.

Witter S, Nunes-Silva P, Lisboa BB, Tirelli FP, Sattler A, Hilgert-Moreira SB, Blochtein B, 2015. Stingless bees as alternative pollinators of canola. Journal of Economic Entomology 108: 880-886. 


\title{
2. POlinizaÇão POR ABElHas AUMENTA A QUALIDAde do ÓleO DE GIRASSOL
}

*Este capítulo foi publicado no periódico Sociobiology

Silva CA, Godoy WA, Jacob CR, Thomas G, Câmara GM, Alves DA, 2018. Bee pollination highly improves oil quality in sunflower. Sociobiology 65: 583-590. doi: 1 0.13102/sociobiology.v65i4.3367

\section{RESUMO}

O girassol é uma cultura agrícola dependente de polinizadores e uma das oleaginosas mais cultivadas do mundo, abastecendo importantes setores da indústria agrícola, como a alimentícia, por ser uma importante fonte de vitamina $\mathrm{E}$ e ácidos graxos insaturados para a saúde humana. Embora seja bem estabelecido que a polinização provida pelas abelhas aumente o número de sementes de girassol, ainda não se sabe se os polinizadores influenciam em sua composição nutricional. Considerando a importância econômica dos girassóis para vários setores agrícolas brasileiros, o objetivo deste estudo foi avaliar o efeito da comunidade de abelhas para (1) qualidade do aquênio (peso e composição nutricional) e (2) valor de mercado. Experimentos de exclusão foram realizados com girassóis híbridos e mostraram que a polinização por abelhas aumentou o peso dos aquênios em $91 \%$, os níveis de vitamina $\mathrm{E}$ em $45 \%$ e os ácidos graxos insaturados em 0,3\%. Além disso, estimou-se que, devido aos serviços de polinização fornecidos pelas abelhas, o produtor do cultivar de girassol utilizado neste estudo praticamente duplica o valor de venda dos aquênios por hectare de área cultivada. Assim, o presente estudo destaca a importância das abelhas como promotoras de polinização cruzada e autopolinização para a qualidade nutricional de aquênios de girassol e fornece dados básicos úteis para futuras avaliações dos efeitos dos polinizadores na dieta e saúde humana.

Palavras-chave: Polinizadores, Produtividade, Aquênios, Vitamina E, Ácidos graxos

\begin{abstract}
Sunflower is a pollinator-dependent crop and one of the most cultivated oilseeds in the world, supporting important sectors of the agricultural industry, such as the food supply, because it is an important source of vitamin $\mathrm{E}$ and unsaturated fatty acids for human health. Although it is well established that bee pollination improves sunflower seed set, it is still unknown if pollinators influence the nutritional composition. Considering the economic importance of sunflowers for several Brazilian agricultural sectors, the aim of this study was to evaluate the effect of the bee community for (1) achene quality (weight and nutritional composition) and (2) market value. Exclusion experiments were performed with hybrid sunflowers and showed that bee pollination enhanced the achene weight by $91 \%$, the levels of vitamin $\mathrm{E}$ by $45 \%$ and unsaturated fatty acids by $0.3 \%$. Also, it was estimated that due to the pollination services provided by bees, the grower of the sunflower cultivar used in this study nearly duplicates the sale value of the achenes per hectare of cultivated area. Thus, the current study highlights the importance of bees as providers of cross- and self-pollination to nutritional quality of sunflower achenes and provides useful baseline figures to further evaluations of the effects of pollinators on human diets and health.
\end{abstract}


Keywords: Pollinators, Productivity, Achenes, Vitamin E, Fatty acids

\subsection{INTRODUÇÃO}

Recentemente, a população mundial ultrapassou os sete bilhões de habitantes e, de acordo com as projeções das Nações Unidas para 2050, chegará a 9,8 bilhões (UN, 2017). Esse rápido crescimento populacional tem imposto significativos desafios para atender as elevadas demandas na produção de alimento (Godfray et al., 2010), como a expansão das fronteiras agrícolas, que contribui com a perda de biodiversidade e seus valiosos serviços ecossistêmicos (Tilman et al., 2011). Dentre os serviços ecossistêmicos ligados diretamente com a agricultura está a polinização mediada por animais, que beneficia, em algum grau, 75\% das culturas agrícolas globais usadas diretamente na alimentação humana (Klein et al., 2007).

Mais de 90\% dessas culturas são polinizadas pelas abelhas, acarretando no incremento da produtividade e/ou da qualidade dos frutos e sementes formados (Klein et al., 2007; Potts et al., 2016). Os frutos formados a partir de flores polinizadas adequadamente são mais pesados, têm cores mais intensas, maior firmeza e tempo de prateleira, apresentam menores taxas de malformações (Klatt et al., 2014), e são fontes de macro- e micronutrientes essenciais à dieta humana (Eilers et al., 2011; Smith et al., 2015). Além das culturas destinadas à alimentação humana, as abelhas também polinizam culturas destinadas à produção de forragem para gado, adubo verde, insumos medicinais, fibras e biocombustíveis (Potts et al., 2016). Esse processo natural, muitas vezes desconsiderado nas políticas agrícolas nacionais e internacionais, contribui com 35\% da produção agrícola global (Klein et al., 2007) e tem valor econômico estimado em US\$ 235-577 bilhões anuais (Potts et al., 2016). Dessa forma, a segurança alimentar e nutricional, a diversidade e a estabilidade dos preços dos produtos agrícolas dependem fortemente das abelhas como agentes polinizadores (Steffan-Dewenter et al., 2005).

Entre as mais de 20.000 espécies de abelhas descritas, Apis mellifera é a mais utilizada em programas de polinização agrícola em diversas regiões do mundo. Contudo, por não ser eficiente na polinização de muitas plantas, o uso integrado de A. mellifera com as espécies de abelhas silvestres incrementa substancialmente os rendimentos das culturas agrícolas e os lucros dos produtores, ao mesmo tempo em que conserva a biodiversidade e os serviços ecossistêmicos além da polinização (Garibaldi et al., 2013; Isaacs et al., 2017). Embora $A$. mellifera seja a visitante floral mais abundante em cultivos de girassol (Free, 1993; Parker, 1981; Carvalheiro et al., 2011), espécies de abelhas silvestres contribuem significativamente 
para a produção de sementes (Greenleaf \& Kremen, 2006; Carvalheiro et al., 2011). Além disso, a polinização biótica também influencia a qualidade das sementes do girassol, devido ao aumento do teor de óleo (Parker, 1981). Mesmo os híbridos de girassol mais modernos, com altos níveis de autocompatibilidade, se beneficiam da polinização efetuada pelas abelhas (Degrandi-Hoffman \& Chambers 2006), já que suas visitas são importantes para transferir o pólen das flores na fase masculina para aquelas na fase feminina do mesmo capítulo ou de plantas diferentes (McGregor 1976; Free 1993).

O girassol (Helianthus annuus L.) é uma das culturas oleaginosas mais cultivadas no mundo, pois abastece importantes setores da indústria agrícola, como a de biocombustível, de sucessão e rotação de culturas, de forragem animal e de alimentação humana. O óleo extraído das sementes tem alto valor nutricional, pois é rico em ácidos graxos, como os ácidos linoleico (ômega-6) e o oleico (ômega-9), tocoferóis (incluindo a vitamina E) e fitoesteróis (FAO/WHO, 2015). Embora o Brasil não se destaque entre os maiores produtores de girassol no mundo, a produção em território nacional aumentou em 155\% entre 2005 e 2015 (IBGE 2017). Por ser altamente dependente de polinizadores, $65 \%$ do valor de produção dessa cultura no país (US\$ 40,8 milhões) corresponde à polinização mediada majoritariamente pelas abelhas (Giannini et $a l ., 2015)$. Aliada às condições climáticas brasileiras, a expansão na produtividade do girassol é favorecida pelo alto número de espécies de abelhas, sendo o segundo país com maior riqueza desses insetos (Ascher \& Pickering, 2018). Contudo, projeções para 2050 indicam que o aquecimento global reduzirá a probabilidade de ocorrência de polinizadores, impactando negativamente todos dos municípios produtores dessa cultura (Giannini et al., 2017), um cenário preocupante para a agricultura brasileira. Dessa forma, considerando a importância econômica do girassol para diferentes segmentos industriais brasileiros, nosso objetivo neste estudo foi avaliar a contribuição da comunidade de abelhas (1) na produção de sementes de girassol, (2) na composição nutricional do óleo e (3) no seu valor de mercado. 


\subsection{MATERIAL E MÉTODOS}

\subsubsection{Delineamento experimental}

O experimento foi conduzido na Escola Superior de Agricultura "Luiz de Queiroz", Universidade de São Paulo (Piracicaba, Estado de São Paulo; 2242’26.70” S, 47³7’58.54” O) de outubro de 2015 a fevereiro de 2016 (referido como 2015/16) e de outubro de 2016 a fevereiro de 2017 (2016/17). Em outubro de cada ano, sementes híbridas de girassol (BRS 323; EMBRAPA 2013) foram semeadas em cinco fileiras, espaçadas regularmente em 0,80m, em uma área de 25 x 6,25m. O canteiro de cultivo do girassol foi dividido em quatro blocos, com duas parcela cada, totalizando oito parcelas com 50 plantas de girassóis. Os experimentos para a semeadura do girassol foram planejados de forma a evitar qualquer variação aleatória que pudesse impedir as comparações analíticas entre os conjuntos de dados. Os procedimentos envolviam essencialmente o manejo usual do solo (mistura do solo, fertilização, irrigação), remoção manual de ervas-daninha e de insetos pragas e mesma época experimental entre os períodos de amostragem.

Das oito parcelas totais, quatro delas, no início da antese do girassol, tiveram sete capítulos escolhidos aleatoriamente e ensacados com nylon branco com malha de $1 \mathrm{~mm}$ para impedir a ação de polinizadores bióticos, ocorrendo apenas a autopolinização. E para cada uma das outras quatro parcelas, os capítulos permaneceram expostos e acessíveis aos visitantes e à autopolinização. Após o término da antese, foram escolhidos ao acaso sete capítulos em cada uma das quatro parcelas que estavam expostos e estes foram ensacados, a fim de evitar a ação de possíveis predadores de sementes. Assim, todos os capítulos ( $\mathrm{n}=56$ capítulos por período) permaneceram ensacados até o momento de sua coleta para avaliação dos aquênios formados.

\subsubsection{Comunidade de abelhas}

Cada parcela foi percorrida aleatoriamente por $5 \mathrm{~min}$, a cada hora, e todas as abelhas observadas nas flores foram coletadas com rede entomológica. A amostragem ocorreu quando mais de $90 \%$ das flores dos capítulos estavam abertas, em dia ensolarado, com temperatura superior a $20^{\circ} \mathrm{C}$, entre 7:00 e 16:00h, totalizando 9 coletas por parcela.

A riqueza e a diferença na composição de espécies foram comparadas nas amostragens realizadas com coletas ativas de 2015/16 e 2016/17 (Kindt \& Coe, 2005). A diversidade também foi estimada, tendo como referência o índice de Simpson, dada a evidência de espécies dominantes nas coletas e, consequentemente, por capturar a variância da distribuição da abundância das espécies. A diferença na composição de espécies foi estimada utilizando 
matrizes de distância ecológica, pelo método de Bray-Curtis, dada a necessidade de considerar a influência das maiores diferenças de abundância das espécies e por haver alta discrepância entre o número de indivíduos de algumas espécies coletadas, em especial Plebeia droryana, Tetragonisca angustula e A. mellifera. A matriz de distância produz valores entre 0 e 1 , indicando completa similaridade na composição de espécies encontradas em cada período quando igual a zero e completa dissimilaridade quando igual a 1. A distância ecológica também foi estimada pela distância de Hellinger, que leva em conta diferenças na proporção de espécies, sobretudo por considerar espécies com baixas abundâncias. Em virtude da alta discrepância entre os valores de abundância de algumas espécies, as matrizes de distância ecológica foram produzidas pressupondo diferentes cenários: (1) todas as espécies de abelhas; (2) abelhas sociais e solitárias; (3) abelhas sociais, excluindo as espécies mais abundantes em três diferentes cenários, $P$. droryana, T. angustula e A. mellifera. As análises foram realizadas utilizando linguagem e ambiente estatístico R (R Core Team 2011), empregando o pacote BiodiversityR (Kindt, 2016).

\subsubsection{Qualidade dos aquênios e valor de mercado}

Em janeiro de 2016 e 2017, 56 capítulos de girassol foram coletados (28 capítulos que foram ensacados e 28 capítulos que permaneceram expostos), secos à temperatura ambiente e debulhados manualmente para obter os aquênios. Para cada parcela, 1.000 aquênios de cada tratamento foram pesados aleatoriamente. Posteriormente, se analisou os dados usando o teste T com nível de significância de $5 \%$ ( $\mathrm{p}<0,05)$.

Para avaliar a qualidade nutricional, 500g de aquênios de cada grupo (ensacados e expostos) foram enviados para o Instituto de Tecnologia de Alimentos (ITAL; Campinas), onde foram submetidos a um processo de prensagem a frio para extração do óleo e de determinação do perfil de ácidos graxos e tocoferóis, segundo métodos da American Oil Chemists' Society (AOCS). Para distinguir os ésteres metílicos de ácidos graxos (saturados, mono- e poliinsaturados), as amostras foram submetidas à preparação de acordo com Hartman e Lago (1973), com adaptações do método proposto por Firestone (2014). Análises em cromatografia gasosa (Agilent Technologies, modelo 7890A) foram realizadas com equipamento contendo detector de ionização de chama. Após saponificação e esterificação, as amostras foram extraídas com hexano e o sobrenadante foi injetado no cromatógrafo. Os compostos foram separados em coluna capilar de sílica fundida CP-Sil 88 (100m x 0,25mm x 0,20mm; Agilent Technologies). A programação de temperatura da coluna foi iniciada em $130^{\circ} \mathrm{C}$ por 2 min., aquecida a 
$10^{\circ} \mathrm{C} \cdot \mathrm{min}^{-1}$ até $230^{\circ} \mathrm{C}$ e mantida em isotermia durante $20 \mathrm{~min}$. As temperaturas utilizadas no injetor e no detector foram 230 e $260^{\circ} \mathrm{C}$, respectivamente. As amostras foram injetadas no volume de $1 \mu 1$, adotando-se a razão de 1:75. O gás de arraste foi o hidrogênio com fluxo de 1 $\operatorname{ml} \cdot \min ^{-1}$.

Os ácidos graxos foram identificados pela comparação dos tempos de retenção de padrões puros de ésteres metílicos de ácidos graxos com os componentes separados das amostras, a quantificação foi realizada por normalização de área (\%) e os resultados expressos em g.100g $\mathrm{g}^{-}$ ${ }^{1}$ de amostra. A detecção e quantificação dos tocoferóis (alfa, beta e gama) foram realizadas em equipamento para cromatografia líquida (Prominence LC-20A), acoplado ao detector de fluorescência RF-10AXL (Shimadzu), utilizando o comprimento de onda de excitação em 292nm e de emissão em 336nm. Pesou-se 0,50g de óleo, que foi diluído em $n$-hexano. Os analitos foram separados em uma coluna de fase normal de LiChrospher Si 60 (12,5cm de comprimento x $4 \mathrm{~mm}$ de d.i. e partículas de $5 \mu \mathrm{m}$, Merck), tendo como fase móvel uma mistura de 97,6\% de $n$-hexano, 1,8\% de acetato de etila e 0,6\% ácido acético, em sistema isocrático. A quantificação foi por padronização externa, utilizando o padrão Tocoferol set (artigo 613424, Calbiochem).

Para o cálculo do valor de mercado dos aquênios, assumiu-se que (1) cada capítulo de girassol continha 1.000 flores férteis (Pisanty et al., 2014), (2) 40.000 plantas de girassol estavam espaçadas regularmente, em uma área de 1ha, como neste estudo, (3) pesos obtidos de 1.000 aquênios formados em capítulos ensacados e expostos a visitantes e no (4) preço de venda para os Estados Unidos (US\$ 379,00/t de aquênios, estabelecido em março de 2017 pela Companhia Nacional de Abastecimento (CONAB 2017).

\subsection{RESULTADOS}

\subsubsection{Comunidade de abelhas}

No total, foram amostrados 653 indivíduos pertencentes a 20 espécies de 18 gêneros de abelhas (Tabela 1). Apidae foi à família mais representativa, com 574 indivíduos de 13 espécies (Tabela 1), o que correspondeu a 87,9\% do total de abelhas. A segunda família mais amostrada foi Halictidae, com 79 abelhas pertencentes a sete espécies (Tabela 1).

Augochloropsis cupreola (Cockerell), Bombus morio (Swederus), Diadasina sp., Friesella schrottkyi (Friese), Neocorynura codion (Vachal), Pseudaugochlora graminea (Fabricius), Tetragona clavipes (Fabricius) foram amostrados exclusivamente em 2015/16, e 
representou 50\% das 18 espécies (Tabela 1). As espécies altamente eussociais, A. mellifera e T. clavipes, exibiram a maior frequência de indivíduos (36,47\% e 27,65\%, respectivamente). Em 2016/17, Geotrigona subterranea (Friese) e Melipona quadrifasciata Lepeletier foram coletadas exclusivamente durante este período e correspondiam a 18,18\% das 11 espécies capturadas, das quais a abelha sem ferrão $P$. droryana era a mais abundante, com 49,07\% dos indivíduos amostrados (Tabela 1).

Tabela 1. Espécies de abelhas, e respectivos números de indivíduos, amostradas com rede entomológica em área com plantio de girassol em 2015/16 e 2016/17.

\begin{tabular}{|c|c|c|c|c|}
\hline \multirow{2}{*}{ Família } & \multirow{2}{*}{ Tribo } & \multirow{2}{*}{ Espécie } & \multicolumn{2}{|c|}{$\mathrm{N}^{\circ}$ de indivíduos } \\
\hline & & & 2015/16 & $2016 / 17$ \\
\hline \multirow[t]{13}{*}{ Apidae } & Apini & Apis mellifera Linnaeus, 1758 & 62 & 57 \\
\hline & Bombini & Bombus (Fervidobombus) morio (Swederus, 1787) & 1 & 0 \\
\hline & Ceratinini & Ceratina sp. & 1 & 0 \\
\hline & Emphorini & Diadasina sp. & 3 & 0 \\
\hline & Exomalopsini & Exomalopsis (Exomalopsis) auropilosa Spinola, 1853 & 2 & 24 \\
\hline & Meliponini & Friesella schrottkyi (Friese, 1900) & 1 & 0 \\
\hline & & Geotrigona subterranea (Friese, 1901) & 0 & 6 \\
\hline & & Melipona quadrifasciata Lepeletier, 1836 & 0 & 1 \\
\hline & & Nannotrigona testaceicornis (Lepeletier, 1836) & 3 & 25 \\
\hline & & Plebeia droryana (Friese, 1900) & 5 & 237 \\
\hline & & Tetragona clavipes (Fabricius, 1804) & 47 & 0 \\
\hline & & Tetragonisca angustula (Latreille, 1811) & 10 & 69 \\
\hline & & Trigona spinipes Fabricius, 1793 & 7 & 13 \\
\hline \multirow[t]{7}{*}{ Halictidae } & Augochlorini & Augochlora (Augochlora) esox (Vachal, 1911) & 18 & 5 \\
\hline & & Augochlora (Oxystoglossella) morrae Strand, 1910 & 3 & 14 \\
\hline & & Augochlora sp. & 2 & 32 \\
\hline & & Augochloropsis cupreola (Cockerell, 1900) & 2 & 0 \\
\hline & & Neocorynura codion (Vachal, 1904) & 1 & 0 \\
\hline & & Pseudaugochlora graminea (Fabricius, 1804) & 1 & 0 \\
\hline & Halictini & Dialictus creusa (Schrottky, 1910) & 1 & 0 \\
\hline Total & & & 170 & 483 \\
\hline
\end{tabular}

A riqueza de espécies e o índice de Simpson tiveram seus valores ligeiramente reduzidos entre os períodos: 18 e 0,77 para 2015/16 e 11 e 0,71 para 2016/17. Entretanto, a abundância geral aumentou substancialmente, resultando em 170 indivíduos em 2015/16 e 483 em 2016/17. $\mathrm{O}$ aumento na abundância geral de abelhas pode ser explicado pela dominância de algumas espécies, sobretudo em 2016/17, quando 237 indivíduos de P. droryana, 69 de T. angustula e 57 de A. mellifera visitaram os capítulos de girassol. 
De maneira geral, observando a distância ecológica de Hellinger, havia uma tendência para baixo valor de matriz $(0,42)$, mostrando aumento na similaridade nos padrões de diversidade entre 2015/16 e 2016/2017. Quando os cenários foram avaliados de forma comparativa, as abelhas altamente eussociais apresentaram valor matricial $(0,46)$ muito próximo do valor obtido para as abelhas no total $(0,42)$, o que sugere que os padrões de similaridade entre os períodos foram determinados pelas espécies eussociais, provavelmente devido à alta abundância de algumas delas, como mencionado anteriormente. Quando o cenário avaliado foi composto apenas por abelhas solitárias, houve uma diminuição no valor da matriz $(0,33)$ quando comparado com o valor encontrado para abelhas eussociais $(0,46)$. Isso pode indicar que, quando a proporção de espécies com baixa abundância é considerada, as espécies solitárias tendem para a similaridade mais do que as abelhas eussociais. Das três espécies eussociais consideradas mais abundantes, a remoção de $P$. droryana resultou em menor valor matricial $(0,28)$ de todos os cenários (sem T. angustula: 0,51; sem A. mellifera: 0,52), sugerindo que sua remoção indica maior tendência à semelhança entre 2015/16 e 2016/17. Portanto, os cenários que indicaram a maior similaridade na composição de espécies entre os dois períodos foram aqueles com a remoção de $P$. droryana das espécies eussociais, e com as abelhas solitárias.

\subsubsection{Qualidade dos aquênios e valor de mercado}

O peso médio dos aquênios formados em capítulos expostos (média \pm s.d.: $74,27 \pm$ $7,35 \mathrm{~g})$ foi significativamente maior que aqueles formados em flores ensacadas $(38,82 \pm 10,27 \mathrm{~g})$ $(\mathrm{t}=-7,9388 ; p=0,000003)$. Ou seja, os visitantes florais contribuíram com o aumento no peso médio dos aquênios em 91,31\%. Considerando os períodos separadamente, os aquênios formados em capítulos expostos em 2015/16 foram 107,35\% mais pesados que os dos capítulos ensacados, enquanto que essa diferença de peso foi de 79,72\% nos capítulos de 2016/17 (Fig. $1)$. 


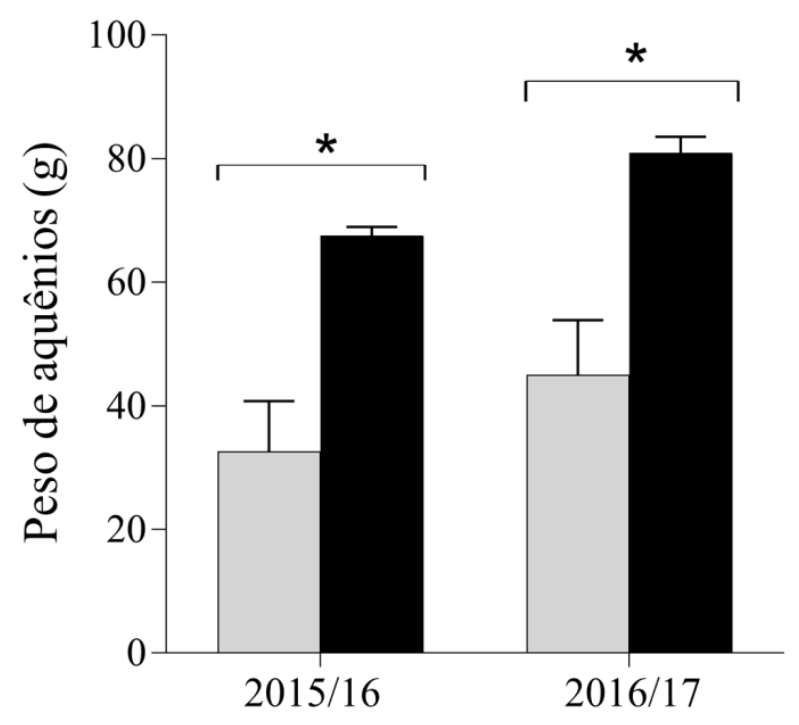

Fig. 1. Peso médio ( \pm desvio-padrão) de 1000 aquênios formados em capítulos de girassol expostos (pretos) e ensacados (cinzas) em 2015/16 e 2016/17. * Teste $\mathrm{t}, p<0,005$.

Para cada hectare de cultivo de girassol, a estimativa do preço de venda dos aquênios formados em capítulos ensacados foi de US\$ 588,51, enquanto os formados em capítulos expostos resultaram na estimativa de US\$1.125,93. Assim, os polinizadores incrementaram no valor de venda de aquênios de girassol em 91,31\%.

Considerando o valor nutricional do óleo de girassol, os níveis de ácidos graxos insaturados foram maiores em relação aos saturados, predominando o ácido oleico (ômega-9) entre os monoinstaurados e o ácido linoleico (ômega-6) entre os poli-insaturados (Tabela 2). , O alfa-tocoferol foi predominante entre os demais tocoferóis (Tabela 2).

Como em 2015/16 a maioria dos aquênios dos capítulos ensacados estava vazia (quando há falha na polinização, o resultado é um aquênio vazio), não foi possível extrair o óleo para as análises químicas. Dos capítulos expostos aos polinizadores nesse mesmo período, $23 \%$ da composição de $500 \mathrm{~g}$ de aquênios corresponderam a lipídeos. Entre os tocoferóis, o alfatocoferol correspondeu a 96,34\%, seguido pelo beta- e gama-tocoferol, 2,22\% e 1,44\%, respectivamente. Quanto aos ácidos graxos, o ômega-9 correspondeu a 99,46\% dos monoinsaturados, o ômega-6 a 100\% dos poli-insaturados, e ácidos palmítico e esteárico em $51,69 \%$ e 32,77\% dos saturados, respectivamente (Tabela 2). Em 2016/17, o óleo das sementes de capítulos expostos apresentou maiores teores de gama- $(160,71 \%)$, beta- $(54,90 \%)$ e alfatocoferol (40,06\%), e e ácidos linolênico (ômega-3; 13,33\%), behênico $(9,88 \%)$ e lignocérico $(7,14 \%)$, araquídico $(4,17 \%)$, esteárico $(4,05 \%)$ e linoleico $(3,83 \%)$, em comparação com óleo extraído das sementes dos capítulos ensacados no mesmo período. Entretanto, houve um 
decréscimo de teor dos ácidos palmítico (2,07\%), palmitoleico (ômega-7; 9,09\%) e oleico $(1,76 \%)$ (Tabela 2$)$.

Tabela 2. Composição do óleo de girassol obtido de sementes formadas em capítulos expostos a visitantes florais e por capítulos ensacados em 2015/16 e 2016/17.

\begin{tabular}{|c|c|c|c|c|}
\hline \multirow{2}{*}{ Componentes } & \multicolumn{2}{|c|}{$2015 / 16$} & \multicolumn{2}{|c|}{ 2016/17 } \\
\hline & expostos & ensacados & expostos & ensacados \\
\hline \multicolumn{5}{|l|}{ Tocoferois ( $\mathrm{mg} / 100 \mathrm{~g}$ ) } \\
\hline alfa-tocoferol (vitamina E) & 57,68 & - & 40,66 & 29,03 \\
\hline beta-tocoferol & 1,33 & - & 0,79 & 0,51 \\
\hline gama-tocoferol & 0,86 & - & 2,92 & 1,12 \\
\hline \multicolumn{5}{|l|}{ Ácidos graxos $(\mathrm{g} / 100 \mathrm{~g})$} \\
\hline Saturados & 8,30 & & 8,77 & 8,70 \\
\hline monoinsaturados & 47,89 & - & 51,44 & 52,53 \\
\hline poli-insaturados & 39,42 & - & 35,39 & 34,07 \\
\hline \multicolumn{5}{|c|}{ Composição em ácidos graxos $(\mathrm{g} / \mathrm{l} 100 \mathrm{~g})$} \\
\hline Palmítico & 4,29 & - & 4,25 & 4,34 \\
\hline palmitoleico (ômega-7) & 0,10 & - & 0,10 & 0,11 \\
\hline Esteárico & 2,72 & - & 3,08 & 2,96 \\
\hline oleico (ômega-9) & 47,63 & - & 51,35 & 52,27 \\
\hline linoleico (ômega-6) & 39,42 & - & 35,22 & 33,92 \\
\hline Araquídico & 0,22 & - & 0,25 & 0,24 \\
\hline linolênico (ômega-3) & 0,00 & - & 0,17 & 0,15 \\
\hline Behênico & 0,78 & - & 0,89 & 0,81 \\
\hline Lignocérico & 0,29 & - & 0,30 & 0,28 \\
\hline
\end{tabular}

\subsection{DISCUSSÃO}

Este estudo mostra que os polinizadores desempenham um papel essencial no aumento da qualidade dos aquênios e, portanto, no valor de mercado dos híbridos de girassóis. Embora haja esforços para o desenvolvimento de cultivares híbridas de girassol com altos níveis de autocompatibilidade e menos dependentes da polinização cruzada, surpreendentemente, os polinizadores contribuíram com aumento de $91 \%$ no peso dos aquênios e no aumento dos níveis de alguns ácidos graxos, especialmente, de tocoferóis no óleo.

Mesmo em uma pequena área de cultivo de girassol $\left(100 \mathrm{~m}^{2}\right)$, registrou-se elevado número de espécies de abelhas, corroborando estudos anteriores realizados no Brasil (Morgado et al. 2002), Estados Unidos (Parker, 1981; Greenleaf \& Kremen, 2006), Espanha (Hevia et al., 2016) e África do Sul (Carvalheiro et al., 2011). Considerando as 20 espécies amostradas nos capítulos de girassol, 50\% eram espécies altamente eussociais. Estas espécies foram visitantes florais dominantes, e as abelhas nativas sem ferrão (P. droryana, T. clavipes e T. angustula) e 
a exótica $A$. mellifera corresponderam a $56,4 \%$ e $18,3 \%$ dos indivíduos, respectivamente. $\mathrm{O}$ predomínio de abelhas altamente eussociais era esperado, pois suas colônias perenes consistem de uma rainha-mãe e um alto número de operárias (por exemplo, A. mellifera: dezenas de milhares de operárias (Michener, 1974); P. droryana: 3.000 operárias; T clavipes: 7.000 operárias; T. angustula: 5.000 operárias (Tóth et al., 2004)) que necessitam de suprimento nutricional constante para garantir sua sobrevivência, especialmente durante períodos de escassez de recursos florais (Maia-Silva et al., 2016). Assim, há uma diversidade de estratégias de forrageamento e sinais utilizados pelas abelhas para orientar suas companheiras de ninho a fontes ricas de alimentos (Jarau \& Hrncir, 2009), pois necessitam de um suprimento constante de néctar e pólen que são obtidos a partir de uma ampla gama de espécies de plantas (Kleinert et al., 2009).

O girassol é uma fonte altamente atraente de néctar e pólen para abelhas (Parker, 1981), especialmente para as espécies sem ferrão. Devido às suas características biológicas e comportamentais anteriormente mencionadas, elas são ecologicamente dominantes em comparação com os outros visitantes florais nativos na região Neotropical (Roubik, 1989). Durante 2015/16, T. clavipes foi a espécie nativa mais dominante, enquanto $P$. droryana mostrou maior abundância entre os visitantes florais no segundo período. Quando $P$. droryana foi removida do grupo de abelhas altamente eussociais com relação à análise de distância de Hellinger, a composição de espécies desse grupo foi mais similar considerando os dois períodos. Este resultado, assim como nas análises obtidas com abelhas solitárias, mostrou que a alta abundância de poucas espécies pode influenciar negativamente a diversidade geral das espécies de abelhas, uma vez que tanto a riqueza como a diversidade de espécies tiveram baixos declínios nos dois períodos.

No entanto, o aumento expressivo no peso médio dos aquênios, com 67,64g em 2015/16 e 80,90g em 2016/17, pode ser em parte atribuído ao aumento da abundância total de abelhas. Mesmo que a comunidade de visitantes florais fosse composta por vários taxa, a eficiência de polinização das abelhas em uma determinada cultura depende de seu comportamento nas flores e sobre a probabilidade de transferir o pólen de seus corpos para os estigmas das flores de plantas coespecíficas (Woodcock et al., 2013). Mesmo que A. mellifera seja o visitante mais abundante em diversas culturas que necessitam de polinização animal, incluindo os girassóis (Morgado et al., 2002; Greenleaf \& Kremen, 2006; Carvalheiro et al., 2011), a produtividade das culturas aumenta substancialmente com os serviços de polinização providos por insetos nativos silvestres (Garibaldi et al., 2013). Os resultados obtidos neste estudo são consistentes 
com estudos anteriores, sugerindo que os visitantes florais nativos interagem eficazmente com as culturas e contribuem significativamente para a polinização e produção da maioria das culturas, independentemente da abundância de A. mellifera (Garibaldi et al., 2013), reafirmando que a abundância de espécies de abelhas nativas é relevante para a estabilidade das culturas (Garibaldi et al., 2011).

A maior densidade de visitantes florais poderia aumentar a produtividade das culturas em uma média de $24 \%$ em cultivos com menos de 2 hectares, que são muito comuns em países em desenvolvimento como o Brasil, aumentando assim os meios de subsistência de pequenos produtores (Garibaldi et al., 2016). Considerando que, devido aos serviços de polinização providos pelas abelhas, os produtores do cultivar de girassol utilizado neste estudo quase duplicaram o valor de venda dos aquênios por hectare de área cultivada, a restauração e conservação de habitats para polinizadores silvestres, incluindo os recursos florais e locais de nidificação dentro da paisagem agrícola, aumentam a biodiversidade e os serviços ecossistêmicos que esses organismos fornecem (Garibaldi et al., 2011; Wratten et al., 2012).

Os polinizadores incrementaram, além do peso dos aquênios, a composição do óleo de girassol. O óleo das sementes de girassóis expostos apresentou um aumento de 44,7\% do total de tocoferóis quando em comparação com o óleo de sementes das flores em que os polinizadores foram excluídos. Os tocoferóis e tocotrienóis compõem a família da vitamina E, considerada o antioxidante mais importante na dieta humana (Mathur et al., 2015), e uma grande parcela está presente nas culturas dependentes de polinizadores (alfa-: 36\% das culturas; beta-: 99\%; gama-tocoferol: 67\%, Eilers et al., 2011). Entre os tocoferóis encontrados no óleo de girassol, o alfa-tocoferol constitui a maior porção e aumentou 40,1\% nos girassóis expostos. No entanto, o gama-tocoferol mostrou um aumento substancial de 160,7\%. Embora o alfatocoferol seja o análogo mais conhecido da vitamina E, os estudos mais recentes sugerem que o gama-tocoferol apresenta efeitos antioxidantes, cardioprotetores e anti-inflamatórios mais potentes do que o alfa-tocoferol (revisado por Mathur et al., 2015).

Em relação aos ácidos graxos presente no óleo de girassol foi detectado pequena diferença entre girassóis expostos e ensacados, ao contrário dos tocoferóis. Entre os ácidos graxos poliinsaturados, o nível de ômega- 6 foi 3,8\% maior em aquênios de girassóis expostos. Embora o nível de ômega-3 seja extremamente inferior ao nível de ômega-6, os polinizadores afetaram o primeiro em 13,3\%. Em relação aos ácidos saturados, eles compuseram menos de $10 \%$ de ácidos graxos, e o óleo extraído de aquênios de girassóis expostos apresentou níveis ligeiramente inferiores de ácido palmítico e um nível de ácido esteárico um pouco mais alto do 
que os dos girassóis ensacados. Como óleos de girassol com alto teor de ômega-9 (ácido monoinsaturado) e ômega-6 (ácido poli-insaturado) e baixos teores de ácidos saturados são mais saudáveis, estratégias têm sido implementadas para o desenvolvimento de cultivares de girassol com essas características (Raß et al., 2008), como é o caso do híbrido BRS 323 utilizado neste estudo. Óleos com maiores teores de ômega-9 e ômega-6 apresentaram maior nível de estabilidade oxidativa, o que é desejável para frituras, refino e armazenamento, e também, melhor propriedade dietética, uma vez que reduz o colesterol no sangue (Flagella et al., 2002). No entanto, o mesmo cultivar de girassol pode apresentar diferenças nos níveis de ácidos graxos, dependendo das condições, tais como temperatura, luz e disponibilidade de água e no período de semeadura (Flagella et al., 2002).

Semelhante a este estudo, os polinizadores melhoraram a composição nutricional de frutos e sementes de várias culturas globalmente importantes. Por exemplo, os insetos polinizadores, particularmente as abelhas, influenciaram no teor de clorofila da canola (Brassica napus, Bommarco et al., 2012), nas proporções de ácido oleico e do linoleico na amêndoa (Prunus dulcis, Brittain et al., 2014) e na relação açúcar-ácido em morango (Fragaria $x$ ananassa, Klatt et al., 2014). Assim, o presente estudo destaca a importância das abelhas, como provedoras de polinização cruzada, para a qualidade nutricional e o valor de mercado dos aquênios de girassol. Além disso, esses resultados fornecem dados básicos úteis para avaliações adicionais dos efeitos dos polinizadores na dieta e saúde humana (Eilers et al., 2011; Potts et al., 2016).

\section{REFERÊNCIAS}

Ascher JS, Pickering J, 2018. Discover life: bee species guide and world checklist (Hymenoptera: Apoidea: Anthophila). http://www.discoverlife.org/mp/20q?guide=Apoidea_species\&flags=HAS (accessed 08 April 2018).

Bommarco R, Marini L, Vaissière BE, 2012. Insect pollination enhances seed yield, quality, and market value in oilseed rape. Oecologia 169: 1025-1032.

Brittain C, Kremen C, Garber A, Klein A-M, 2014. Pollination and plant resources change the nutritional quality of almonds for human health. PLoS ONE 9: e90082.

Carvalheiro LG, Veldtman R, Shenkute AG, Tesfay GB, Pirk CWW, Donaldson JS, Nicolson SW, 2011. Natural and within-farmland biodiversity enhances crop productivity. Ecology Letters 14: 251-259.

Degrandi-Hoffman G, Chambers M, 2006. Effects of honey bee (Hymenoptera: Apidae) foraging on seed set in self-fertile sunflowers (Helianthus annuus L.). Environmental Entomology 35: 1103-1108.

Eilers EJ, Kremen C, Greenleaf SS, Garber AK, Klein A-M, 2011. Contribution of pollinatormediated crops to nutrients in the human food supply. PLoS ONE 6: e21363. 
FAO/WHO, 2015. Codex Standards for Named Vegetable Oils. CODEX-STAN 210 - 1999 $\begin{array}{llll}\text { (Amended 2005, 2011, 2015). } & \text { 2013, }\end{array}$ http://www.fao.org/docrep/004/y2774e/y2774e04.htm (accessed 21/02/2018).

Firestone D, 2014. Official Method Ce 1a-13 e Ce 1h-05. Official methods and recommended practices of the AOCS. AOCS Press, Illinois.

Flagella Z, Rotunno T, Tarantino E, Di Caterina R, De Caro A, 2002. Changes in seed yield and oil fatty acid composition of high oleic sunflower (Helianthus annuus L.) hybrids in relation to the sowing date and the water regime. European Journal of Agronomy 17: 221-230.

Free JB, 1993. Insect pollination of crops. Academic Press, London.

Garibaldi LA, Carvalheiro LG, Vaissière BE, Gemmill-Herren B, Hipólito J, Freitas BM, Ngo HT, Azzu N, Sáez A, Åström J, 2016. Mutually beneficial pollinator diversity and crop yield outcomes in small and large farms. Science 351: 388-391.

Garibaldi LA, Steffan-Dewenter I, Kremen C, Morales JM, Bommarco R, Cunningham SA, Carvalheiro LG, Chacoff NP, Dudenhoeffer JH, Greenleaf SS, 2011. Stability of pollination services decreases with isolation from natural areas despite honey bee visits. Ecology Letters 14: 1062-1072.

Garibaldi LA, et al., 2013. Wild pollinators enhance fruit set of crops regardless of honey bee abundance. Science 339: 1608-1611.

Giannini TC, Cordeiro GD, Freitas BM, Saraiva AM, Imperatriz-Fonseca VL, 2015. The dependence of crops for pollinators and the economic value of pollination in Brazil. Journal of Economic Entomology 108: 849-857.

Giannini TC, Costa WF, Cordeiro GD, Imperatriz-Fonseca VL, Saraiva AM, Biesmeijer J, Garibaldi LA, 2017. Projected climate change threatens pollinators and crop production in Brazil. PLoS ONE 12: e 0182274.

Godfray HCJ, Beddington JR, Crute IR, Haddad L, Lawrence D, Muir JF, Pretty J, Robinson S, Thomas SM, Toulmin C, 2010. Food security: the challenge of feeding 9 billion people. Science 327: 812-818.

Greenleaf SS, Kremen C, 2006. Wild bees enhance honey bees' pollination of hybrid sunflower. Proceedings of the National Academy of Sciences, USA 103: 13890-13895.

Hartman L, Lago R, 1973. Rapid preparation of fatty acid methyl esters from lipids. Laboratory Practice 22: 475-756.

Hevia V, Bosch J, Azcárate FM, Fernández E, Rodrigo A, Barril-Graells H, González JA, 2016. Bee diversity and abundance in a livestock drove road and its impact on pollination and seed set in adjacent sunflower fields. Agriculture, Ecosystems \& Environment 232: 336-344.

Isaacs R, Williams N, Ellis J, Pitts-Singer TL, Bommarco R, Vaughan M, 2017. Integrated Crop Pollination: Combining strategies to ensure stable and sustainable yields of pollinationdependent crops. Basic and Applied Ecology 22: 44-60.

Jarau S, Hrncir M (Eds.), 2009. Food exploitation by social insects: ecological, behavioral, and theoretical approaches. CRC Press, Taylor \& Francis Group, Boca Raton.

Kindt R, 2016. Package 'BiodiversityR'. http://www.r-project.org (accessed 02/02/2018).

Kindt R, Coe R, 2005. Tree diversity analysis: a manual and software for common statistical methods for ecological and biodiversity studies. World Agroforestry Centre, Nairobi.

Klatt BK, Holzschuh A, Westphal C, Clough Y, Smit I, Pawelzik E, Tscharntke T, 2014. Bee pollination improves crop quality, shelf life and commercial value. Proceedings of the Royal Society B 281: 20132440. 
Klein AM, Vaissière BE, Cane JH, Steffan-Dewenter I, Cunningham SA, Kremen C, Tscharntke T, 2007. Importance of pollinators in changing landscapes for world crops. Proceedings of the Royal Society B 274: 303-313.

Kleinert AMP, Ramalho M, Cortopassi-Laurino M, Imperatriz-Fonseca VL, 2009. Abelhas sociais (Bombini, Apini, Meliponini). In: Panizzi, A.R., Parra, J.R.P. (Eds.), Bioecologia e nutrição de insetos. EMBRAPA Informação Tecnológica, Brasília, pp. 371-424.

Maia-Silva C, Hrncir M, Imperatriz-Fonseca VL, Schorkopf DLP, 2016. Stingless bees (Melipona subnitida) adjust brood production rather than foraging activity in response to changes in pollen stores. Journal of Comparative Physiology A 202: 723-732.

Mathur P, Ding Z, Saldeen T, Mehta JL, 2015. Tocopherols in the prevention and treatment of atherosclerosis and related cardiovascular disease. Clinical Cardiology 38: 570-576.

Michener CD, 1974. The social behavior of the bees: a comparative study. Belknap Press of Harvard University Press, Massachusetts.

Morgado LN, Carvalho CF, Souza B, Santana MP, 2002. Fauna de abelhas (Hymenoptera: Apoidea) nas flores de girassol Helianthus annuus L. Ciencia e Agrotecnologia 26: 1167-1177.

Parker FD, 1981. Sunflower pollination: abundance, diversity and seasonality of bees and their effect on seed yields. Journal of Apicultural Research 20: 49-61.

Pisanty G, Klein A-M, Mandelik Y, 2014. Do wild bees complement honeybee pollination of confection sunflowers in Israel? Apidologie 45: 235-247.

Potts SG, Imperatriz-Fonseca VL, Ngo HT, Aizen MA, Biesmeijer JC, Breeze TD, Dicks LV, Garibaldi LA, Hill R, Settele J, Vanbergen AJ, 2016. Safeguarding pollinators and their values to human well-being. Nature 540: 220-229.

$\mathrm{Raß} \mathrm{M,} \mathrm{Schein} \mathrm{C,} \mathrm{Matthäus} \mathrm{B,} \mathrm{2008.} \mathrm{Virgin} \mathrm{sunflower} \mathrm{oil.} \mathrm{European} \mathrm{Journal} \mathrm{of} \mathrm{Lipid} \mathrm{Science}$ and Technology 110: 618-624.

Roubik DW, 1989. Ecology and natural history of tropical bees. Cambridge University Press, Cambridge.

Smith MR, Singh GM, Mozaffarian D, Myers SS, 2015. Effects of decreases of animal pollinators on human nutrition and global health: a modelling analysis. The Lancet 386: 1964-1972.

Steffan-Dewenter I, Potts SG, Packer L, 2005. Pollinator diversity and crop pollination services are at risk. Trends in Ecology \& Evolution 20: 651-652.

Tilman D, Balzer C, Hill J, Befort BL, 2011. Global food demand and the sustainable intensification of agriculture. Proceedings of the National Academy of Sciences, USA 108: 20260-20264.

Tóth E, Queller DC, Dollin A, Strassmann JE, 2004. Conflict over male parentage in stingless bees. Insectes Sociaux 51: 1-11.

UN, 2017. World Population Prospects: The 2017 Revision, Key Findings and Advance Tables. In: Department of Economic and Social Affairs, P.D. (Ed.). United Nations, New York.

Woodcock B, Edwards M, Redhead J, Meek W, Nuttall P, Falk S, Nowakowski M, Pywell R, 2013. Crop flower visitation by honeybees, bumblebees and solitary bees: Behavioural differences and diversity responses to landscape. Agriculture, Ecosystems \& Environment 171: 1-8.

Wratten SD, Gillespie M, Decourtye A, Mader E, Desneux N, 2012. Pollinator habitat enhancement: benefits to other ecosystem services. Agriculture, Ecosystems \& Environment 159: 112-122. 


\title{
3. EFEITOS DA COBERTURA FLORESTAL E DA HETEROGENEIDADE ESPACIAL NA COMUNIDADE DE INSETOS
}

\section{RESUMO}

A perda de habitat é um dos principais fatores para o declínio da população de insetos, ameaçando os diversos serviços ecossistêmicos em sistemas naturais e agrícolas. O objetivo deste estudo foi avaliar os efeitos da cobertura florestal e do uso de solo na comunidade de insetos que visitam as flores do girassol. Para isso, cinquenta plantas com flores foram disponibilizadas em 12 paisagens, com $1 \mathrm{~km}$ de raio, em um gradiente de cobertura florestal e heterogeneidade espacial na Mata Atlântica, Corredor Cantareira-Mantiqueira, Estado de São Paulo. Com uso de rede entomológica, foram amostrados 2.181 indivíduos pertencentes a 130 espécies de insetos de 40 famílias de seis ordens. As abelhas foram os visitantes florais mais abundantes $(77,2 \%)$ e com maior riqueza (36,9\%). A exótica Apis mellifera foi a espécie mais representativa em todos os insetos, seguida pela abelha sem ferrão nativa Trigona spinipes. Dentre os fatores abióticos, a temperatura foi a única que influenciou positivamente os índices de diversidade das abelhas que visitaram os girassóis. Em relação à composição da paisagem, a proporção de cobertura florestal afetou negativamente a riqueza de insetos e a heterogeneidade espacial não exerceu efeito significativo nos índices de diversidade. Contudo, ao interpretar esses dados, é necessário levar em consideração a qualidade dos habitats naturais, os traços comportamentais e ecológicos e adaptações de cada espécie a ambientes degradados. Este estudo fornece informações importantes sobre a resposta das comunidades de insetos que visitam girassóis ao uso de solo, fornecendo dados básicos úteis para estratégias políticas que podem auxiliar na proteção dos polinizadores tropicais.

Palavras-chave: Ações antrópicas, Paisagem, Mata Atlântica, Biodiversidade, Girassol

\begin{abstract}
Habitat loss is one of the main drivers to insect declines, threating many ecosystem services in natural and agricultural systems. The aim of this study was to evaluate the effects of forest cover and land use on sunflower-visiting insect community. Fifty flowering plants were allocated in 12 landscapes, with $1 \mathrm{~km}$ radius, across a gradient of spatial heterogeneity and Atlantic Rainforest cover, in the Cantareira-Mantiqueira Corridor, São Paulo State. With an entomological net, 2,181 insects belonging to 130 species of 40 families (six orders) were sampled. Bees were the most abundant (77.2\%) and the richest (36.9\%) sunflower visitor. The exotic Apis mellifera was the most representative species of all insects, followed by the native stingless bee Trigona spinipes. Among the abiotic factors, temperature positively influenced on bee diversity. In relation to the landscape composition, the proportion forest cover negatively affected insect richness, while spatial heterogeneity did not have a significant effect on diversity indexes. However, it is necessary to interpret these data with caution and to take in account the quality of the natural habitats surrounding the sunflowers and the behavioral and ecological traits of each insect species. This study provides important data related to the responses of sunflower-visiting insect community to the land use, providing useful baseline figures to policy strategies that can help to safeguard tropical pollinators.
\end{abstract}


Keywords: Anthropic actions, Landscape, Atlantic rainforest, Biodiversity, Sunflower

\subsection{INTRODUÇÃO}

Diversas ações antrópicas vêm ocasionando a perda da biodiversidade em todo o planeta (Laurance et al., 2014; Newbold et al., 2015). O desmatamento e a fragmentação de habitats naturais acarretaram a formação de pequenas manchas de floresta e de mosaicos da paisagem (Bennett \& Saunders, 2010). Essas modificações ambientais são mais agravantes nos trópicos, uma vez que mais de $50 \%$ da sua floresta original foram convertidas em terras agriculturáveis (Hansen et al. 2013; Laurance et al., 2014), com perda anual de $2.101 \mathrm{~km}^{2}$ (Hansen et al., 2013). Além da expansão agrícola, a urbanização e a industrialização também são responsáveis pela redução de habitats naturais nessas regiões (Newbold et al., 2015), apresentando efeitos drásticos na biodiversidade (Foley et al., 2005), em especial os insetos (Janzen \& Hallwachs, 2019).

Os insetos são os animais mais abundantes e diversos da Terra, com cerca de 5,5 milhões de espécies (IPBES, 2019). Além disso, os insetos provêm importantes serviços ecossistêmicos em sistemas naturais e agrícolas (Costanza et al., 1997), uma vez que participam da ciclagem de nutrientes e fertilidade do solo (Nichols et al., 2008; Evans et al., 2011; Culliney, 2013), são agentes naturais de controle de pragas e polinizadores (Losey \& Vaughan, 2006; Kremen et al., 2007; Aizen et al., 2009; Garibaldi et al., 2011). Contudo, a provisão desses serviços está ameaçada tanto pela diminuição de suas populações, quanto na mudança da composição das comunidades (Potts et al., 2016). Neste sentido, as ações antrópicas podem acarretar no deslocando de algumas espécies de insetos para comunidades com menor riqueza e dominadas por generalistas (Giannini et al., 2012).

Diversos estudos evidenciaram a resposta das comunidades de insetos frente às alterações na composição da paisagem, mais especificamente a quantidade de habitats (semi-)naturais e heterogeneidade (e.g., Steffan-Dewenter et al., 2002; Ricketts, 2004; Kremen et al., 2004; Brosi et al., 2007, 2009; Moreira et al., 2015; Boscolo et al., 2017; Fijen et al., 2019). Paisagens com mais floresta tropical influenciaram positivamente a comunidade de insetos polinizadores (Ricketts, 2004; Saturni et al., 2016), uma vez que fornecem locais adequados para nidificação, reprodução e obtenção de alimentos (Roubik, 1989; Wratten et al., 2012). Contudo, ambientes não-florestados também são importantes para esses organismos, uma vez que em paisagens mais heterogêneas a abundância e riqueza tendem a ser maiores (Boscolo et al., 2017; Nery et 
al. 2018). No entanto, esses dois efeitos de composição também podem interagir na mesma paisagem (Moreira et al., 2015).

A Mata Atlântica brasileira tem sido considerada um importante modelo de estudo, pois está altamente fragmentada e cercada por matrizes comportas por pastagens e campos agrícolas (Ribeiro et al., 2009). Também, comporta diversificada biota, incluindo visitantes florais exclusivos (Boscolo et al., 2017; Nery et al. 2018), porém é uma das florestas mais ameaçadas do mundo (Mittermeier et al., 2004; Joly et al., 2014). Neste sentido, o girassol também constitui um excelente modelo, devido à alta atratividade de espécies de visitantes florais, uma vez que produz muito néctar e pólen (Parker, 1981). Além disso, essa cultura agrícola é altamente dependente de insetos para realização da polinização cruzada (Greenleaf \& Kremen, 2006; Carvalheiro et al. 2012; Sardiñas \& Kremen, 2015; Giannini et al. 2015).

O girassol é utilizado na sucessão e rotação de culturas e na nutrição animal. A partir de 2004 foi uma das oleaginosas inseridas no Programa Nacional de Produção e Uso do Biodiesel (PNPB), ganhando maior destaque no cenário agrícola brasileiro (BRASIL, 2004). O PNPB visa a produção e o mercado de biocombustível, a inclusão social na cadeia produtiva e o menor impacto do meio ambiente (BRASIL, 2004). Apesar do Brasil não ser um dos maiores produtores de girassol do mundo, ele possui atualmente 95,5 mil hectares de área cultivadas, produzindo 149.000 toneladas, sendo o Centro-Oeste a região mais representativa no país (CONAB, 2019). Assim, a fim de prover mais dados e contribuir para o entendimento da resposta da biodiversidade às alterações na composição da paisagem na região tropical, pretende-se investigar (1) como a cobertura florestal e (2) a heterogeneidade espacial afetam a comunidade de insetos que visitam as flores do girassol na Mata Atlântica.

\subsection{MATERIAL E MÉTODOS}

\subsubsection{Região de estudo e período de estudo}

O estudo foi realizado na porção sudeste da Mata Atlântica, entre as Serras da Cantareira e da Mantiqueira, no Estado de São Paulo, Brasil (Fig. 1). Essa região possui vegetação do tipo ombrófila densa e é considerada um corredor ecológico por promover a conectividade dos fragmentos florestais e protegem a recursos hídricos (Whately \& Cunha, 2007). O sistema de abastecimento Cantareira é o maior reservatório de água da Região Metropolitana de São Paulo (ANA, 2019) e abastece mais de 50\% da cidade (Ditt et al., 2010), em torno de 8,8 milhões de pessoas (Whately \& Cunha, 2007). Diante disso, a região da Cantareira foi inserida na Reserva da Biosfera do Cinturão Verde da cidade de São Paulo pela UNESCO (Jaeger, 2005; Nery et 
al., 2018). As altitudes são de 700 a 2000m, com uma estação seca entre abril e agosto e outra chuvosa de setembro a março (Barbosa et al., 2017). O experimento foi conduzido em janeiro de 2017 , quando a temperatura variou de 16,5 a $35,8^{\circ} \mathrm{C}$ e a umidade relativa de 30,4 a $98,3 \%$ durante o período da manhã e à tarde (Anexo A).

\subsubsection{Seleção das paisagens e Métricas de paisagem}

Para quantificação das métricas de paisagem da região, foram utilizadas imagens aéreas e de satélite com menos de $1 \mathrm{~m}$ de resolução, disponíveis na extensão Basemap, além das informações de campo sobre a região. A partir disso, foram recortados diferentes ambientes na escala de 1:5000 e, posteriormente, foram atribuídas 19 classes do uso e ocupação do solo a cada recorte (Fig. 1). Foram identificadas 19 classes da paisagem: corpo hídrico, cerca-viva, solo exposto, áreas degradadas, pasto, pasto com arbustos, agricultura anual, agricultura perene, silvicultura (eucaliptos), pântano, pântano com arbustos, pântano com floresta inicial, área rural, área urbana, rodovia, e florestas pioneira, inicial, intermediária e madura (Fig. 1). A heterogeneidade da paisagem foi calculada a partir do índice de diversidade de Shannon (Shannon \& Weaver 1998; McGarigal et al., 2012), utilizando janelas móveis de 1000m e a proporção de floresta foi calculada no GRASS 6.4.

Foram selecionadas 12 paisagens com raio de $1 \mathrm{~km}$ (Fig. 1), considerando um gradiente de diversidade de Shannon da paisagem de 1,27 a 2,35 e de cobertura florestal entre 13 e $61 \%$ (Fig. 1). Para reduzir a autocorrelação espacial entre os pontos de amostragem, a distância mínima entre as paisagens selecionadas foi de $3 \mathrm{~km}$, devido às distâncias de voo das abelhas (revisão em Zurbuchen et al., 2010). 


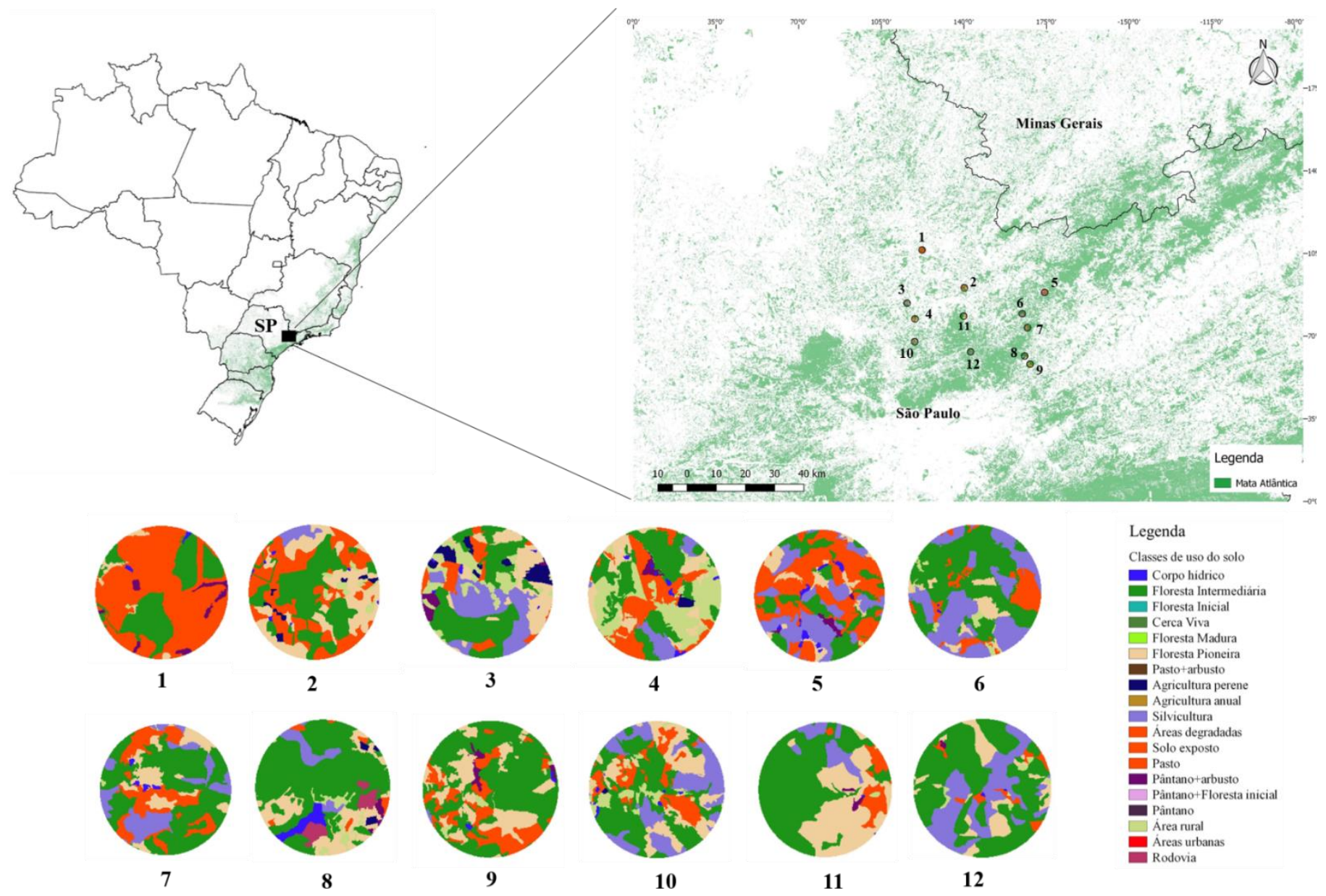

Fig. 1. Região de estudo no Corredor Cantareira-Mantiqueira, porção sudeste da Mata Atlântica, Estado de São Paulo, Brasil. As 12 paisagens, com raio de $1 \mathrm{~km}$, apresentam, respectivamente, a cobertura florestal e as classes de uso de solo: (1) 13,3\% e 2,04; (2) 19,9\% e 2,03 ; (3) $35,8 \%$ e 2,06 ; (4) $38,6 \%$ e 1,79 ; (5) $43,5 \%$ e 1,52 ; (6) $45,3 \%$ e 1,73 ; (7) $47,4 \%$ e 1,82 ; (8) $48,6 \%$ e 1,27 ; (9) $49,2 \%$ e 2,14 ; (10) $56,5 \%$ e 1,83 ; (11) $57,4 \%$ e 1,63 ; (12) $60,6 \%$ e 2,35 .

\subsubsection{Modelo de estudo}

O girassol é planta dicotiledônea com inflorescência do tipo capítulo, composto por um receptáculo onde estão inseridas flores tubulares e liguladas. As flores tubulares são férteis e hermafroditas, e cada uma apresenta cinco estames. O ovário é um pistilo alongado, cujo estigma bífido curvo aparece na parte superior da flor quando ela está em plena antese. Essas flores estão distribuídas em toda a superfície do receptáculo e podem ter entre 1.000 e 2.000 por capítulo (Rossi, 1998; Pisanty et al., 2014; Witter et al., 2015). Essas flores férteis abrem da periferia para o centro, de dois a quatro discos por dia, sendo que cada flor passa primeiro pelo estágio masculino e o segundo feminino, ou seja, as anteras amadurecem antes do estigma estar receptivo ao pólen (Free, 1993). O período de florescimento do girassol ocorre de 6 a 10 
dias (Free, 1993). As flores liguladas são incompletas, com um ovário e cálice rudimentar, e uma corola transformada, semelhante a uma pétala, nesse caso de cor amarelo-alaranjado. Essas flores têm forma oval-lanceolada e estão distribuídas em todo o perímetro do capítulo. Geralmente, encontram-se de trinta a setenta flores liguladas por capítulo (Rossi, 1998; Witter et al., 2015). Apesar da autofecundação ser possível, especialmente dos cultivares híbridos, o girassol tem uma baixa taxa de polinização anemófila, mas é altamente dependente de insetos para mediar a polinização cruzada entre flores da mesma planta (McGregor, 1976; Free, 1993). O híbrido de girassol utilizado neste estudo foi o BRS 323 (EMBRAPA, 2013).

\subsubsection{Delineamento experimental}

Em novembro de 2016, 600 vasos foram semeados com girassol em casa de vegetação, submetidos às mesmas condições de irrigação, de solo, temperatura e umidade relativa no Departamento de Entomologia e Acarologia da Escola Superior de Agricultura "Luiz de Queiroz", Universidade de São Paulo (LEA, ESALQ/USP). Em janeiro de 2017, quando as flores atingiram o estágio reprodutivo em 60 a $80 \%$ das flores tubulares abertas, 50 vasos foram transportados e instalados em propriedades rurais particulares localizadas em cada uma das 12 áreas de estudo em oito municípios: Atibaia, Bragança Paulista, Bom Jesus dos Perdões, Jarinu, Nazaré Paulista, Piracaia, Santa Isabel e Mairiporã (Fig. 2).

\subsubsection{Amostragem dos visitantes florais}

Dois observadores percorreram aleatoriamente os espaços entre os vasos com as plantas durante 20min, a cada hora, em cada área de estudo e todos os insetos avistados nos capítulos de girassol foram coletados com rede entomológica (Fig. 2). A amostragem de insetos foi realizada nove vezes, entre 7:00 e15:00h, durante três dias consecutivos, totalizando 27 amostras por área. As abelhas foram identificadas pelo Prof. Dr. Eduardo A. B. Almeida, do Laboratório de Biologia Comparada e Abelhas (LBCA) do Departamento de Biologia, FFCLRP/USP. Grande parte das espécies de moscas foi identificada pelo Prof. Dr. Roberto A. Zucchi e outros grupos de insetos pelo Prof. Dr. Sinval Silveira-Neto, ambos do Departamento de Entomologia e Acarologia, LEA, ESALQ/USP. 


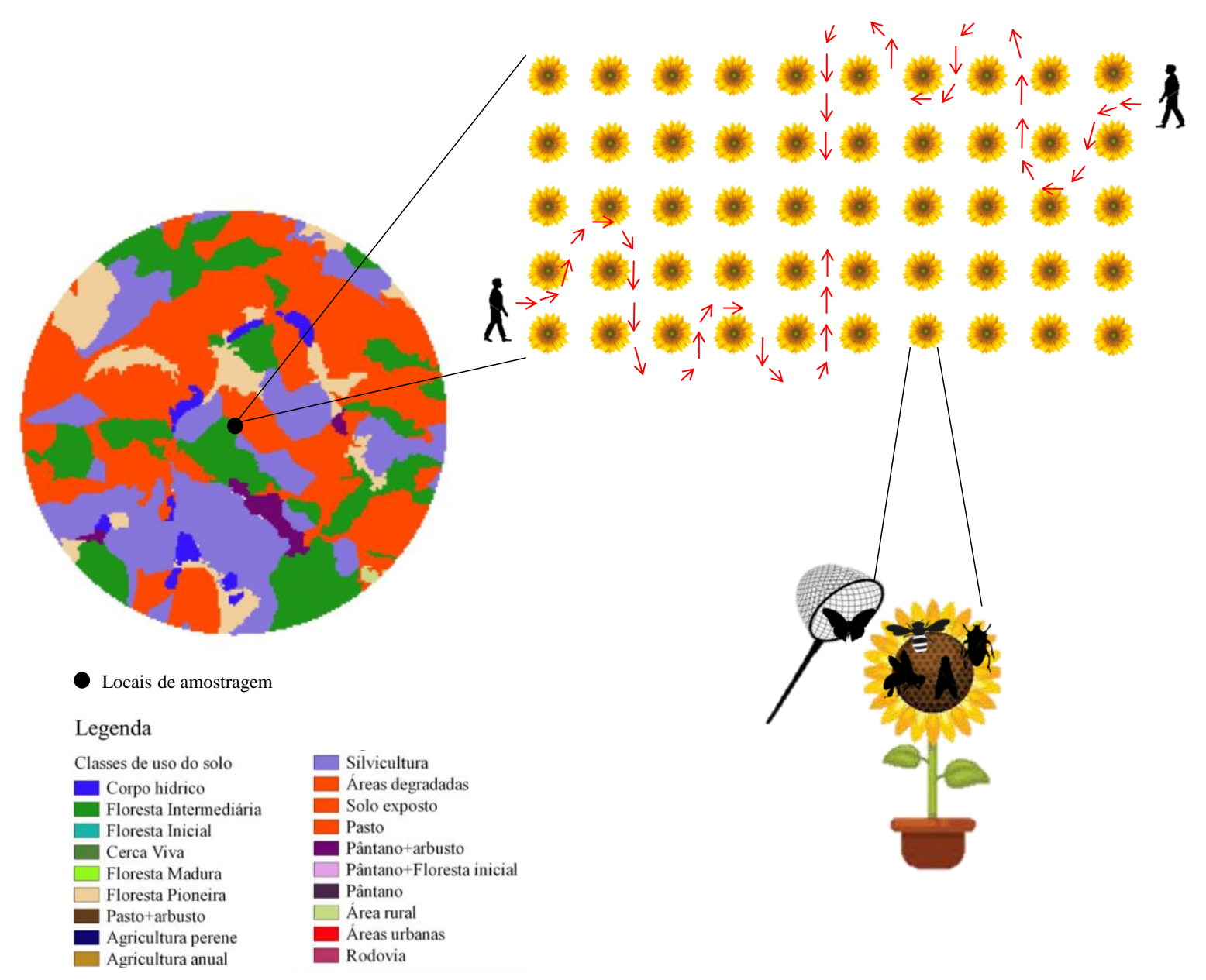

Fig. 2. Representação esquemática do desenho amostral em uma das 12 áreas de estudo no Corredor Cantareira-Mantiqueira, Estado de São Paulo. Com rede entomológica, os visitantes florais foram coletados em 50 capítulos de girassóis, durante três dias consecutivos em janeiro de 2017.

\subsubsection{Avaliação dos fatores abióticos}

Para entender a relação de fatores abióticos com a comunidade de insetos, para cada área e a cada $60 \mathrm{~min}$, foi utilizado um Datalogger para o registro da temperatura $\left({ }^{\circ} \mathrm{C}\right)$ e umidade relativa (\%) nos horários das coletas de visitantes florais (Anexo A).

\subsubsection{Análise de dados}

Para avaliar a riqueza, foi considerado o número de espécies de insetos amostrados. A diversidade foi estimada com o índice de Shannon (H'), usando o pacote Vegan (Oksanen et al., 2016). Para todas as análises, foi aplicado um teste de homogeneidade das variâncias, 
presença de valores discrepantes por meio da análise de resíduos, teste de normalidade dos resíduos e verificação da independência dos mesmos.

O efeito dos fatores abióticos nos índices de diversidade foi investigado por meio da Análise de Componentes Principais (PCA), Modelos Lineares Generalizados Mistos (GLMM) e Análise de Razão de Verossimilhança (RV) com valor de significância de p < 0,05, usando pacote ggplot2 (Wickham, 2009) e lme4 (Bates et al., 2014). Para a avaliação das métricas de paisagem (porcentagem de cobertura florestal (soma das florestas pioneira, inicial, intermediária e madura) e heterogeneidade espacial) sobre a riqueza, abundância e a diversidade de visitantes florais, foram utilizados modelos de regressão linear (LM), modelos lineares generalizados (GLM) e análise de variância usando teste $F(p<0,05)$ no programa $R$ versão 3.2.1 (R Development Core Team, 2014).

\subsection{RESULTADOS}

\subsubsection{Comunidade de insetos}

Um total de 2.181 indivíduos de 130 espécies de insetos, compreendidas em 40 famílias, foi amostrado visitando os girassóis, sendo distribuídos em seis ordens: Hymenoptera $(80,11 \%)$, Coleoptera $(8,94 \%)$, Diptera $(4,81 \%)$, Hemiptera $(5,09 \%)$, Lepidoptera $(0,82 \%)$ e Orthoptera (0,23\%) (Anexo B). Hymenoptera foi a ordem com o maior número de espécies amostradas, representando 46,1\% do total, seguida por Hemiptera e Coleoptera $(19,2 \%$ e 14,6\%, respectivamente). Hemiptera e Coleoptera apresentaram o maior número de famílias, ambas com nove, representando $22,5 \%$ do total (Anexo B).

As abelhas foram os visitantes florais mais abundantes, representando 77,2\% dos indivíduos, sendo um total de 1.685 indivíduos de 48 espécies e 23 gêneros (Anexo B). Das cinco famílias de abelhas encontradas no Brasil, quatro foram amostradas, sendo Apidae a mais representativa, com 1.450 indivíduos de 30 espécies, o que correspondeu a 86\% do total de abelhas (Anexo B; Fig. 3). Dentre as espécies de Apidae, Apis mellifera (Apini) foi a mais abundante, com 1.203 indivíduos, representando 71,4\% do total de abelhas e 55,1\% do total de insetos amostrados, seguida por Trigona spinipes (Meliponini), com 115 indivíduos, representando $6,8 \%$ do total de abelhas e $5,2 \%$ de insetos (Anexo B).

Como é bem estabelecido que as abelhas são os principais visitantes do girassol, os taxa foram agrupados em "insetos" (quando todos os insetos eram considerados) e "abelhas". 


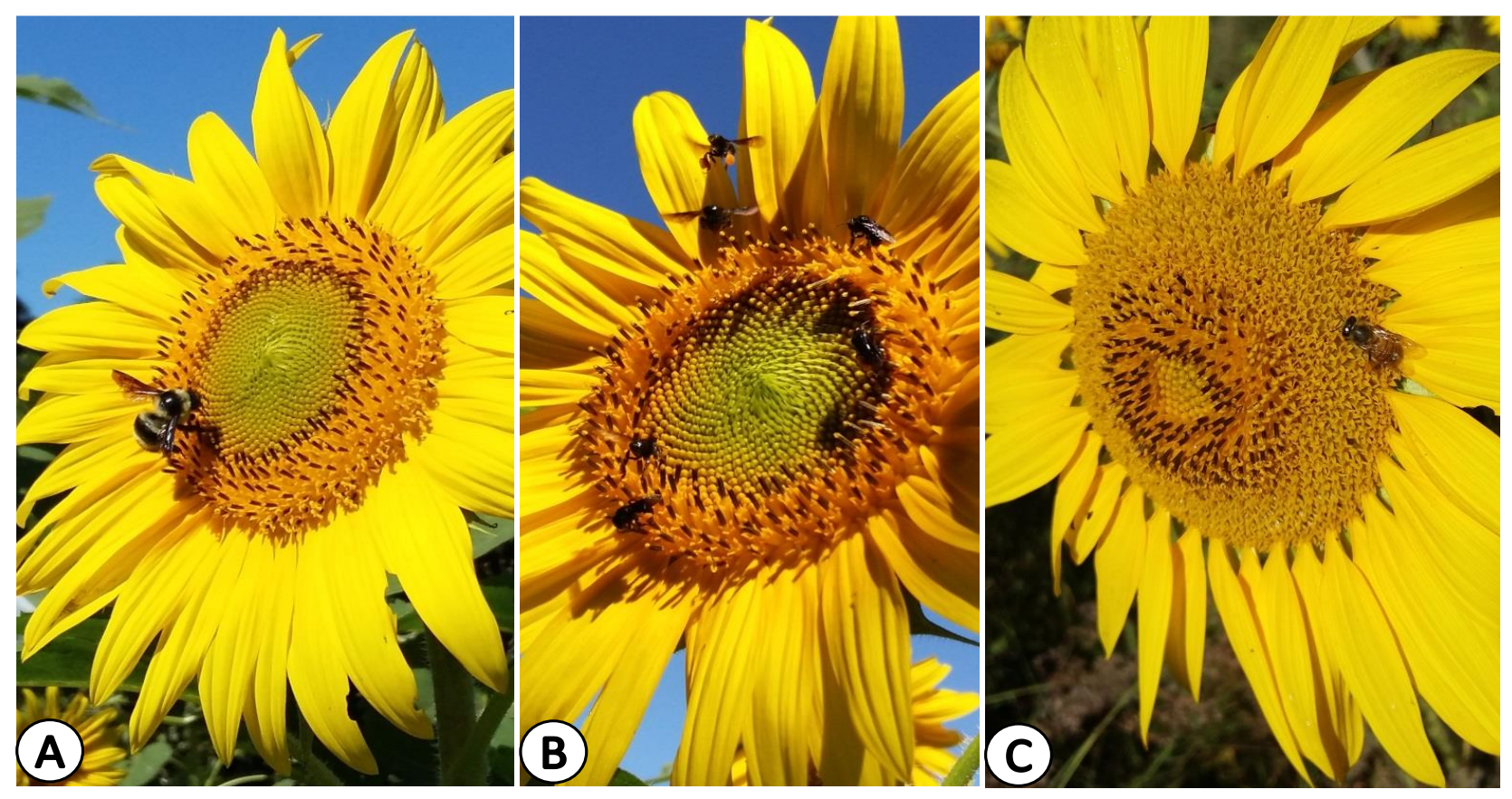

Fig. 3. Abelhas sociais [Bombus brasiliensis (A); Trigona spinipes (B) e Apis mellifera; (C)] visitando capítulos de girassol.

\subsubsection{Efeitos da paisagem na comunidade de insetos}

Por meio da PCA, verificou-se que os dois primeiros componentes explicaram 69,8\% da variabilidade total dos dados para os "insetos" (Fig. 4a) e 70,4\% para as "abelhas" (Fig. 4b). Em relação aos "insetos", o primeiro componente principal (PC1) concentrou 49,8\% da variação observada e separou as variáveis temperaturas das umidades relativas, indicando correlação negativa entre elas. Entretanto, a correlação dentro das variáveis temperatura foi alta, bem como dentro da variável umidade relativa. Nota-se então que temperaturas mais altas estão associadas a menores umidades relativas e vice-versa. O PC1 separou temperatura de umidade relativa e heterogeneidade espacial. Já o PC2 separou os índices de abundância da cobertura florestal total (Fig. 4a), explicando $20 \%$ da variação e correlação negativa entre a porcentagem da cobertura florestal com os índices de diversidade (Fig. 4a). Para as "abelhas", o resultado foi muito semelhante. O PC1 concentrou 46,9\% da variação observada e apresentou correlação negativa entre as temperaturas e umidades relativas na diversidade, riqueza e abundância desse táxon (Fig. 4b). O PC2 explicou 23,5\% da variação observada e mostrou que os índices de diversidade avaliados não foram relacionados com a heterogeneidade espacial, mas tiveram correlação negativa com porcentagem de cobertura florestal (Fig. 4b). 

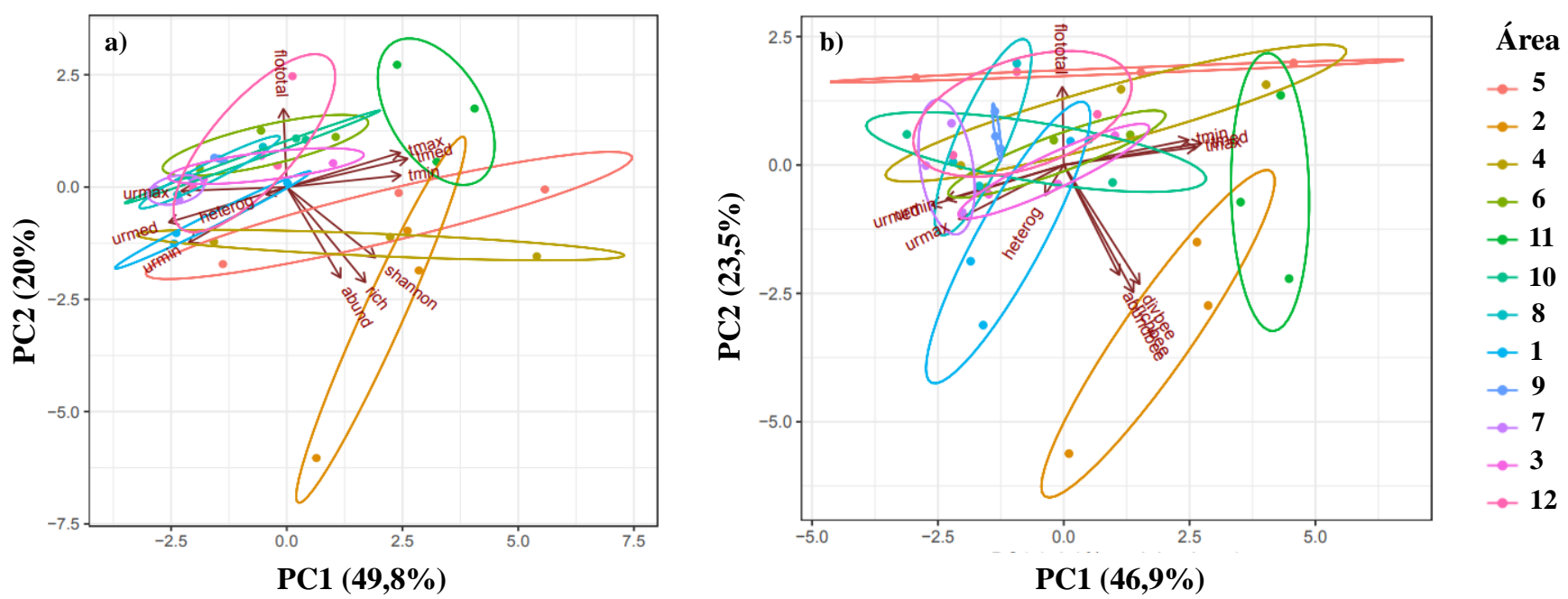

Fig. 4. Biplot da Análise de Componentes Principais (PCA) para as variáveis da paisagem e dos fatores abióticos em relação à riqueza, abundância e diversidade (Shannon) de (a) "insetos" e (b) "abelhas" nas flores de girassol. flototal: \% de cobertura florestal; heterog: índice de Shannon para o uso e ocupação do solo; T: temperatura (min: mínima; med: média; max: máxima); UR: umidade relativa (min: mínima; med: média e max: máxima); shannon: índice de Shannon para diversidade de "insetos"; rich: riqueza de "insetos"; abund: abundância de "insetos"; divbee: índice de Shannon para diversidade de "abelhas"; richbee: riqueza de "abelhas"; abund: abundância de "abelhas". Cada cor representa uma das 12 unidades amostrais e a elipse o agrupamento dos três dias de amostragem em cada área.

Dentre os fatores abióticos, a temperatura foi a única a influenciar a visitação nas flores de girassol. A abundância $(\mathrm{RV}=10,398$, g.l. $=1, \mathrm{p}=0,001261)$, riqueza $(\mathrm{RV}=8,8067$, g.l. $=$ $1, \mathrm{p}=0,003001)$ e diversidade de "abelhas" $(\mathrm{RV}=5,2816$, g.l. $=1, \mathrm{p}=0,02155)$ foram positivamente correlacionadas com a temperatura. No entanto, a temperatura não afetou os índices de diversidade dos "insetos" que visitaram o girassol.

Em relação à composição da paisagem, a proporção de cobertura florestal circundante às áreas onde os girassóis foram instalados afetou negativamente a riqueza de "insetos" (Tabela 1; Fig. 5) e "abelhas" (Tabela 1; Fig. 6a), bem como a sua diversidade (Tabela 1; Fig. 6b). Sendo assim, a cobertura florestal parece ter influenciado negativamente a riqueza e diversidade dos visitantes florais (Fig. 5 e 6). Já a heterogeneidade espacial não teve efeito significativo nos índices de diversidade (Tabela 1). 


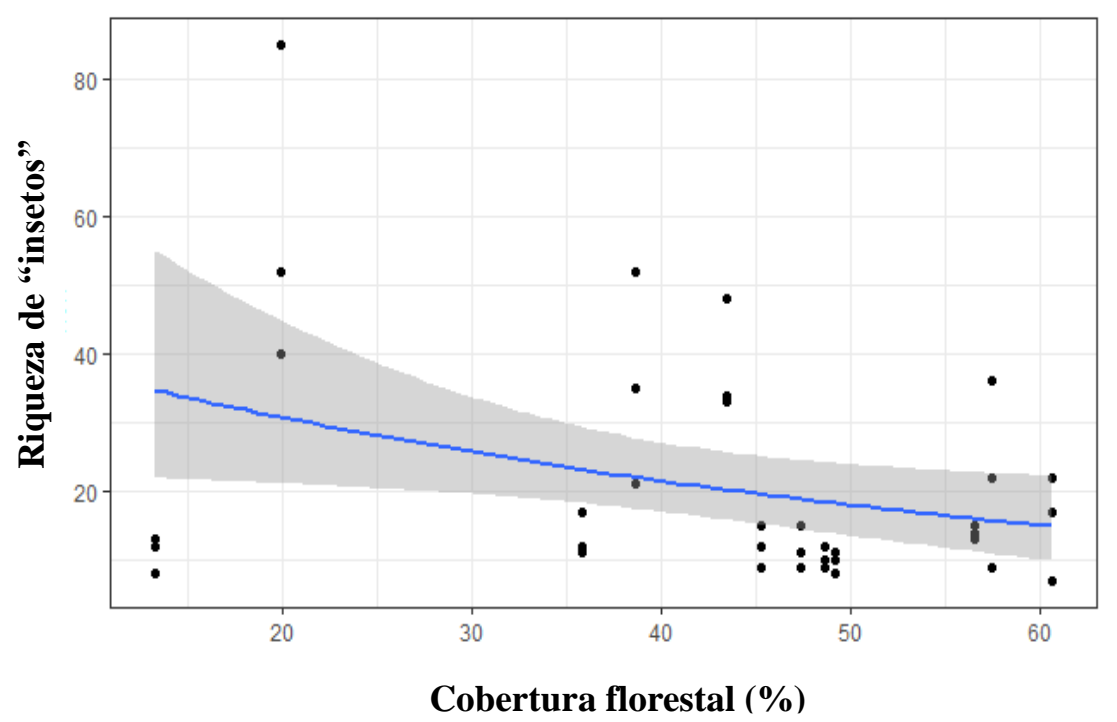

Fig. 5. Relação da cobertura florestal com a riqueza de "insetos" (a). A linha azul representa a variável resposta média predita da riqueza de "insetos" e a área cinza o intervalo de confiança de $95 \%$ para a média a ser considerada.
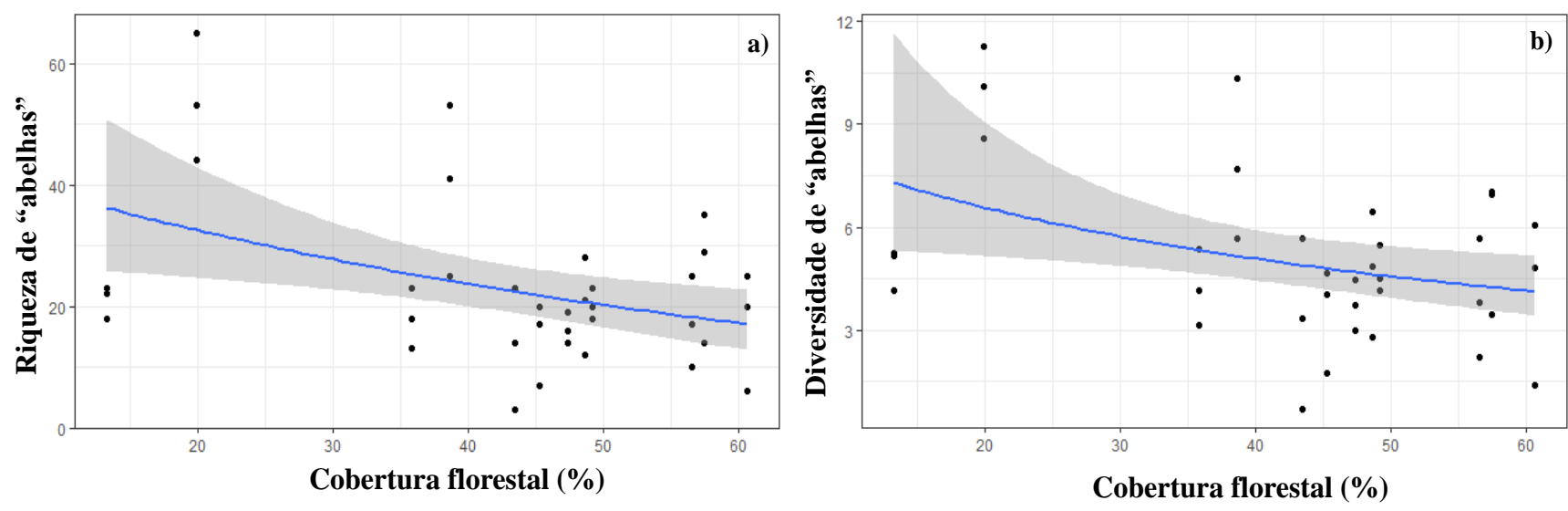

Fig. 6. Relação da cobertura florestal com (a) riqueza e (b) diversidade de abelhas. A linha azul representa a variável resposta média predita da riqueza e diversidade de "abelhas" e a área cinza o intervalo de confiança de $95 \%$ para a média a ser considerada. 
Tabela 1. Efeitos das variáveis da paisagem na riqueza, abundância e diversidade de "insetos" e de "abelhas" que visitaram as flores de girassol em 2017, no Corredor Cantareira-Mantiqueira. CF: porcentagem de cobertura florestal; HE: heterogeneidade espacial; g.l: grau de liberdade; F: teste F. Os valores em negrito foram estatisticamente significativos $(p<0,05)$.

\begin{tabular}{lcccccccccc}
\hline & \multicolumn{3}{c}{ Riqueza } & \multicolumn{4}{c}{ Abundância } & \multicolumn{3}{c}{ Diversidade } \\
\hline Efeitos & g.l. & F & $\mathbf{p}$ & g.l. & $\mathbf{F}$ & $\mathbf{p}$ & g.l. & $\mathbf{F}$ & $\mathbf{p}$ \\
\hline "insetos" & & & & & & & & & & \\
HE ${ }^{*}$ CF & 1,32 & 1,9869 & 0,16831 & 1,32 & 0,4419 & 0,5110 & 1,32 & 2,4342 & 0,1285 \\
CF & $\mathbf{1 , 3 4}$ & $\mathbf{4 , 9 1 2 5}$ & $\mathbf{0 , 0 3 3 8 9}$ & 1,34 & 2,6710 & 0,1120 & 1,34 & 2,1869 & 0,1490 \\
HE & 1,33 & 0,6386 & 0,43011 & 1,33 & 1,5396 & 0,2237 & 1,33 & 0,2653 & 0,6100 \\
"abelhas" & & & & & & & & & \\
HE ${ }^{*}$ CF & 1,32 & 0,1231 & 0,72795 & 1,32 & 0,0056 & 0,9406 & 1,32 & 0,3995 & 0,53183 \\
CF & $\mathbf{1 , 3 4}$ & $\mathbf{6 , 9 3 1 9}$ & $\mathbf{0 , 0 1 2 9 3}$ & 1,34 & 2,8306 & 0,1022 & $\mathbf{1 , 3 4}$ & $\mathbf{5 , 0 9 1 6}$ & $\mathbf{0 , 0 3 1 0 1}$ \\
HE & 1,33 & 0,0168 & 0,89775 & 1,33 & 0,6098 & 0,4406 & 1,33 & 0,0193 & 0,89037 \\
\hline
\end{tabular}

\subsection{DISCUSSÃO}

Este estudo mostrou que a comunidade de visitantes florais no girassol foi influenciada pela composição da paisagem. Surpreendentemente, a riqueza e a diversidade de espécies de “insetos" e de "abelhas" diminuíram em áreas com maior cobertura florestal. Esses resultados não corroboram a hipótese inicial deste estudo, uma vez que os habitats (semi-)naturais são essenciais para a manutenção da diversidade de polinizadores em cultivos agrícolas, pois fornecem locais para nidificação, reprodução e obtenção de alimentos (Roubik, 1989; Wratten et al., 2012). Apesar de diversos estudos evidenciarem a importância de habitats (semi-)naturais para os polinizadores (Steffan-Dewenter et al., 2002; Kremen et al., 2004; Ricketts, 2004; Hambäck et al., 2010; Ricarte et al., 2011; Zou et al., 2017), reforçando que a perda de habitats é fator-chave para o declínio das populações desses organismos em todo mundo (Potts et al., 2010, 2016), há estudos mostrando que ambientes florestais podem não afetar a comunidade de insetos polinizadores (Williams \& Winfree, 2013; Nery et al., 2018) ou, ainda, podem eventualmente diminuir a abundância e a riqueza de espécies (Winfree et al., 2007).

É possível que o efeito negativo da composição da paisagem sobre a riqueza e diversidade dos visitantes florais do girassol possa estar relacionado com: (1) a baixa qualidade dos habitats da paisagem, uma vez que as matrizes agrícolas e urbanas podem prover menos recursos que os habitats florestais, ocasionando a permanência dos polinizadores nesses ambientes naturais (Holzschuh et al., 2010; Williams \& Winfree, 2013); (2) o fato do estudo ter sido realizado na época do ano com maior taxa de florescimento das plantas nativas da Mata Atlântica (Morellato et al., 2000), o que possibilita o aumento na oferta de recursos alimentares aos visitantes florais 
que residem nos habitats (semi-)naturais circundantes aos girassóis, e; (3) o processo de desmatamento e fragmentação que a Mata Atlântica vem sofrendo há séculos (Joly et al., 2014), hoje com 11,6 a 16\% de sua cobertura florestal (Ribeiro et al., 2009). Em situações como a deste estudo, uma comunidade de espécies mais adaptadas a ambientes degradados pode ter sido selecionada (Williams \& Winfree, 2013). Neste sentido, alguns estudos sugerem que as espécies generalistas são menos afetadas pelas perturbações ambientais, em relação às especialistas (Williams \& Winfree, 2013; Weiner et al., 2014), como é o caso das abelhas A. mellifera e T. spinipes. Estas foram as espécies mais abundantes neste estudo, e são importantes polinizadores em áreas degradadas (Giannini et al., 2015), já que suas populações se mantêm em paisagens mais simplificadas e desfavoráveis a outras espécies de abelhas (Cely-Santos \& Philpott, 2019).

Além dos habitats (semi-)naturais, a heterogeneidade do uso e ocupação do solo pode contribuir substancialmente para o aumento da diversidade de polinizadores (Rundlöf et al., 2008; Kennedy et al., 2013; Fijen et al., 2019), uma vez que ambientes mais heterogêneos disponibilizam mais fontes de recursos e, consequentemente, maior variedade de interações entre plantas e visitantes (Moreira et al., 2015). Neste sentido, em paisagens agrícolas e naturais mais heterogêneas, a abundância e riqueza de polinizadores tendem a ser maiores (Kennedy et al., 2013; Bukovinszky et al., 2017; Boscolo et al., 2017; Fijen et al., 2019).

Não foi encontrado efeito da heterogeneidade espacial nas comunidades de "insetos" e de "abelhas" que visitaram o girassol. Essa ausência de efeito pode estar associada às diferentes respostas dos traços funcionais (como características morfológicas, fisiológicas e/ou comportamentais) dos visitantes às mudanças ambientais (Díaz et al., 2013; Aguirre-Gutiérrez et al., 2017; Cely-Santos \& Philpott, 2019; Fijen et al., 2019). Esses traços estão relacionados com a reprodução e crescimento (Díaz et al., 2013; Aguirre-Gutiérrez et al., 2017), tamanho corporal (Greenleaf et al., 2007), capacidade de dispersão, distância de forrageamento e a percepção dos organismos às diferentes escalas da paisagem (Steffan-Dewenter et al., 2002; Westphal et al., 2003; Benjamin et al., 2014), assim como o nicho trófico (Thies et al., 2003; Steckel et al., 2014).

Neste estudo, foi observada alta riqueza e abundância de insetos que visitaram as flores do girassol, como moscas, besouros, borboletas, percevejos, gafanhotos e cigarrinhas. No entanto, as abelhas constituíram o grupo taxonômico mais abundante, com 77,2\% dos indivíduos, e com maior número de espécies (36,9\% do total de espécies de insetos), assim como em avaliações anteriores (Parker, 1981; Morgado et al., 2002; Greenleaf \& Kremen, 
2006; Kasina et al., 2007; Carvalheiro et al., 2011; Pisanty et al., 2014; Hevia et al., 2016; Bartual et al., 2018; Silva et al., 2018; Perrot et al., 2019). A significativa representatividade das abelhas, em relação aos outros taxa, pode estar associada à sua dependência por recursos florais em todas as suas fases de vida (Michener, 2007) e a diversos outros fatores. Primeiramente, pelo fato do girassol ser uma rica fonte de pólen e néctar (Parker, 1981), as abelhas podem apresentar maior constância floral (Kleinert et al., 2009). Segundo, as flores do girassol são muito atrativas às abelhas devido à sua coloração, uma vez que esses visitantes preferem cores que variam na faixa do amarelo-rosa-violeta-azul (Westerkamp, 1997; Westerkamp \& Classen-Bockhoff, 2007; Varassin \& Amaral-Neto, 2014). Terceiro, as flores do girassol são protândricas (Free, 1993), sendo mais comum a polinização por abelhas e moscas (Sargent \& Otto, 2004).

Dentre as abelhas, a exótica $A$. mellifera foi a espécie mais frequente $(71,4 \%)$, seguida pela abelha sem ferrão nativa $T$. spinipes $(6,8 \%)$, como observado em estudos anteriores com girassol no Brasil (Morgado et al., 2002; Machado \& Carvalho, 2006; Chambó et al., 2011). A alta abundância de A. mellifera e $T$. spinipes pode estar relacionada à organização altamente eussocial (Michener, 1974) e ao comportamento de forrageamento "super generalista", o que possibilita maior exploração de recursos em diversos ambientes (Kleinert et al., 2009; Giannini et al., 2015). No entanto, como descrito em outros estudos, A. mellifera foi muito mais abundante que as outras espécies amostradas no girassol (Parker, 1981; Morgado et al., 2002; Greenleaf \& Kremen, 2006; Kasina et al., 2007; Carvalheiro et al., 2011; Pisanty et al., 2014; Hevia et al., 2016; Bartual et al., 2018; Silva et al., 2018; Perrot et al., 2019). A alta frequência da A. mellifera encontrada neste trabalho pode: i) estar relacionada com o alto número de operárias e a sua dependência de pólen e néctar para a manutenção dos suas colônias perenes (Michener, 1974), e; ii) por ser uma espécie domesticada e muito manejada, sendo o polinizador mais comum nas culturas agrícolas em todo o mundo (Garibaldi et al., 2013). Além disso, na região onde o estudo foi desenvolvido há atividade de silvicultura nas grandes matrizes de eucaliptos (Barbosa et al., 2017) e, como essas plantas possuem alto potencial melífero (HilgertMoreira et al. 2014), esses habitats podem ser utilizados por apicultores comerciais (Falkenberg \& Simões, 2011).

Este estudo também mostrou correlação positiva da diversidade, abundância e riqueza de espécies de "abelhas" com a temperatura. Ou seja, em temperaturas mais elevadas, as flores foram mais visitadas, evidenciando a importância desse fator abiótico como regulador no comportamento de forrageamento de abelhas, corroborando estudos anteriores com espécies 
sem ferrão (Hilário et al., 2001; Pick \& Blochtein, 2002; Maia-Silva et al., 2014; Aleixo et al., 2017) e A mellifera (Kovac \& Stabentheiner, 2011). Diferente da maioria dos insetos, as abelhas são consideradas animais "heterotérmicos" ou "endotérmicos temporais", uma vez que conseguem regular a sua temperatura quando realizam atividades motoras (endotérmicos) e, durante a inatividade, a sua temperatura depende do ambiente (Heinrich, 1993). Quando as abelhas estão voando, os músculos torácicos de voo são responsáveis pelo aumento da temperatura. Contudo, quando pousam sobre as flores, há a possibilidade de resfriar seus corpos, caso a temperatura do ambiente esteja abaixo daquela necessária para o voo (Heinrich, 1993; Roberts \& Harrison, 1998). Para que essa perda de temperatura não influencie na visita de outras flores, as abelhas desenvolveram mecanismos para a produção de calor (Heinrich, 1993). A intensidade e o custo energético desses mecanismos tornam-se maiores à medida que a temperatura diminui e, neste sentido, em ambientes ou horários com temperaturas mais altas, esses mecanismos não serão necessários, diminuindo assim o gasto energético das abelhas (Heinrich, 1993).

A relação positiva entre as abelhas e o microclima local podem estar relacionados com o reconhecimento das flores por meio da temperatura floral (Whitney et al., 2008; Norgate et al., 2010) promovida, na maioria das vezes, pela radiação solar absorvida (Zhang et al., 2010; Atamian et al., 2016). A absorção da luz do sol e a perda de calor vão definir o quanto uma flor aquecerá em determinadas condições (Harrap et al., 2017). Esse aquecimento é influenciado pela pigmentação (Sapir et al., 2006), estrutura (Rejšková et al., 2010) e heliotropismo (Zhang et al., 2010; Atamian et al., 2016). O heliotropismo do girassol, ao longo do dia (do leste (manhã) para oeste (noite)), interfere na atratividade dos polinizadores, mais especificamente das abelhas, uma vez que as flores orientadas para o leste são as mais aquecidas que as orientadas para o oeste, pois recebem mais radiação solar (Atamian et al., 2016), e esse calor pode ter atraído mais visitantes florais nos capítulos. Sendo assim, a temperatura contribui diretamente na visitação dos polinizadores no girassol (Atamian et al., 2016; van der Kooi, 2016) e acredita-se que essa atração por flores com alta temperatura esteja associada à sua preferência por néctar mais quente (Dyer et al., 2006; van der Kooi, 2016). O néctar em temperaturas mais elevadas pode oferecer vantagens energéticas na termorregulação das abelhas e facilidade na ingestão desse recurso, uma vez que o calor diminui a sua viscosidade (Nicolson et al., 2013). Além disso, as plantas produtoras de néctar podem usar a alta temperatura floral para torná-las mais atrativas para os visitantes coletores desse recurso (Rands \& Whitney, 2008). 
Sabendo que as florestas tropicais estão sendo convertidas rapidamente em cultivos agrícolas (Hansen et al. 2013), tornando as paisagens mais simples e pobres em recursos para os visitantes florais, é crucial entender os efeitos da estrutura da paisagem nesses organismos. Os resultados deste estudo evidenciam uma relação positiva, porém não muito, entre os visitantes do girassol e a quantidade de habitats naturais. No entanto, vários fatores devem ser levados em consideração, como por exemplo, a qualidade desses habitats, os traços comportamentais e a possível adaptação de algumas espécies a ambientes degradados. Além disso, diferente da maioria dos estudos (Steffan-Dewenter et al., 2002; Ricketts, 2004; Kremen et al., 2004; Brosi et al., 2007, 2009; Moreira et al., 2015; Boscolo et al., 2017; Fijen et al., 2019), que restringiram suas análises para um único táxon, especificamente as abelhas, este estudo fornece informações importantes sobre a resposta das comunidades de insetos que visitaram as flores do girassol. Tais informações podem servir de base para identificar potenciais polinizadores desse cultivo agrícola, a fim de incrementar o serviço de polinização.

\section{REFERÊNCIAS}

Aguirre-Gutiérrez J, Kissling WD, Biesmeijer JC, WallisDeVries MF, Reemer M, Carvalheiro LG, 2017. Historical changes in the importance of climate and land use as determinants of Dutch pollinator distributions. Journal of Biogeography 44: 696-707.

Aizen M, Garibaldi L, Cunningham S, Klein A, 2009. How much does agriculture depend on pollinators? Lessons from long-term trends in crop production. Annals of Botany 103: 1579-1588.

Aleixo KP, Menezes C, Imperatriz-Fonseca VL, Silva CI, 2017. Seasonal availability of floral resources and ambient temperature shape stingless bee foraging behavior (Scaptotrigona aff. depilis). Apidologie 48: 117-127.

Atamian HS, Creux NM, Brown EA, Garner AG, Blackman BK, Harmer SL, 2016. Circadian regulation of sunflower heliotropism, floral orientation, and pollinator visits. Science 353: 587-590.

ANA, 2019. Sistema Cantareira. http://www3.ana.gov.br/portal/ANA/sala-desituacao/sistema-cantareira/sistema-cantareira-saiba-mais (accessed 24/04/19).

Barbosa KVC, Knogge C, Develey PF, Jenkins CN, Uezua A, 2017. Use of small Atlantic Forest fragments by birds in Southeast Brazil. Perspectives in Ecology and Conservation 15: $42-46$.

Bates D, Maechler M, Bolker B, Walker S, 2014.Ime4: Linea mixed-effects models using Eigen and S4. R package.

Bartual AM, Bocci G, Marini S, Moonen AC, 2018. Local and landscape factors affect sunflower pollination in a Mediterranean agroecosystem. PLoS ONE 13: e0203990.

Benjamin FE, Reilly JR, Winfree R, 2014. Pollinator body size mediates the scale at which land use drives crop pollination services. Journal of Applied Ecology 51: 440-449. 
Bennett AF, Saunders DA, 2010. Habitat fragmentation and landscape change. In: Sodhi, N.S., Ehrlich, P.R. (Eds.), Conservation biology for all. Oxford University Press, Oxford, pp. 88-106.

Boscolo D, Tokumoto PM, Ferreira PA, Ribeiro JW, dos Santos JS, 2017. Positive responses of flower visiting bees to landscape heterogeneity depend on functional connectivity levels. Perspectives in Ecology and Conservation 15: 18-24.

BRASIL, 2004. Ministério do Desenvolvimento Agrário. Programa Nacional de Produção e Uso do Biodiesel (PNPB): inclusão social e desenvolvimento territorial. http://www.mda.gov.br/sitemda/sites/sitemda/files/user_arquivos_64/Biodiesel_Book_fin al_Low_Completo.pdf (accessed 10/03/2019).

Brosi BJ, Daily GC, Chamberlain CP, Mills M, 2009. Detecting changes in habitat-scale bee foraging in a tropical fragmented landscape using stable isotopes. Forest Ecology and Management.

Brosi BJ, Daily GC, Ehrlich PR, 2007. Bee community shifts with landscape context in a tropical countryside. Ecological Applications 17: 418-430.

Bukovinszky T, Verheijen J, Zwerver S, Klop E, Biesmeijer JC, Wäckers FL, Prins HH, Kleijn D, 2017. Exploring the relationships between landscape complexity, wild bee species richness and reproduction, and pollination services along a complexity gradient in the Netherlands. Biological Conservation 214: 312-319.

Carvalheiro LG, Veldtman R, Shenkute AG, Tesfay GB, Pirk CWW, Donaldson JS, Nicolson SW, 2011. Natural and within-farmland biodiversity enhances crop productivity. Ecology Letters 14: 251-259.

Cely-Santos M, Philpott SM, 2019. Local and landscape habitat influences on bee diversity in agricultural landscapes in Anolaima, Colombia. Journal of Insect Conservation 23: 133146.

Chambó ED, Garcia RC, Oliveira NTEd, Duarte-Júnior JB, 2011. Honey bee visitation to sunflower: effects on pollination and plant genotype. Scientia Agricola 68: 647-651.

CONAB, 2019. Acompanhamento da safra brasileira de grãos 2018/19 (levantamento mensal $4^{\mathbf{0}}, \mathbf{5}^{\mathbf{0}}, \mathbf{6}^{\mathbf{0}}$ e $\mathbf{7}^{\mathbf{0}}$ ). https://www.conab.gov.br/info-agro/safras/graos/boletim-da-safrade-graos (accessed 23/04/2019).

Costanza R, de Groot R, Braat L, Kubiszewski I, Fioramonti L, Sutton P, Farber S, Grasso M, 2017. Twenty years of ecosystem services: how far have we come and how far do we still need to go? Ecosystem Services 28: 1-16.

Culliney TW, 2013. Role of Arthropods in Maintaining Soil Fertility. Agriculture 3: 629-659.

Degrandi-Hoffman G, Chambers M, 2006. Effects of honey bee (Hymenoptera: Apidae) foraging on seed set in self-fertile sunflowers (Helianthus annuus L.). Environmental Entomology 35: 1103-1108.

De Marco P, Coelho FM, 2004. Services performed by the ecosystem: forest remnants influence agricultural cultures' pollination and production. Biodiversity and Conservation 13: 1245-1255.

Díaz PC, Arenas A, Fernández VM, Susic Martin C, Basilio AM, Farina WM, 2013. Honeybee cognitive ecology in a fluctuating agricultural setting of apple and pear trees. Behavioral Ecology 24: 1058-1067. 
Ditt EH, Mourato S, Ghazoul J, Knight J, 2010. Forest conversion and provision of ecosystem services in the Brazilian Atlantic Forest. Land Degradation \& Development 21: 591-603.

Dyer AG, Whitney HM, Arnold SEJ, Glover BJ, Chittka L, 2006. Bees associate warmth with floral colour. Nature 442: 525.

Evans TA, Dawes TZ, Ward R, Lo N, 2011. Ants and termites increase crop yield in a dry climate. Nature Communications 2: 262.

Falkenberg DB, Simões T, 2011. Espécies de interesse apícola e sua fenologia de floração. In: Coradin L, Siminski A, Reis A. (Eds.), Espécies nativas da flora brasileira de valor econômico atual ou potencial. Ministério do Meio Ambiente.

Fijen TP, Scheper JA, Boekelo B, Raemakers I, Kleijn D, 2019. Effects of landscape complexity on pollinators are moderated by pollinators' association with mass-flowering crops. Proceedings of the Royal Society B 286: 20190387.

Foley JA, Defries R, Asner GP, Barford C, Bonan G, Carpenter SR, Chapin FS, Coe MT, Daily G, Gibbs HK, Helkowski JH, Holloway T, Howard EA, Kucharik CJ, Monfreda C, Patz JA, Prentice IC, Ramankutty N, Snyder PK, 2005. Global consequences of land use. Science 309: 570-574.

Free JB, 1993. Insect pollination of crops. Academic Press, London.

Garibaldi LA, Carvalheiro LG, Leonhardt SD, Aizen MA, Blaauw BR, Isaacs R, Kuhlmann M, Kleijn D, Klein AM, Kremen C, 2014. From research to action: enhancing crop yield through wild pollinators. Frontiers in Ecology and the Environment 12: 439-447.

Garibaldi LA, Steffan-Dewenter I, Kremen C, Morales JM, Bommarco R, Cunningham SA, Carvalheiro LG, Chacoff NP, Dudenhoeffer JH, Greenleaf SS, 2011. Stability of pollination services decreases with isolation from natural areas despite honey bee visits. Ecology Letters 14: 1062-1072.

Garibaldi LA, et al., 2013. Wild pollinators enhance fruit set of crops regardless of honey bee abundance. Science 339: 1608-1611.

Giannini TC, Garibaldi LA, Acosta AL, Silva JS, Maia KP, Saraiva AM, Guimarães Jr PR, Kleinert AMP, 2015. Native and non-native supergeneralist bee species have different effects on plant-bee networks. PloS One 10: e0137198.

Gliessman SR, 2000. Agroecosystem sustainability: developing practical strategies. CRC Press, Boca Raton.

Greenleaf SS, Kremen C, 2006. Wild bees enhance honey bees' pollination of hybrid sunflower. Proceedings of the National Academy of Sciences, USA 103: 13890-13895.

Greenleaf SS, Williams NM, Winfree R, Kremen C, 2007. Bee foraging ranges and their relationship to body size. Oecologia 153: 589-596.

Hagen M, Kissling WD, Rasmussen C, De Aguiar MA, Brown LE, Carstensen DW, AlvesDos-Santos I, Dupont YL, Edwards FK, Genini J, 2012. Biodiversity, species interactions and ecological networks in a fragmented world. Advances in Ecological Research. Elsevier, pp. 89-210.

Hansen MC, Potapov PV, Moore R, Hancher M, Turubanova SA, Tyukavina A, Thau D, Stehman SV, Goetz SJ, Loveland TR, Kommareddy A, Egorov A, Chini L, Justice CO, Townshend JRG (2013). High-Resolution Global Maps of 21st-Century Forest Cover Change. Science 342: 850-853. 
Hambäck PA, Bergman KO, Bommarco R, Krauss J, Kuussaari M, Pöyry J, Öckinger E, 2010. Allometric density responses in butterflies: the response to small and large patches by small and large species. Ecography 33: 1149-1156.

Harrap JMM, Rands SA, Ibarra NH, Whitney HM, 2017. The diversity of floral temperature patterns, and their use by pollinators. ELife 6: e31262.

Heinrich B, 1993. The hot-blooded insects: strategies and mechanisms of thermoregulation. Springer Verlag, Berlin.

Hevia V, Bosch J, Azcárate FM, Fernández E, Rodrigo A, Barril-Graells H, González JA, 2016. Bee diversity and abundance in a livestock drove road and its impact on pollination and seed set in adjacent sunflower fields. Agriculture, Ecosystems \& Environment 232: 336344.

Hilário SD, Imperatriz-Fonseca VL, Kleinert AMP, 2001. Responses to climatic factors by foragers of Plebeia pugnax Moure (in litt.) (Apidae, Meliponinae). Brazilian Journal Biology 61: 191-196.

Hipólito J, Boscolo D, Viana BF, 2018. Landscape and crop management strategies to conserve pollination services and increase yields in tropical coffee farms. Agriculture, Ecosystems \& Environment 256: 218-225.

Holzschuh A, Steffan-Dewenter I, Tscharntke T, 2010. How do landscape composition and configuration, organic farming and fallow strips affect the diversity of bees, wasps and their parasitoids? Journal of Animal Ecology 79: 491-500.

IPBES, 2016. The assessment report of the Intergovernmental Science-Policy Platform on Biodiversity and Ecosystem Services on pollinators, pollination and food production. IPBES. http://www.ipbes.net/ (accessed 26 April 2018).

IPBES, 2019. Media Release: Nature's Dangerous Decline 'Unprecedented'; Species Extinction Rates 'Accelerating'. IPBES. https://www.ipbes.net/news/Media-ReleaseGlobal-Assessment (accessed 08 may 2019).

Jaeger T. (2005). Nuevas perspectivas para el programa MAB y las reservas de Biosfera. Lecciones aprendidas en América. UNESCO. División de Ciencias Ecológicas y de la Tierra. Programa de Cooperación Sur-Sur. Documento de Trabajo No 35.

Joly CA, Metzger JP, Tabarelli M, 2014. Experiences from the Brazilian Atlantic Forest: ecological findings and conservation initiatives. New Phytologist 204: 459-473.

Kasina M, Nderitu J, Nyamasyo G, Oronje M, 2007. Sunflower pollinators in Kenya: Does diversity influence seed yield?

Kennedy CM, et al., 2013. A global quantitative synthesis of local and landscape effects on wild bee pollinators in agroecosystems. Ecology Letters 16: 584-599.

Kleinert AMP, Ramalho M, Cortopassi-Laurino M, Imperatriz-Fonseca VL, 2009. Abelhas sociais (Bombini, Apini, Meliponini). In: Panizzi, A.R., Parra, J.R.P. (Eds.), Bioecologia e nutrição de insetos. EMBRAPA Informação Tecnológica, Brasília, pp. 371-424.

Kovac H, Stabentheiner A, 2011. Thermoregulation of foraging honeybees on flowering plants: seasonal variability and influence of radiative heat gain. Ecological Entomology 36: 686699.

Kremen C, Williams NM, Bugg RL, Fay JP, Thorp RW, 2004. The area requirements of an ecosystem service: crop pollination by native bee communities in California. Ecology Letters 7: 1109-1119. 
Kreutzweiser, DP, Good KP, Chartrand D, Scarr TA, Thompson DG, 2007. Non-target effects on aquatic decomposer organisms of imidacloprid as a systemic insecticide to control emerald ash borer in riparian trees. Ecotoxicology and Environmental Safety 68: 315-325.

Kreutzweiser DP, Good KP, Chartrand DT, Scarr TA, Thompson DG, 2008. Are leaves that fall from imidacloprid-treated maple trees to control Asian longhorned beetles toxic to nontarget decomposer organisms? Journal of Environmental Quality 37: 639-646.

Laurance WF, Useche DC, Shoo LP, Herzog SK, Kessler M, Escobar F, Brehm G, Axmacher JC, Chen I-C, Gámez LA, 2011. Global warming, elevational ranges and the vulnerability of tropical biota. Biological Conservation 144: 548-557.

Laurance WF, Clements GR, Sloan S, O'Connell SO, Mueller ND, Goosem M, Venter O, Edwards DP, Phalan B, Balmford A, Van Der Ree R, Arrea IB, 2014. A global strategy for road building. Nature 513: 229-232.

Losey JE, Vaughan M, 2006. The economic value of ecological services provided by insects. BioScience 56: 311-323.

Machado CS, Carvalho CAL, 2006. Abelhas (Hymenoptera: Apoidea) visitantes dos capítulos de girassol no Recôncavo Baiano. Ciência Rural 36: 1404-1409.

Magnago LFS, Magrach A, Laurance WF, Martins SV, Meira-Neto AA, Simonelli M, Edwards DP (2015) Would protecting tropical forest fragments provide carbon and biodiversity cobenefits under REDD+? Global Change Biology 9: 3455-3468.

Maia-Silva C, Imperatriz-Fonseca VL, Silva CI, Hrncir M, 2014. Environmental windows for foraging activity in stingless bees, Melipona subnitida Ducke and Melipona quadrifasciata Lepeletier (Hymenoptera: Apidae: Meliponini). Sociobiology 61: 378-385.

McGarigal K, Cushman SA, Neel MC, Ene E, 2012. FRAGSTATS v4: spatial pattern analysis program for categorical maps. Computer software program produced by the authors at the University of Massachusetts. University of Massachusetts, Amherst.

McGregor SE, 1976. Insect pollination of cultivated crop plants. U.S. Department of Agriculture, Agricultural Research Service, Washington.

Michener CD, 1974. The social behavior of the bees: a comparative study. Belknap Press of Harvard University Press, Massachusetts.

Michener CD, 2007. The Bees of the World. The John Hopkins University Press, Baltimore.

Moreira EF, Boscolo D, Viana BF, 2015. Spatial heterogeneity regulates plant-pollinator networks across multiple landscape scales. PloS one 10: e0123628.

Morellato LPC, Talora DC, Takahasi A, Bencke CC, Romera EC, Zipparro VB, 2000. Phenology of Atlantic rain forest trees: a comparative study. Biotropica 32: 811-823.

Morgado LN, Carvalho CF, Souza B, Santana MP, 2002. Fauna de abelhas (Hymenoptera: Apoidea) nas flores de girassol Helianthus annuus L. Ciencia e Agrotecnologia 26: 11671177.

Nery LS, Takata JT, de Camargo BB, Chaves AM, Ferreira PA, Boscolo D, 2018. Bee diversity responses to forest and open areas in heterogeneous Atlantic Forest. Sociobiology 65: 686695.

Newbold T, Hudson LN, Hill SL, Contu S, Lysenko I, Senior RA, Börger L, Bennett DJ, Choimes A, Collen B, 2015. Global effects of land use on local terrestrial biodiversity. Nature 520: $45-50$. 
Newbold T, Hudson LN, Phillips HR, Hill SL, Contu S, Lysenko I, Blandon A, Butchart SH, Booth HL, Day J, 2014. A global model of the response of tropical and sub-tropical forest biodiversity to anthropogenic pressures. Proceedings of the Royal Society B: Biological Sciences 281: 20141371.

Nichols E, Spector S, Louzada J, Larsen T, Amezquita S, Favila ME, 2008. Ecological functions and ecosystem services provided by Scarabaeinae dung beetles. Biological Conservation 141: 1461-1474.

Nicolson SW, Veer L, Köhler A, Pirk CWW, 2013. Honeybees prefer warmer nectar and less viscous nectar, regardless of sugar concentration. Proceedings of the Royal Society B: Biological Sciences 280: 20131597.

Norgate M, Boyd-Gerny S, Simonov V, Rosa MG, Heard TA, Dyer AG, 2010. Ambient temperature influences Australian native stingless bee (Trigona carbonaria) preference for warm nectar. PLoS One 5: e12000.

Ollerton J, Winfree R, Tarrant S, 2011. How many flowering plants are pollinated by animals? Oikos 120: 321-326.

Parker FD, 1981. Sunflower pollination: abundance, diversity and seasonality of bees and their effect on seed yields. Journal of Apicultural Research 20: 49-61.

Perrot T, Gaba S, Roncoroni M, Gautier J-L, Saintilan A, Bretagnolle V, 2019. Experimental quantification of insect pollination on sunflower yield, reconciling plant and field scale estimates. Basic and Applied Ecology 34: 75-84.

Pick RA, Blochtein B, 2002. Atividades de voo de Plebeia saiqui (Holmberg) (Hymenoptera, Apidae, Meliponini) durante o periodo de postura da rainha e em diapausa. Revista Brasileira de Zoologia 19: 827-839.

Pisanty G, Klein A-M, Mandelik Y, 2014. Do wild bees complement honeybee pollination of confection sunflowers in Israel? Apidologie 45: 235-247.

Potts SG, Biesmeijer JC, Kremen C, Neumann P, Schweiger O, Kunin WE, 2010. Global pollinator declines: trends, impacts and drivers. Trends in Ecology \& Evolution 25: 345353.

Potts SG, Imperatriz-Fonseca VL, Ngo HT, Aizen MA, Biesmeijer JC, Breeze TD, Dicks LV, Garibaldi LA, Hill R, Settele J, Vanbergen AJ, 2016. Safeguarding pollinators and their values to human well-being. Nature 540: 220-229.

Rands SA, Whitney HM, 2008. Floral temperature and optimal foraging: is heat a feasible floral reward for pollinators? PLoS One 3: e2007.

Rejšková A, Brom J, Pokorný J, Korečko J, 2010. Temperature distribution in light-coloured flowers and inflorescences of early spring temperate species measured by Infrared camera. Flora Morphology, Distribution, Functional Ecology of Plants 205: 282-289.

Ribeiro MC, Metzger JP, Martensen AC, Ponzoni FJ, Hirota MM, 2009. The Brazilian Atlantic Forest: How much is left, and how is the remaining forest distributed? Implications for conservation. Biological Conservation 142: 1141-1153.

Ricarte A, Marcos-García MÁ, Moreno CE, 2011. Assessing the effects of vegetation type on hoverfly (Diptera: Syrphidae) diversity in a Mediterranean landscape: implications for conservation. Journal of Insect Conservation 15: 865-877.

Ricketts TH, 2004. Tropical forest fragments enhance pollinator activity in nearby coffee crops. Conservation Biology 18: 1262-1271. 
Roberts SP, Harrison JF, 1998. Mechanisms of thermoregulation in flying bees. American Zoologist 38: 492-502.

Rossi RO, 1998. Girassol. Tecnoagro.

Roubik DW, 1989. Ecology and natural history of tropical bees. Cambridge University Press, Cambridge.

Rundlöf M, Nilsson H, Smith HG, 2008. Interacting effects of farming practice and landscape context on bumble bees. Biological Conservation 141: 417-426.

Sapir Y, Shmida A, Ne'eman G, 2006. Morning floral heat as a reward to the pollinators of the Oncocyclus irises. Oecologia 147: 53-59.

Sargent RD, Otto SP, 2004. A phylogenetic analysis of pollination mode and the evolution of dichogamy in angiosperms. Evolutionary Ecology Research 6: 1183-1199.

Saturni FT, Jaffé R, Metzger JP, 2016. Landscape structure influences bee community and coffee pollination at different spatial scales. Agriculture, Ecosystems \& Environment 235: $1-12$.

Shannon CE, Weaver W, 1949. Mathematical Theory of Communication. University of Illinois Press.

Silva CA, Godoy WA, Jacob CR, Thomas G, Câmara GM, Alves DA, 2018. Bee pollination highly improves oil quality in sunflower. Sociobiology 65: 583-590.

Steckel J, Westphal C, Peters MK, Bellach M, Rothenwoehrer C, Erasmi S, Scherber C, Tscharntke T, Steffan-Dewenter I, 2014. Landscape composition and configuration differently affect trap-nesting bees, wasps and their antagonists. Biological Conservation 172: 56-64.

Steffan-Dewenter I, Munzenberg U, Burger C, Thies C, Tscharntke T, 2002. Scale-dependent effects of landscape context on three pollinator guilds. Ecology 83: 1421-1432.

Thies C, Steffan-Dewenter I, Tscharntke T, 2003. Effects of landscape context on herbivory and parasitism at different spatial scales. Oikos 101: 18-25.

Tscharntke T, Klein A, Kruess A, Steffan-Dewenter I, Thies C, 2005. Landscape perspectives on agricultural intensification and biodiversity-ecosystem service management. Ecology Letters 8: 857-874.

Van der Kooi CJ, Elzenga JTM, Staal M, Stavenga DG, 2016. How to colour a flower: on the optical principles of flower coloration. Proceedings of the Royal Society B: Biological Sciences 283: 20160429.

Varassin IG, Amaral-Neto LP, 2014. Atrativos. In: Rech AR, Agostini A, Oliveira PE, Machado IC (Orgs). Biologia da Polinização.

Weiner CN, Werner M, Linsenmair KE, Blüthgen N, 2014. Land-use impacts on plantpollinator networks: interaction strength and specialization predict pollinator declines. Ecology 95: 466-474.

Westerkamp C, 1997. Keel blossoms: Bee flowers with adaptations against bees. Flora 192: 125-132.

Westerkamp C, Classen-Bockhoff R, 2007. Bilabiate flowers: The ultimate response to bees? Annals of Botany 100: 361-374. 
Westphal C, Steffan-Dewenter I, Tscharntke T, 2003. Mass flowering crops enhance pollinator densities at a landscape scale. Ecology Letters 6: 961-965.

Whately M, Cunha P, 2007. Cantareira 2006: um olhar sobre o maior manancial de água da Região Metropolitana de São Paulo.

Whitney HM, Dyer A, Chittka L, Rands SA, Glover BJ, 2008. The interaction of temperature and sucrose concentration on foraging preferences in bumblebees. Naturwissenschaften 95: $845-850$.

Wickham H, 2009. Ggplot2: Elegant Graphics for Data Analysis. Springer, New York.

Williams NM, Winfree R, 2013. Local habitat characteristics but not landscape urbanization drive pollinator visitation and native plant pollination in forest remnants. Biological Conservation 160: 10-18.

Winfree R, Aguilar R, Vázquez D, LeBuhn G, Aizen M, 2009. A meta-analysis of bees' responses to anthropogenic disturbance. Ecology 90: 2068-2076.

Winfree R, Williams NM, Dushoff J, Kremen C, 2007. Native bees provide insurance against ongoing honey bee losses. Ecology Letters 10: 1105-1113.

Witter S, Nunes-Silva P, Blochtein B, Lisboa BB, Imperatriz-Fonseca VL, 2014. Abelhas e a agricultura. EDIPUCRS.

Wratten SD, Gillespie M, Decourtye A, Mader E, Desneux N, 2012. Pollinator habitat enhancement: benefits to other ecosystem services. Agriculture, Ecosystems \& Environment 159: 112-122.

Zhang S, Ai HL, Yu WB, Wang H, Li DZ, 2010. Flower heliotropism of Anemone rivularis (Ranunculaceae) in the Himalayas: effects on floral temperature and reproductive fitness. Plant Ecology 209: 301-312.

Zou Y, Bianchi FJ, Jauker F, Xiao H, Chen J, Cresswell J, Luo S, Huang J, Deng X, Hou L, 2017. Landscape effects on pollinator communities and pollination services in small-holder agroecosystems. Agriculture, ecosystems \& environment 246: 109-116.

Zurbuchen A, Landert L, Klaiber J, Müller A, Hein S, Dorn S, 2010. Maximum foraging ranges in solitary bees: only few individuals have the capability to cover long foraging distances. Biological Conservation 143: 669-676. 


\title{
4. A INFLUÊNCIA DA PAISAGEM NOS VISITANTES FLORAIS E SEUS EFEITOS NA PRODUTIVIDADE DE SEMENTES E DE ÓLEO DE GIRASSOL
}

\section{RESUMO}

O girassol é uma cultura agrícola dependente da polinização cruzada realizada pelos insetos e se beneficia da ação desses agentes no aumento da produção de sementes e de óleo. No entanto, esse serviço está ameaçado devido a muitos fatores e, entre eles, a perda de habitats (semi-)naturais que mantêm e garantem a sobrevivência dos polinizadores em paisagens agrícolas. Assim, o objetivo deste estudo foi avaliar os efeitos da cobertura florestal nos visitantes florais e a influência desses insetos na produtividade do girassol. Experimentos com cinquenta plantas com flores foram realizados em 12 paisagens, com $1 \mathrm{~km}$ de raio, em um gradiente de cobertura florestal e heterogeneidade espacial na Mata Atlântica, Corredor Cantareira-Mantiqueira, Estado de São Paulo. Este estudo mostrou que a riqueza de insetos e o peso dos aquênios por capítulo diminuíram em áreas com maior cobertura florestal. Em capítulos de girassol com maior diâmetro havia maior riqueza, abundância e diversidade de visitantes florais. Apesar da visitação da abelha Apis mellifera incrementar a produtividade do girassol, a polinização realizada por outros insetos foi mais eficiente e efetiva, uma vez que influenciou positivamente no aumento do número e peso dos aquênios por capítulo, quantidade de óleo extraído das sementes e o nível do gama-tocoferol contido no óleo. Além disso, houve também a diminuição no teor de ácidos graxos saturados. Como seu consumo aumenta a concentração de colesterol no sangue humano, a melhora da composição nutricional do óleo de girassol foi auxiliada pela ação de polinizadores. Assim, fica evidente a importância de produtores rurais incorporarem práticas amigáveis aos polinizadores em seus sistemas agrícolas, tanto para a conservação dos polinizadores quanto dos serviços que eles provêm, podendo alcançar altos rendimentos nas colheitas e lucros.

Palavras-chave: Cobertura florestal, Insetos, Polinização, Conservação, Agricultura

\begin{abstract}
The sunflowers dependent on cross-pollination provided by insects, rendering heavier seeds with higher oil contents. However, pollination service is threatened by several stressors, and among them the loss of (semi-)natural habitats that maintain pollinator survival in agricultural landscapes. Thus, the aim of this study was to evaluate the effects of forest cover on flower visitors and the influence of these insects on the sunflower productivity. Experiments with fifty flowering plants were performed in 12 landscapes, with $1 \mathrm{~km}$ radius, across a gradient of spatial heterogeneity and Atlantic Rainforest cover, in the Cantareira-Mantiqueira Corridor, São Paulo State. This study showed that insect richness and the weight of achenes per sunflower head decreased in areas with higher forest cover. In larger sunflower heads, there was a higher number of species, abundance and diversity of flower visitors. Although Apis mellifera contributed to increase sunflower productivity, the pollination services performed by other insect taxa were more efficient and effective, as they contributed to increase the number and weight of achenes per sunflower head, the quantity of oil extracted from seeds and the gammatocopherol oil concentration. In addition, there was a decrease in levels of saturated fatty acids. Since their consumption increases the concentration of cholesterol in human blood, the pollinators had an important role in the improvement of the nutritional composition of
\end{abstract}


sunflower oil. Thus, it is evident that it is of paramount importance farmers incorporate pollinator-friendly practices into their agricultural systems, both for the conservation of pollinators and the services they provide, in order to achieve high crop yields and profits.

Keywords: Forest cover, Insects, Pollination, Conservation, Agriculture

\subsection{INTRODUÇÃO}

Os ecossistemas fornecem uma ampla variedade de serviços que afetam direta- e indiretamente o bem-estar, a saúde, a subsistência e a sobrevivência humana (Costanza et al., 1997, 2014). Dentre os serviços ecossistêmicos regulatórios está a polinização (Costanza et al., 1997), processo vital para a manutenção da biodiversidade em áreas naturais (Bawa, 1990), bem como para a produção de alimentos e biocombustíveis (Potts et al., 2016). Embora o serviço de polinização de algumas culturas agrícolas seja realizado por agentes abióticos, a grande maioria é mediada por animais, especialmente os insetos (Klein et al., 2007; Potts et al., 2016). Nos últimos 50 anos, houve um aumento expressivo de mais de $300 \%$ na proporção de culturas que dependem de polinizadores (Aizen \& Harder, 2009). A ausência desses agentes implicaria em redução de 3 a $8 \%$ na produção agrícola mundial (Aizen et al., 2009). Embora essas estimativas pareçam irrisórias, a escassez de polinizadores impõe demanda desproporcional para o aumento das áreas agrícolas para atender o crescente consumo humano global, acelerando ainda mais a destruição de áreas naturais (Winfree et al., 2009; GonzálezVaro et al., 2013). Essa pressão é ainda mais severa em países em desenvolvimento, que compreendem quase dois terços da terra destinada ao cultivo agrícola no mundo (Aizen et al., 2009).

No Brasil, cerca de $60 \%$ das culturas agrícolas de importância econômica para alimentação humana, vestuário, pecuária e biocombustível se beneficia da ação de polinizadores, que contribuem com quase $30 \%$ do valor anual da produção agrícola nacional (Giannini et al., 2015b). Em 2012, o valor do serviço de polinização do girassol equivaleu a $65 \%$ do valor de sua produção, estimado em US\$ 40,8 milhões (Giannini et al., 2015b), sendo essa cultura altamente dependente da polinização realizada pelos insetos (Free, 1993). As flores do girassol são protândricas e passam por dicotomia temporal, na qual o grão de pólen é liberado antes dos estigmas estarem receptivos (Free, 1993). Assim, mesmo havendo autopolinização, em especial nos cultivares híbridos, a ação de polinizadores tende a aumentar a produção de sementes (Parker, 1981; Degrandi-Hoffman \& Chambers, 2006; Bartual et al., 2018; Silva et 
al., 2018; Perrot et al., 2019) e o teor de óleo (Parker, 1981; Bartual et al., 2018), bem como a sua qualidade (Silva et al., 2018).

Contudo, para que a manutenção do serviço de polinização continue acessível para o girassol e outras culturas agrícolas de importância econômica, é preciso incentivar medidas de preservação e manejo que assegurem a sobrevivência dos polinizadores (Tscharntke et al., 2005; Winfree et al., 2009; Kennedy et al., 2013). Uma dessas medidas é a conservação de habitats (semi-)naturais no entorno dos cultivos, uma vez que essas áreas proporcionam recursos alimentares, locais para nidificação, abrigo contra inimigos naturais e oportunidade de reprodução aos insetos polinizadores (Winfree, 2010; Wratten et al., 2012). Em paisagens agrícolas mais heterogêneas (e.g., com diferentes culturas agrícolas, faixas com vegetação nativa), a abundância e a riqueza de polinizadores tende a ser maior (Kennedy et al., 2013; Bukovinszky et al., 2017). Em paisagens agrícolas, quando os remanescentes florestais estão a distâncias superiores a $1 \mathrm{~km}$ dos cultivos, há uma redução de $27 \%$ nas taxas de visitas dos insetos nas flores e, consequentemente, uma perda de 16\% na produção de frutos (Garibaldi et $a l ., 2011)$. No entanto, tão importante como analisar a relação entre os serviços de polinização em uma dada cultura agrícola e sua distância aos habitats (semi-)naturais que abrigam as populações desses agentes (Ricketts et al., 2008; Garibaldi et al., 2011), também se faz necessário compreender melhor como as alterações do uso e ocupação do solo impactam as

populações dos polinizadores (Steffan-Dewenter et al., 2002) e, consequentemente, a produtividade agrícola (Kremen et al., 2007; Klein et al., 2007; Garibaldi et al., 2011) segurança alimentar (Eilers et al., 2015; Smith et al., 2015).

Neste sentido, o presente estudo teve como objetivos a avaliação (1) dos efeitos da composição da paisagem nos visitantes florais do girassol e (2) da influência dos insetos na provisão do serviço de polinização nesse cultivo, no que diz respeito à quantidade e qualidade das sementes produzidas.

\subsection{MATERIAL E MÉTODOS}

\subsection{1. Área de estudo e seleção das unidades amostrais}

O estudo foi realizado em áreas rurais entre as serras da Cantareira e da Mantiqueira, no Estado de São Paulo, Brasil (Fig. 1). Essa região pertence à Mata Atlântica e é considerada corredor ecológico, pois promove a conectividade dos fragmentos florestais e a proteção e fonte de recursos hídricos (Whately \& Cunha 2007). Com uma estação chuvosa durante o período de 
setembro a março e uma estação mais seca entre abril e agosto (Barbosa et al., 2017), a coleta de dados ocorreu em janeiro de 2017 , quando a temperatura variou de 16,5 a $35,8^{\circ} \mathrm{C}$ (Anexo A).

Foram selecionadas 12 paisagens com raio de $1 \mathrm{~km}$ (Fig. 1), considerando um gradiente de diversidade de Shannon da paisagem de 1,27 a 2,35 (Shannon \& Weaver 1998; McGarigal et al., 2012) e cobertura florestal floresta entre 13 e $61 \%$ (Fig. 1; descrição no item 3.2.2. do Capítulo 3). Para reduzir a autocorrelação espacial entre pontos de amostragem, a distância mínima entre as paisagens selecionadas foi de $3 \mathrm{~km}$, devido às distâncias de voo das abelhas (Zurbuchen et al., 2010).

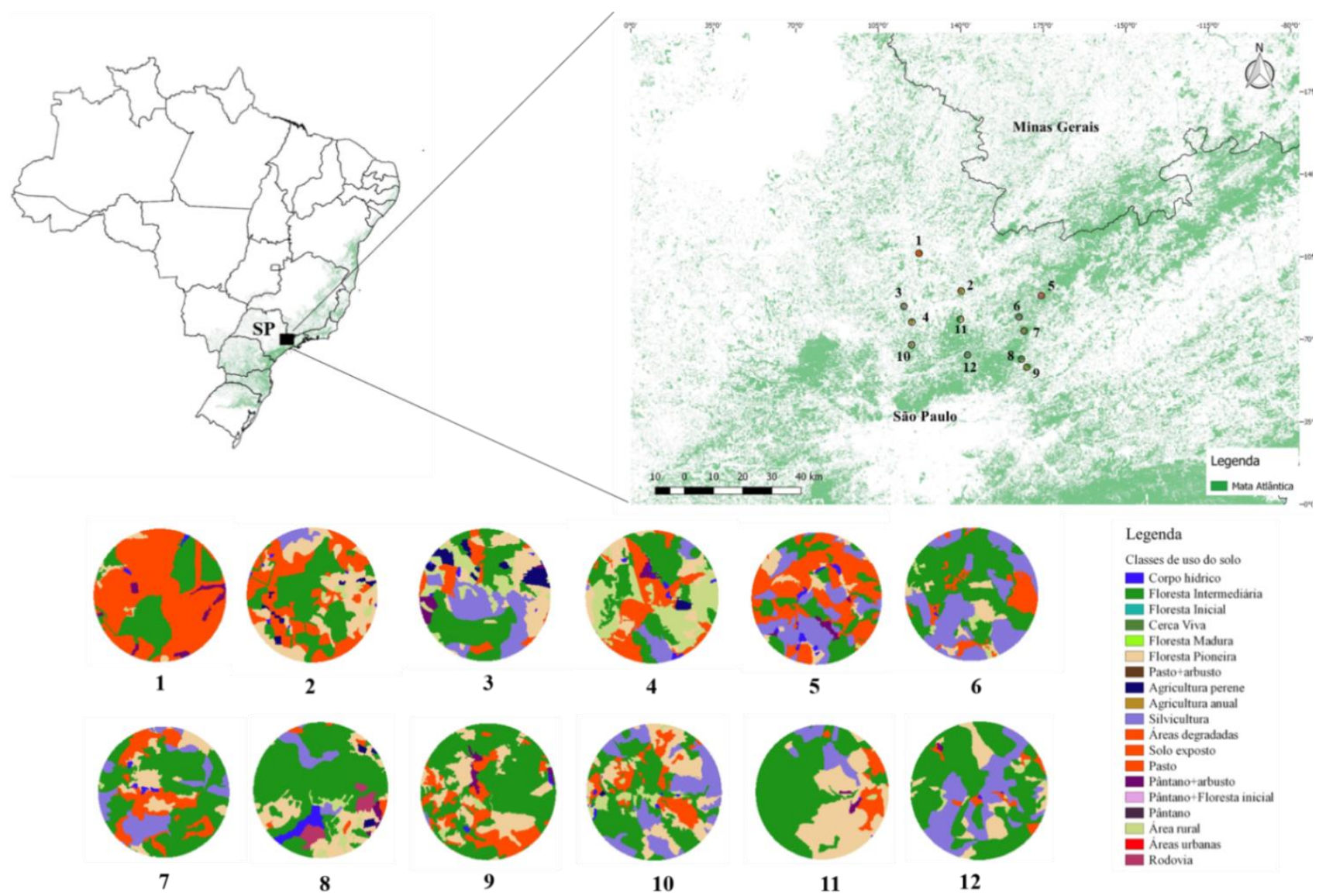

Fig. 1. Região de estudo no Corredor Cantareira-Mantiqueira, porção sudeste da Mata Atlântica, Estado de São Paulo, Brasil. As 12 paisagens, com raio de $1 \mathrm{~km}$, apresentam, respectivamente, a cobertura florestal e as diferentes classes de uso de solo: (1) 13,3\% e 2,04; (2) $19,9 \%$ e 2,03 ; (3) $35,8 \%$ e 2,06 ; (4) $38,6 \%$ e 1,79 ; (5) $43,5 \%$ e 1,52 ; (6) $45,3 \%$ e 1,73 ; (7) $47,4 \%$ e 1,82 ; (8) $48,6 \%$ e 1,27 ; (9) $49,2 \%$ e 2,14 ; (10) $56,5 \%$ e 1,83 ; (11) $57,4 \%$ e 1,63 ; (12) $60,6 \%$ e 2,35 . 


\subsubsection{Delineamento experimental}

Foram instalados 50 vasos com girassol (híbrido BRS 323; EMBRAPA 2013) no estágio reprodutivo em que 60 a $80 \%$ das flores que compunham os capítulos estavam em antese em cada uma das 12 áreas de estudo. No final do período de floração, os capítulos de girassol foram ensacados com malha de nylon branco ( $1 \mathrm{~mm}$ de largura de malha), a fim de evitar predadores de sementes e mantidas assim até a maturação das sementes.

\subsubsection{Amostragem dos insetos}

A amostragem dos insetos foi realizada entre 7:00 e 15:00h, durante três dias consecutivos, totalizando 27 amostras da comunidade de insetos por área. Os coletores percorriam aleatoriamente os espaços entre os vasos durante 20min, a cada hora, e capturava com rede entomológica todos os insetos avistados nos capítulos de girassol.

\subsubsection{Quantidade e qualidade de aquênios e valor nutricional do óleo de girassol}

Dos 50 capítulos de girassol de cada área, foram escolhidos cinco de forma aleatória para avaliar as seguintes variáveis: 1) diâmetro dos capítulos, 2) número e 3) peso de aquênios formados. Posteriormente, os 50 capítulos foram secos à temperatura ambiente e debulhados manualmente para obter os aquênios e avaliar o peso de 1.000 aquênios (BRASIL, 2009).

Para avaliar a qualidade nutricional, 500g de aquênios de girassol de cada área foram encaminhados ao Instituto de Tecnologia de Alimentos (ITAL, Campinas/SP), onde foram submetidos a um processo de lipídios totais para a extração do óleo (mg e g/100g) e identificação de tocoferóis e ácidos graxos, utilizando métodos da American Oil Chemists 'Society (AOCS). Os métodos para obtenção e quantificação dos ácidos graxos saturados, mono e poli-insaturados e tocoferóis estão detalhadamente descritos no Capítulo 3.

\subsubsection{Análise de dados}

Para todas as análises foi aplicado um teste de homogeneidade das variâncias, presença de valores discrepantes por meio da análise de resíduos, teste de normalidade dos resíduos e verificação da independência dos mesmos. Para a avaliação das métricas de paisagem (porcentagem de cobertura florestal e heterogeneidade espacial) sobre a riqueza, abundância e 
a diversidade de visitantes florais, foram utilizados modelos de regressão linear simples (LM), modelos lineares generalizados (GLM) e análise de variância (ANOVA), utilizou-se os pacotes ggplot2 (Wickham, 2009) e lme4 (Bates et al., 2014) (R Development Core Team, 2014). Como os dados do diâmetro dos capítulos estavam dentro da normalidade, a distribuição original foi avaliada com envelope de simulação meio normal, utilizando o pacote hnp (Moral et al., 2014) e posteriormente, os dados foram analisados GLM e ANOVA usando teste $F(p<0,05)$ no programa R versão 3.2.1 (R Development Core Team, 2014). Para avaliar os efeitos da visitação dos insetos nas flores de girassol na produtividade, também foram utilizados MLG (número e peso de aquênios por capítulo) e LM (peso de 1.000 aquênios; teor de óleo extraído das sementes, alfa e gama-tocoferol, ômega 3, 6 e 9, ácidos graxos saturados e monoinsaturados), posteriormente, se realizou ANOVA usando teste $F(p<0,05)$ no programa $R$ versão 3.2.1 ( $R$ Development Core Team, 2014).

\subsection{RESULTADOS}

\subsubsection{Comunidade de insetos}

Foi amostrado um total de 2.181 indivíduos de 130 espécies de insetos visitando as flores de girassol, sendo que 77,26\% deles corresponderam a abelhas, 8,94\% a besouros, 4,81\% a moscas, $3,94 \%$ a percevejos, $2,3 \%$ a formigas, $1,15 \%$ a cigarrinhas, $0,82 \%$ a borboletas e mariposas, $0,55 \%$ a vespas e $0,23 \%$ a gafanhotos (Anexo B). As abelhas compuseram o maior grupo em riqueza, com 48 espécies. A espécie mais abundante foi Apis mellifera (Apidae: Apini), com 1.203 indivíduos, correspondendo a 55,1\% do total de insetos. Para as análises, os taxa foram divididos em três grupos: "insetos"; "insetos não-Apis" (designação para todos os insetos excluindo A. mellifera) e "Apis" (abundância de A. mellifera).

\subsubsection{Paisagem e serviço de polinização}

A riqueza de insetos foi influenciada pela paisagem avaliada, sendo que em áreas com maior porcentagem de cobertura florestal houve diminuição da quantidade de espécies amostradas $\left(F_{1}=4,9346, p=0,03309\right.$; Fig. $\left.2 a\right)$ e do peso dos aquênios por capítulo $\left(F_{1}=7,0652\right.$, $\mathrm{p}=0,01014$; Fig. 2b).

Os índices de diversidade apresentaram relação positiva com o tamanho dos capítulos, ou seja, em inflorescências maiores havia também maior riqueza, abundância e diversidade de 
visitantes florais (grupo "insetos" - riqueza: $F_{1}=7,38, p<0,001$; (Fig. 3a) e abundância: $F_{1}=$ 3,7337, $\mathrm{p}=$ 0,05821 (Fig. 3b); grupo “insetos não-Apis" - riqueza: $\mathrm{F}_{1}=7,9089, \mathrm{p}=$ 0,006702;

(Fig. 4b), abundância: $F_{1}=7,0741, p=0,01009$; (Fig. 4a) e diversidade: $F_{1}=6,7104, p=$ 0,0121; (Fig. 3c)).
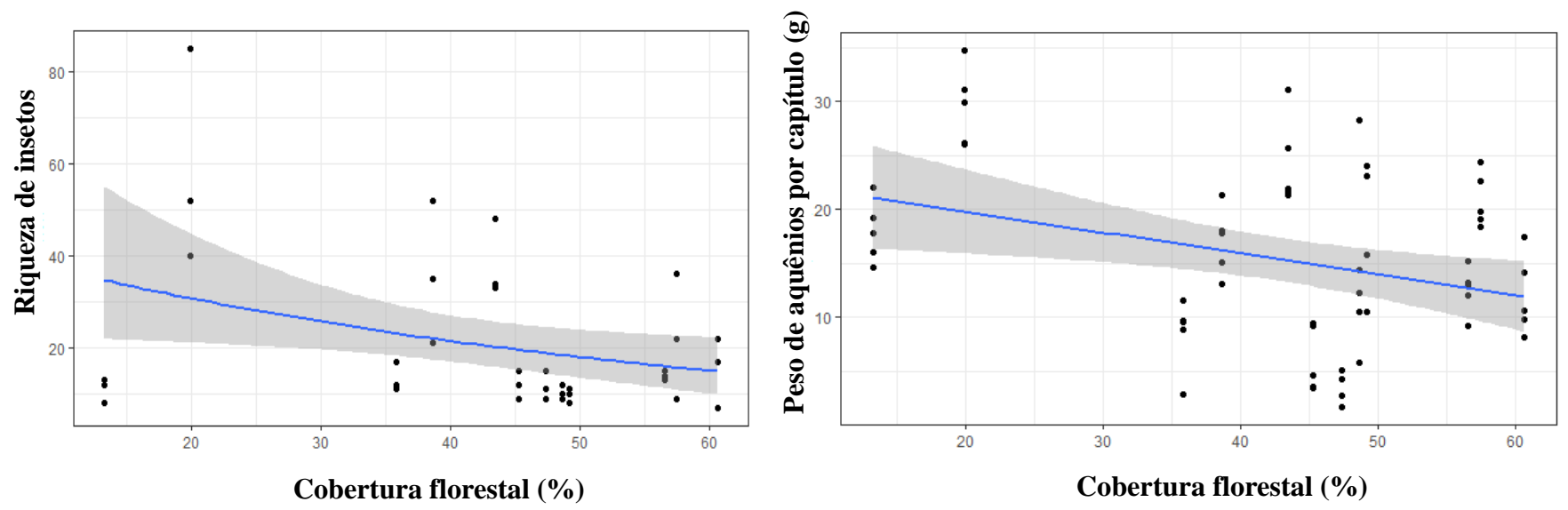

Fig. 2. Relação da cobertura florestal com (a) riqueza de insetos e (b) peso de aquênios por capítulo. A linha azul representa a variável resposta média predita da riqueza de "insetos" e do peso de aquênios por capítulo e a área cinza o intervalo de confiança de $95 \%$ para a média a ser considerada.
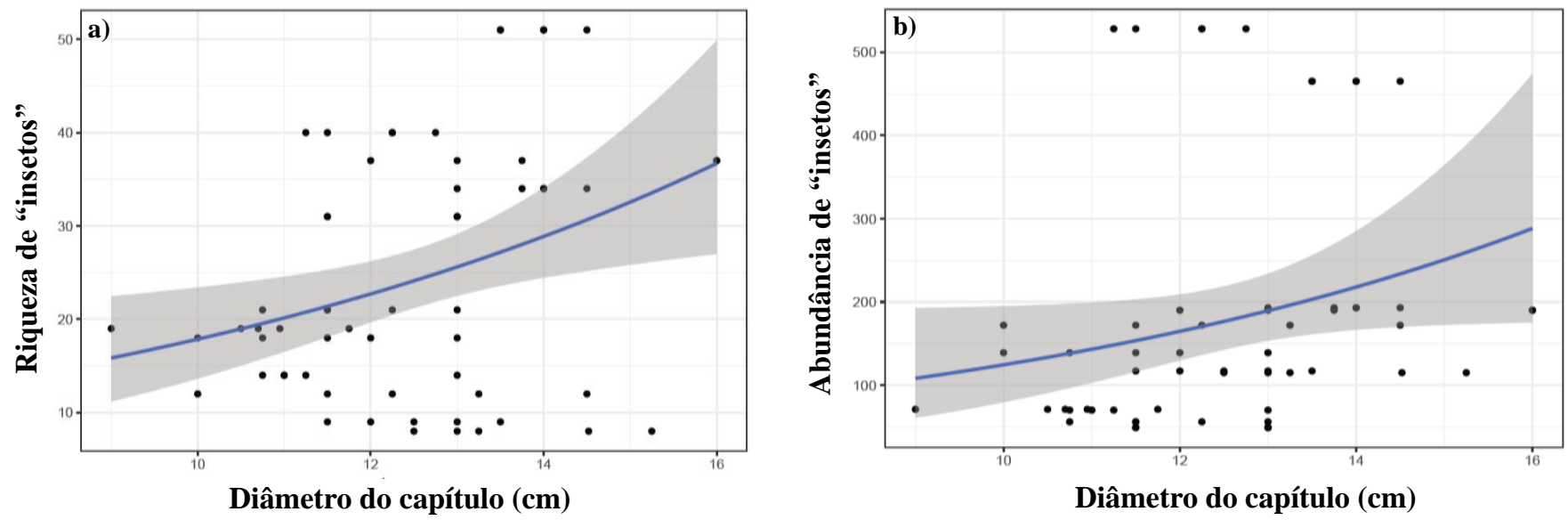

Fig. 3. Relação entre o tamanho dos capítulos de girassol e (a) riqueza e (b) abundância de "insetos". A linha azul representa a variável resposta média predita da riqueza e abundância de “insetos" e a área cinza o intervalo de confiança de 95\% para a média a ser considerada. 

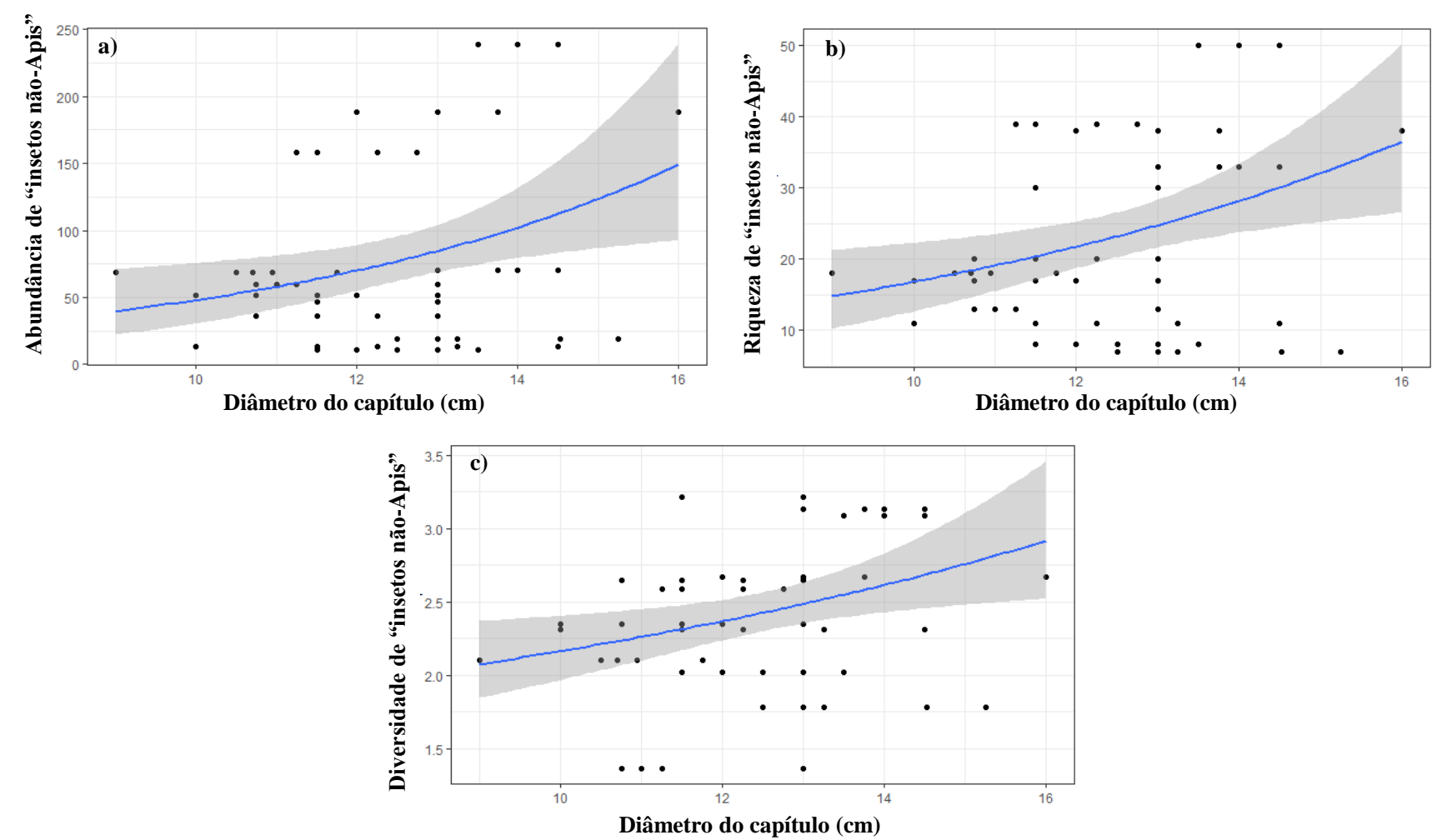

Fig. 4. Relação entre o tamanho dos capítulos de girassol e (a) riqueza, (b) abundância e (c) diversidade de "insetos não-Apis". A linha azul representa a variável resposta média predita da abundância, riqueza e diversidade de "insetos não-Apis" e a área cinza o intervalo de confiança de $95 \%$ para a média a ser considerada.

Em relação à produtividade do girassol, o grupo de visitantes florais "insetos" e "insetos não-Apis" tiveram resultados muito semelhantes (Tabelas 1 e 2), principalmente em relação à riqueza (Fig. 5). Já a abundância de "Apis" não teve relação significativa com alguns parâmetros de produtividade avaliados, diferente dos outros dois grupos (Tabelas 2). A maioria das variáveis da produtividade do girassol foram positivamente relacionadas com os "insetos" e os “insetos não-Apis”, como o aumento no número de aquênios (por capítulo) (Tabelas 1 e 2; Fig. 6a-b), peso dos aquênios por capítulo (Tabelas 1 e 2; Fig. 6d-e), peso de mil aquênios (Tabelas 1 e 2; Fig. 6g-h), quantidade de óleo extraído das sementes (Tabelas 1 e 2; Fig. 7a-b) e o nível do gama-tocoferol contido no óleo (Tabelas 1 e 2; Fig. 8g-h). Além disso, tiveram relação negativa nos teores de ácidos graxos saturados (Tabelas 1 e 2; Fig. 8d-e) e no alfa-tocoferol do óleo de girassol (Tabelas 1 e 2; Fig. 8a-b). Os níveis dos ácidos graxos monoinsaturados e poliinsaturados, mais especificamente, os ácidos linoleico (ômega-6) e oleico (ômega-9) não foram relacionados com os grupos (Tabelas 1 e 2). Para "Apis", a sua abundância aumentou o peso dos aquênios por capítulo (Tabela 2; Fig. 6f) e de mil aquênios (Tabela 2; Fig. 6i), quantidade de óleo extraído das sementes (Tabela 2; Fig. 7c) e diminuiu o teor dos ácidos graxos saturados 
no óleo analisado (Tabela 2; Fig. 8f). Diferente dos grupos de "insetos" e "insetos não-Apis", a abundância de "Apis" não interferiu no número de aquênios por capítulo (Tabela 2; Fig. 6c) e nos teores de alfa (Tabela 2; Fig. 8c) e gama-tocoferol (Tabela 2; Fig. 8i).

Tabela 1. Relação entre as variáveis de produtividade do girassol e a riqueza, abundância e diversidade de "insetos" que visitaram as flores em 2017, no Corredor Cantareira-Mantiqueira, Estado de São Paulo. g.l: grau de liberdade; F: teste F. Os valores em negrito foram estatisticamente significativos $(\mathrm{p}<0,05)$.

\begin{tabular}{|c|c|c|c|c|c|c|}
\hline \multirow{3}{*}{ Variáveis de produtividade } & \multicolumn{6}{|c|}{ "Insetos" } \\
\hline & \multicolumn{3}{|c|}{ Riqueza } & \multicolumn{3}{|c|}{ Abundância } \\
\hline & g.l. & $\mathbf{F}$ & $\mathbf{p}$ & g.l. & $\mathbf{F}$ & $\mathbf{p}$ \\
\hline \multicolumn{7}{|l|}{ Produção de aquênios } \\
\hline $\mathrm{N}^{\circ}$ de aquênios por capítulo & 1,00 & 17,8430 & $<0,001$ & 1,00 & 7,5716 & 0,007899 \\
\hline Peso de aquênios por capítulo (g) & 1,58 & 23,9630 & $<0,001$ & $\mathbf{1 , 5 8}$ & 27,6850 & $<0,001$ \\
\hline Peso de mil aquênios (g) & 1,10 & 11,6380 & 0,006642 & 1,10 & $\mathbf{2 4 , 4 4 7}$ & $<0,001$ \\
\hline Quantidade de óleo extraído $(\mathrm{g} / 100 \mathrm{~g})$ & 1,10 & 11,3580 & 0,007119 & 1,10 & 5,8941 & 0,03559 \\
\hline \multicolumn{7}{|l|}{ Qualidade do óleo } \\
\hline \multicolumn{7}{|l|}{ Tocoferois $(\mathrm{mg} / \mathrm{lo0g})$} \\
\hline Alfa-tocoferol & 1,10 & 1,8687 & 0,2016 & 1,10 & 9,1006 & $\mathbf{0 , 0 1 2 9 7}$ \\
\hline Gama-tocoferol & 1,9 & 7,9871 & $\mathbf{0 , 0 1 7 9 7}$ & 1,9 & 14,775 & 0,00394 \\
\hline \multicolumn{7}{|l|}{ Ácidos graxos (g/lo0g) } \\
\hline Saturados & 1,10 & 15,3150 & 0,002897 & 1,10 & 21,901 & $<0,001$ \\
\hline Monoinsaturados & 1,10 & 0,4508 & 0,5172 & 1,10 & 0,8112 & 0,3889 \\
\hline \multicolumn{7}{|c|}{ Composição em ácidos graxos ( $\mathrm{g} / \mathrm{l00g}$ ) } \\
\hline Linoleico (ômega-6) & 1,10 & 1,0367 & 0,3326 & 1,10 & 1,631 & 0,2304 \\
\hline Oleico (ômega-9) & 1,10 & 0,4568 & 0,5144 & 1,10 & 0,824 & 0,3854 \\
\hline
\end{tabular}


Tabela 2. Relação entre as variáveis de produtividade do girassol e a riqueza, abundância e diversidade de "insetos não-Apis" e "Apis" que visitaram as flores em 2017, no Corredor Cantareira-Mantiqueira, Estado de São Paulo. df: grau de liberdade; F: teste F. Os valores em negrito foram estatisticamente significativos $(\mathrm{p}<0.05)$.

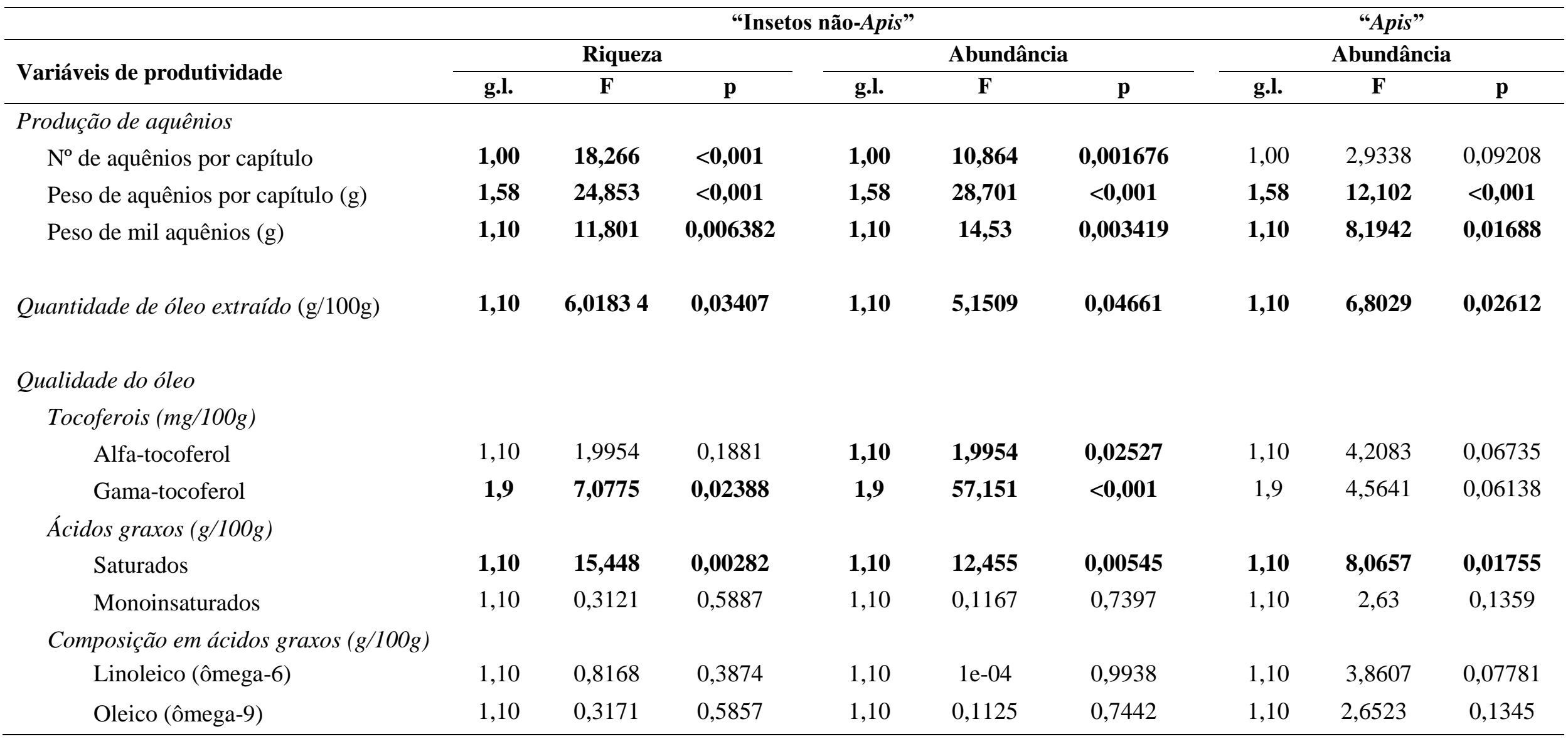



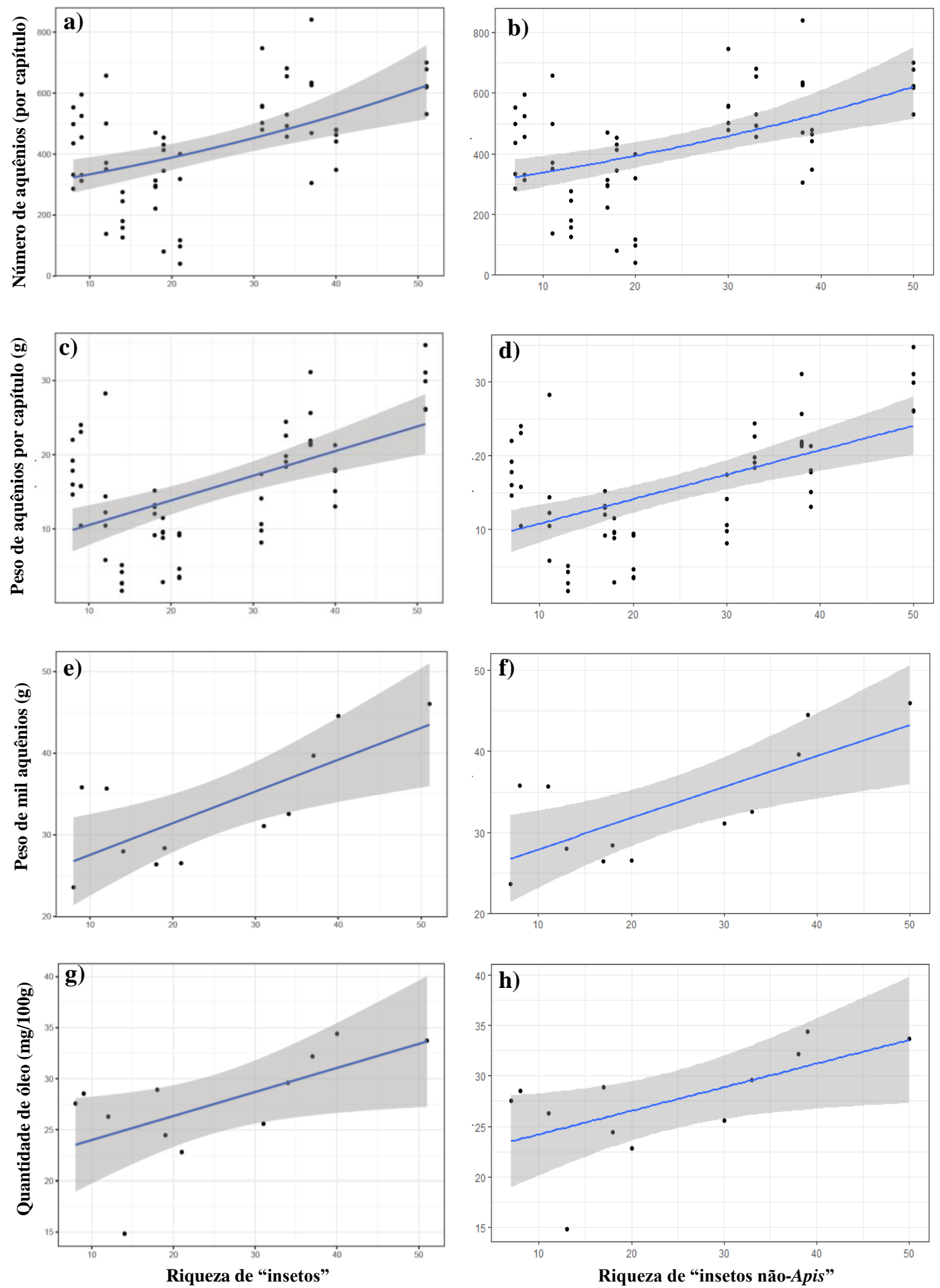

Fig. 5. Relações entre a riqueza de "insetos" (a, c, e, g) e "insetos não-Apis" (b, d, f, h) e o número de aquênios por capítulo (a-b), peso de aquênios por capítulo (c-d), peso de mil aquênios (e-f) e a quantidade de óleo extraído das sementes do girassol (g-h). A linha azul representa a variável resposta média predita do número de aquênios por capítulo, peso de aquênios por capítulo, peso de mil aquênios, quantidade de óleo e a área cinza o intervalo de confiança de $95 \%$ para a média a ser considerada. 

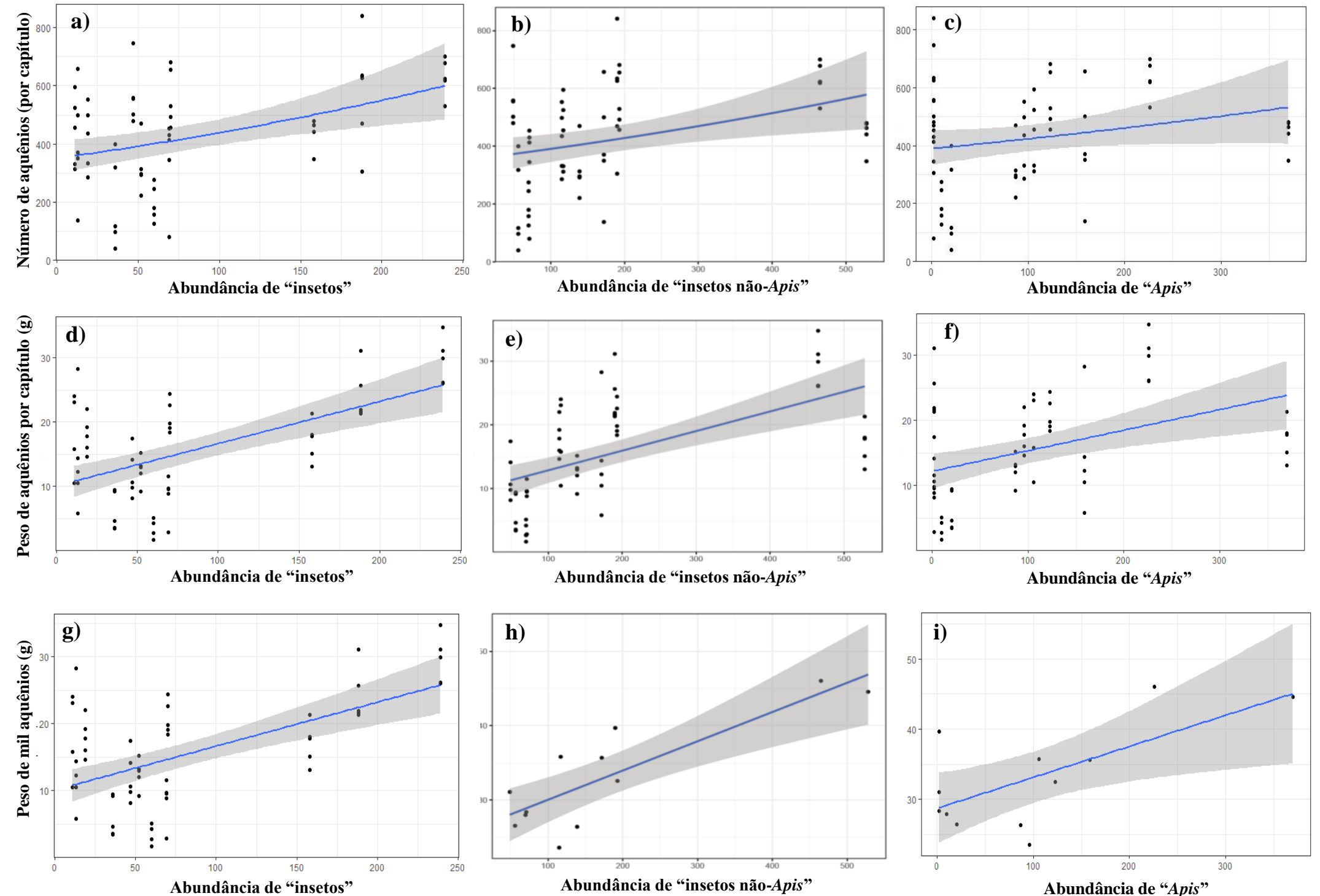

Fig. 6. Relações entre a abundância de "insetos" (a, d, g), "insetos não-Apis" (b, e e h) e "Apis" (c, f, i) e o número de aquênios por capítulo (a-c), peso de aquênios por capítulo (c-e) e de mil aquênios (g-i). Os pontos representam os dados, a linha azul a variável resposta média predita do número de aquênios por capítulo, peso de aquênios por capítulo e peso de mil aquênios, e a área cinza o intervalo de confiança de $95 \%$ para a média a ser considerada. 

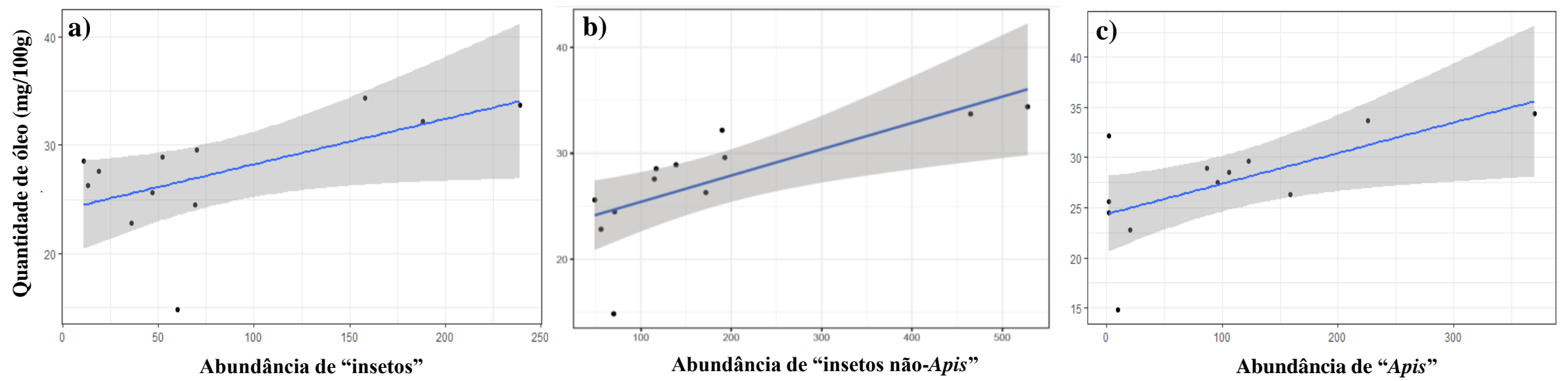

Fig. 7. Relações entre a abundância de "insetos" (a) "insetos não-Apis" (b) e "Apis" (c) e a quantidade de óleo extraído das sementes do girassol (a-c). A linha azul representa a variável resposta média predita da quantidade de óleo e a área cinza o intervalo de confiança de $95 \%$ para a média a ser considerada. 

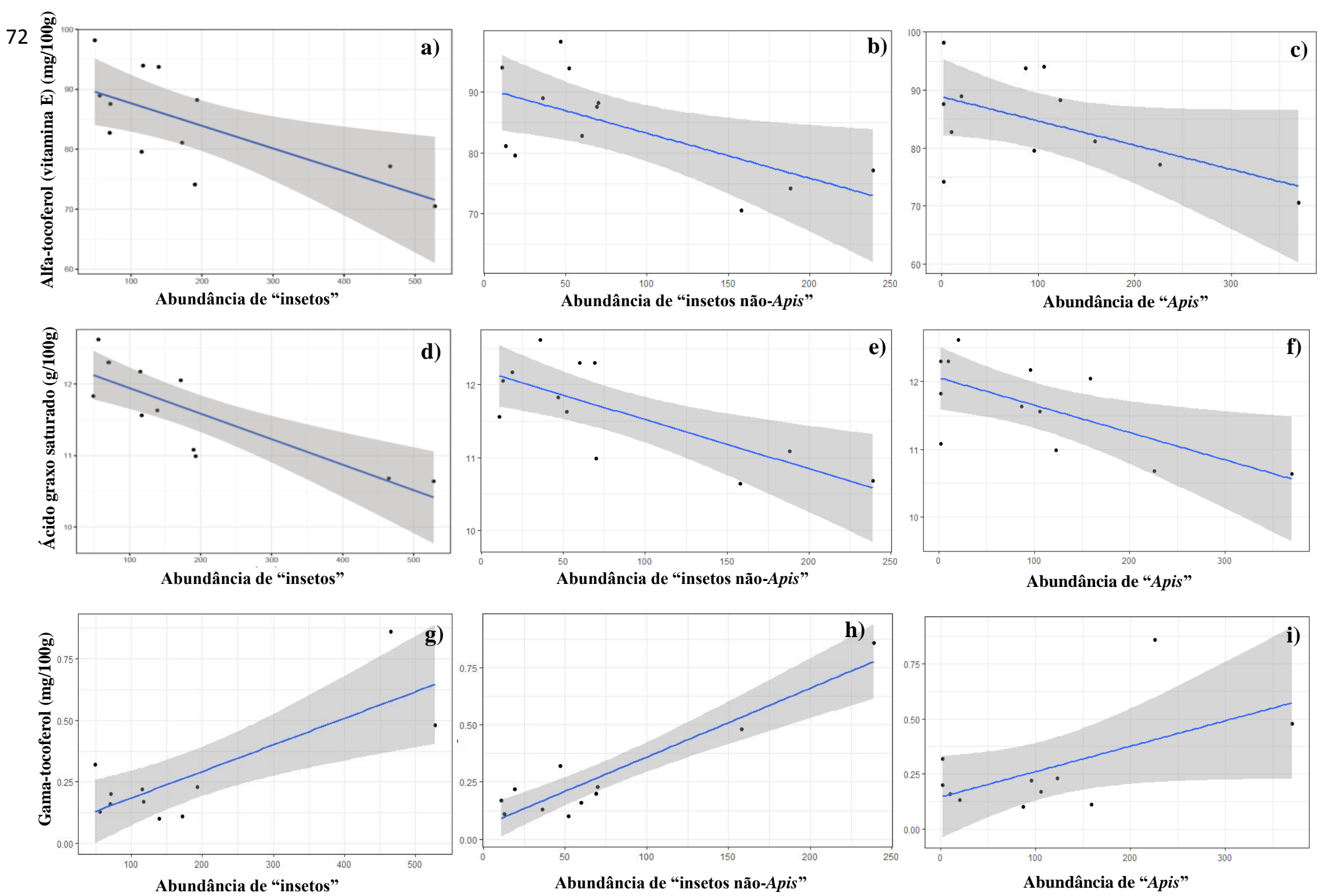

Fig. 8. Relações entre a abundância de "insetos" (a, d, g), "insetos não-Apis" (b, e, h) e "Apis" (c, f, i) e o teor de alfa-tocoferol (a-c), ácido graxo saturado (c-e) e de gama-tocoferol (g-i) no óleo de girassol. A linha azul representa a variável resposta média predita do teor de alfa-tocoferol, ácido graxo saturado e gama-tocoferol, e a área cinza o intervalo de confiança de $95 \%$ para a média a ser considerada. 


\subsection{DISCUSSÃO}

Este estudo mostra importantes resultados para a compreensão da relação da paisagem com a provisão do serviço de polinização pelos insetos. A riqueza de insetos que visitaram as flores do girassol não foi influenciada pela cobertura florestal. Ao contrário do que se presumia, a riqueza de insetos diminuiu com o aumento da cobertura florestal nas áreas de estudo, divergindo da maioria dos estudos que evidencia a importância da heterogeneidade de habitats na manutenção da diversidade de polinizadores, como borboletas (Hambäck et al., 2010), moscas (Ricarte et al., 2011) e abelhas (Steffan-Dewenter et al., 2002; Ricketts, 2004; Zou et $a l ., 2017)$. De maneira geral, já se sabe que fragmentos florestais desempenham importante papel na bioecologia de polinizadores, provendo-lhes habitats adequados para nidificação, reprodução e obtenção de alimentos (Roubik, 1989; Wratten et al., 2012). Há pelo menos duas hipóteses que podem dar suporte à resposta negativa da riqueza de insetos em relação à paisagem estudada: i) as coletas foram realizadas na estação chuvosa e nessa época do ano as plantas nativas da Mata Atlântica têm alta taxa de florescimento (Morellato et al., 2000), ofertando maior quantidade de pólen e/ou néctar aos visitantes forais que residem nos habitats onde os girassóis foram alocados; ii) devido à quantidade de plantas instaladas em cada área de estudo, os girassóis podem não ter sido as fontes de recursos únicas para os insetos nativos, quanto as outras fontes disponíveis nos fragmentos florestais. Contudo, seriam importantes novas avaliações em diferentes escalas espaciais (Perrot et al., 2019), uma vez que as análises foram baseadas apenas na escala da planta (Perrot et al., 2019).

Por outro lado, em áreas com maior abundância, riqueza e diversidade de insetos, a produção de aquênios e óleo de girassol aumentou expressivamente, bem como a sua qualidade. Além da influência na riqueza e abundância dos polinizadores, os habitats também têm efeitos na provisão do serviço de polinização realizada por insetos em diversas culturas agrícolas no Brasil, como café (Coffea arabica: De Marco \& Coelho, 2004; Saturni et al., 2016; Hipólito et al., 2018), caju (Anacardium occidentale: Freitas et al., 2014) e canola (Brassica napus: Witter et al., 2015). Não se observou claramente influência positiva da cobertura florestal sobre o peso de aquênios, pelo contrário, o aumento dessa variável diminuiu a qualidade das sementes avaliadas. Assim como já observado em estudos na Mata Atlântica, paisagens que continham mais habitats semi-naturais de vegetação herbácea também tiveram diminuição no peso do conjunto de sementes de girassol (Bartual et al., 2018). Neste sentido, pode estar havendo um trade-off dos visitantes florais em cultivos agrícolas que possuem habitats (semi-)naturais circundantes. A vegetação natural pode fornecer locais de nidificação e recursos alimentares 
aos polinizadores, aumentando a sua abundância (Wratten et al., 2012). Ela também pode atrair esses organismos quando ocorre o florescimento de espécies de plantas nativas no mesmo período que em plantas cultivadas, diminuindo assim o serviço de polinização nas culturas agrícolas (Bartual et al., 2018).

A riqueza e abundância dos "insetos", assim como a diversidade dos "insetos não-Apis" aumentaram em capítulos de girassóis maiores. Essa escolha em relação ao diâmetro da inflorescência pode estar relacionada ao aumento de recompensa por recursos florais, como néctar e pólen (Neff \& Simpson, 1990; Pisanty et al., 2014). Dentre os visitantes do girassol, as abelhas foram os insetos mais coletados nos capítulos, tanto no que diz respeito à riqueza quanto à abundância, representando $36,9 \%$ e $77,2 \%$, respectivamente em relação ao total. Apis mellifera foi a espécie mais abundante, assim como em outras avaliações (Parker, 1981; Morgado et al., 2002; Greenleaf \& Kremen, 2006; Kasina et al., 2007; Carvalheiro et al., 2011; Pisanty et al., 2014; Hevia et al., 2016; Bartual et al., 2018; Perrot et al., 2019). A alta frequência de A. mellifera nas flores de girassol já era esperada, pois suas colônias contem geralmente milhares de operárias que dependem de pólen e néctar para crescimento e manutenção de suas colônias, já que esses recursos são responsáveis pela quantidade de cria produzida, longevidade e saúde dos adultos (Michener, 1974). Além disso, A. mellifera é uma espécie muito manejada com distribuição cosmopolita em quase todos os continentes do mundo, exceto a Antártida e ilhas oceânicas (Hung et al., 2018).

Diversos estudos comprovaram a eficiência da polinização de A. mellifera no girassol (Degrandi-Hoffman \& Chambers, 2006; Pisanty et al., 2014; Perrot et al., 2019), sugerindo ainda que apenas uma única visita do inseto em flores pode contribuir com até $20 \%$ sobre a produção total de sementes (Pisanty et al., 2014). Pressupõe-se que essa eficácia seja, principalmente, devido ao fato das forrageiras coletarem muito mais néctar que pólen nos girassóis (Pisanty et al., 2014). Esse comportamento de forrageamento acaba beneficiando a polinização cruzada, uma vez que o capítulo é formado por centenas de flores que abrem em sequência, da extremidade para o centro da inflorescência (Free, 1993). Essas flores passam primeiro pela fase masculina, em que liberam pólen, seguida pela feminina, quando se tornam receptivas à fecundação pelo pólen. Assim, as abelhas coletoras de pólen limitam suas visitas às flores na fase masculina, enquanto que forrageadores de néctar visitam todas as flores, polinizando as que estão na fase feminina (Free, 1993). No entanto, nosso estudo mostrou que apesar da presença da A. mellifera influenciar a polinização no híbrido de girassol utilizado, os “insetos não-Apis" contribuíram com o aumento de mais parâmetros de produtividade avaliados 
dessa cultura. É possível que a eficiência no processo de polinização realizada por "insetos não-Apis" no girassol seja em consequência das interações entre diversas espécies amostradas (129 espécies, excluindo a A. mellifera) e dos diferentes comportamentos de forrageamento nos capítulos (Greenleaf \& Kremen, 2006).

A hipótese de que em paisagens com maior riqueza e abundância de "insetos" a produtividade do girassol seria mais expressiva foi confirmada, em relação ao número e peso de aquênios, assim como o teor de óleo. A presença de insetos polinizadores, especialmente as abelhas, já foi relatada como fator de aumento da produção de sementes de girassol em diferentes partes do mundo [África do Sul (Carvalheiro et al., 2011), Estados Unidos (DegrandiHoffman \& Chambers, 2006; Greenleaf \& Kremen, 2006), França (Perrot et al., 2019), Israel (Pisanty et al., 2014) e Itália (Bartual et al., 2018)]. No Brasil, já foi observado acréscimo de $43 \%$ na produção de sementes (Chambó et al., 2011) e 91\% no peso de aquênios (Silva et al., 2018). Além disso, em girassóis que receberam visita de polinizadores, o teor de óleo produzido por suas sementes foi superior quando comparado com aquelas em que visitantes florais não tiveram acesso. Esses resultados são importantes, pois evidenciam a relevância da diversidade de insetos presentes na paisagem e os benefícios da polinização nos híbridos de girassol (Greenleaf \& Kremen, 2006; Carvalheiro et al., 2011; Silva et al., 2018).

Os polinizadores também contribuíram para o incremento do valor nutricional do óleo de girassol. O nível de gama-tocoferol aumentou em áreas mais ricas e abundantes de "insetos" e “insetos não-Apis". Em contraste, o nível de alfa-tocoferol diminuiu. Em capítulos de girassóis polinizados por insetos, houve um complemento de 40,1\% de alfa- e 160\% de gama-tocoferol no óleo extraído das sementes (Silva et al., 2018). Os óleos vegetais são as principais fontes de vitamina E na dieta humana, sendo encontrados nos alimentos na forma de tocoferóis e tocotrienóis, os quais possuem vários isômeros (alfa, beta, delta e gama) (Shahidi \& Camargo, 2016). Embora o alfa-tocoferol seja isômero mais encontrado no girassol, com $93 \%$ (Shahidi \& Camargo, 2016), a forma gama- vem se destacando em diversos estudos, pois além de ação antioxidante, possui também propriedades anti-inflamatórias e anti-tumorais (revisado por Mathur et al., 2015). Em relação aos ácidos graxos, houve redução de gordura saturada no óleo nos três grupos de visitantes florais avaliados. Assim, sabendo que o consumo desse tipo de gordura na dieta aumenta a concentração de colesterol no sangue (veja Raß et al., 2008), a presença de polinizadores proporcionou melhora na qualidade do óleo dessa cultura. A composição de ácidos graxos poli-insaturados, especificamente, o ácido linoleico (ômega-6) e o oleico (ômega-9) não tiveram seus níveis influenciados pela comunidade de "insetos", 
"insetos não-Apis" e "Apis" que visitaram as flores do girassol, assim como observado por Bartual et al. (2018).

Contudo, para que esse serviço de polinização realizado por esses visitantes florais no girassol, em especial das abelhas, sejam mantidos e incrementados, é necessário que os recursos essenciais para sua sobrevivência devem ser manejados e conservados nos campos de cultivo (Imperatriz-Fonseca et al., 2012), como habitats adequados para a construção de ninhos (cavidades arbóreas, bambus, substratos no solo), para obtenção de alimentos (flores que ofertem pólen e/ou néctar) e outros recursos necessários para sobrevivência (água, sombra, óleo, resina, fibras, barro) (Viana et al., 2012). Assim, fica evidente a importância de ações que visem o aumento de investimento de práticas agrícolas que estimulem a presença polinizadores em propriedades rurais, que não só aumentam a renda do agricultor, mas também promovem a melhoria da regulação natural de populações de pragas, a proteção dos mananciais e a fertilidade do solo (Wratten et al., 2012). Dessa forma, se faz necessário compreender que as práticas agrícolas e as medidas de conservação são complementares, e não antagônicas, permitindo que a agricultura se beneficie em ampla escala com o manejo sustentável da biodiversidade e serviços ecossistêmicos (Imperatriz-Fonseca et al., 2012).

Por fim, apesar da importância dos insetos, em especial das abelhas, já ter sido demonstrada em diversas culturas agrícolas (Klein et al., 2007; Garibaldi et al., 2011, 2013; Giannini et al., 2015a), pouco se sabe sobre os efeitos da estrutura da paisagem na provisão do serviço de polinização no girassol, especialmente nos trópicos, visto que é uma espécie de oleaginosa muito cultivada no mundo. Além disso, devido ao aumento da demanda por esse serviço ecossistêmico, principalmente por insetos, são necessárias mais informações sobre a eficiência dos polinizadores e suas contribuições na produtividade de alimentos na dieta humana. Neste sentido, o presente estudo mostrou que apesar da riqueza de insetos no girassol não apresentar relação positiva com a quantidade de habitats (semi-)naturais circundante, a visitação desses agentes foi extremamente importante na produção de aquênios e óleo, assim como na sua qualidade nutricional.

\section{REFERÊNCIAS}

Aizen M, Garibaldi L, Cunningham S, Klein A, 2009. How much does agriculture depend on pollinators? Lessons from long-term trends in crop production. Annals of Botany 103: $1579-1588$.

Aizen M, Harder L, 2009. The global stock of domesticated honey bees is growing slower than agricultural demand for pollination. Current Biology 19: 915-918. 
Barbosa KVC, Knogge C, Develey PF, Jenkins CN, Uezu A, 2017. Use of small Atlantic Forest fragments by birds in Southeast Brazil. Perspectives in Ecology and Conservation 15: $42-46$.

Bates D, Maechler M, Bolker B, Walker S, 2014.Ime4: Linea mixed-effects models using Eigen and S4. R package.

Bartual AM, Bocci G, Marini S, Moonen AC, 2018. Local and landscape factors affect sunflower pollination in a Mediterranean agroecosystem. PLoS ONE 13: e0203990.

Bawa K, 1990. Plant-pollinator interactions in tropical rain forests. Annual Review of Ecology and Systematics 21: 399-422.

BRASIL, 2006. Ministério da Agricultura, Pecuária e Abastecimento. Plano Nacional de Agroenergia: 2006-2011. Informação Tecnológica Embrapa.

BRASIL, 2009. Ministério da Agricultura, Pecuária e Abastecimento. Regras para análise de sementes. $\quad \mathrm{ttp}: / / \mathrm{www}$.agricultura.gov.br/assuntos/insumos-agropecuarios/arquivospublicacoes-insumos/2946_regras_analise_sementes.pdf (accessed 20/07/2015).

Bukovinszky T, Verheijen J, Zwerver S, Klop E, Biesmeijer JC, Wäckers FL, Prins HH, Kleijn D, 2017. Exploring the relationships between landscape complexity, wild bee species richness and reproduction, and pollination services along a complexity gradient in the Netherlands. Biological Conservation 214: 312-319.

Carvalheiro LG, Veldtman R, Shenkute AG, Tesfay GB, Pirk CWW, Donaldson JS, Nicolson SW, 2011. Natural and within-farmland biodiversity enhances crop productivity. Ecology Letters 14: 251-259.

Castro C, Leite RMVBC, 2018. Main aspects of sunflower production in Brazil. Oilseeds \& fats Crops and Lipids 25: D104.

Chambó ED, Garcia RC, Oliveira NTEd, Duarte-Júnior JB, 2011. Honey bee visitation to sunflower: effects on pollination and plant genotype. Scientia Agricola 68: 647-651.

CONAB, 2019. Acompanhamento da safra brasileira de grãos 2018/19 (levantamento mensal $4^{\mathbf{0}}, \mathbf{5}^{\mathbf{0}}, \mathbf{6}^{\mathbf{0}} \mathbf{e ~}^{\mathbf{0}}$ ). https://www.conab.gov.br/info-agro/safras/graos/boletim-da-safrade-graos (accessed 23/04/2019).

Costanza R, d'Arge R, de Groot R, Farber S, Grasso M, Hannon B, Limburg K, Naeem S, ONeill RV, Paruelo J, Raskin RG, Sutton PL, van den Belt M, 1997. The value of the world's ecosystem services and natural capital. Nature 387: 253-260.

Costanza R, de Groot R, Sutton P, van der Ploeg S, Anderson SJ, Kubiszewski I, Farber S, Turner RK, 2014. Changes in the global value of ecosystem services. Global Environmental Change 26: 152-158.

De Marco P, Coelho FM, 2004. Services performed by the ecosystem: forest remnants influence agricultural cultures' pollination and production. Biodiversity and Conservation 13: 1245-1255.

Degrandi-Hoffman G, Chambers M, 2006. Effects of honey bee (Hymenoptera: Apidae) foraging on seed set in self-fertile sunflowers (Helianthus annuus L.). Environmental Entomology 35: 1103-1108. 
FAO/WHO, 2015. Codex Standards for Named Vegetable Oils. CODEX-STAN 210 - 1999 $\begin{array}{llll}\text { (Amended 2005, 2011, 2013, } & \text { 2015). }\end{array}$ http://www.fao.org/docrep/004/y2774e/y2774e04.htm (accessed 21/02/2018).

Free JB, 1993. Insect pollination of crops. Academic Press, London.

Freitas BM, Pacheco Filho AJ, Andrade PB, Lemos CQ, Rocha EE, Pereira NO, Bezerra AD, Nogueira DS, Alencar RL, Rocha RF, 2014. Forest remnants enhance wild pollinator visits to cashew flowers and mitigate pollination deficit in NE Brazil. Journal of Pollination Ecology 12.

Garibaldi LA, Steffan-Dewenter I, Kremen C, Morales JM, Bommarco R, Cunningham SA, Carvalheiro LG, Chacoff NP, Dudenhoeffer JH, Greenleaf SS, 2011. Stability of pollination services decreases with isolation from natural areas despite honey bee visits. Ecology Letters 14: 1062-1072.

Garibaldi LA, et al., 2013. Wild pollinators enhance fruit set of crops regardless of honey bee abundance. Science 339: 1608-1611.

Giannini TC, Boff S, Cordeiro GD, Cartolano Jr EA, Veiga AK, Imperatriz-Fonseca VL, Saraiva AM, 2015a. Crop pollinators in Brazil: a review of reported interactions. Apidologie 46: 209-223.

Giannini TC, Cordeiro GD, Freitas BM, Saraiva AM, Imperatriz-Fonseca VL, 2015b. The dependence of crops for pollinators and the economic value of pollination in Brazil. Journal of Economic Entomology 108: 849-857.

González-Varo JP, Biesmeijer JC, Bommarco R, Potts SG, Schweiger O, Smith HG, SteffanDewenter I, Szentgyörgyi H, Woyciechowski M, Vilà M, 2013. Combined effects of global change pressures on animal-mediated pollination. Trends in Ecology \& Evolution 28: 524-530.

Greenleaf SS, Kremen C, 2006. Wild bees enhance honey bees' pollination of hybrid sunflower. Proceedings of the National Academy of Sciences, USA 103: 13890-13895.

Hambäck PA, Bergman KO, Bommarco R, Krauss J, Kuussaari M, Pöyry J, Öckinger E, 2010. Allometric density responses in butterflies: the response to small and large patches by small and large species. Ecography 33: 1149-1156.

Hevia V, Bosch J, Azcárate FM, Fernández E, Rodrigo A, Barril-Graells H, González JA, 2016. Bee diversity and abundance in a livestock drove road and its impact on pollination and seed set in adjacent sunflower fields. Agriculture, Ecosystems \& Environment 232: 336344.

Hipólito J, Boscolo D, Viana BF, 2018. Landscape and crop management strategies to conserve pollination services and increase yields in tropical coffee farms. Agriculture, Ecosystems \& Environment 256: 218-225.

Hung K-LJ, Kingston JM, Albrecht M, Holway DA, Kohn JR., 2018 The worldwide importance of honey bees as pollinators in natural habitats. Proceedings of the Royal Society B 285: 20172140.

Kasina M, Nderitu J, Nyamasyo G, Oronje M, 2007. Sunflower pollinators in Kenya: Does diversity influence seed yield? African Crop Science Conference Proceedings 8: 11491153.

Kennedy CM, et al., 2013. A global quantitative synthesis of local and landscape effects on wild bee pollinators in agroecosystems. Ecology Letters 16: 584-599. 
Klein AM, Vaissière BE, Cane JH, Steffan-Dewenter I, Cunningham SA, Kremen C, Tscharntke T, 2007. Importance of pollinators in changing landscapes for world crops. Proceedings of the Royal Society B 274: 303-313.

Mathur P, Ding Z, Saldeen T, Mehta JL, 2015. Tocopherols in the prevention and treatment of atherosclerosis and related cardiovascular disease. Clinical Cardiology 38: 570-576.

Michener CD, 1974. The social behavior of the bees: a comparative study. Belknap Press of Harvard University Press, Massachusetts.

Moral RA, Hinde J, Demetrio CGB, 2014. Hnp: Half-Normal Plots with Simulation Envelopes. R packages.

Morellato LPC, Talora DC, Takahasi A, Bencke CC, Romera EC, Zipparro VB, 2000. Phenology of Atlantic rain forest trees: a comparative study. Biotropica 32: 811-823.

Morgado LN, Carvalho CF, Souza B, Santana MP, 2002. Fauna de abelhas (Hymenoptera: Apoidea) nas flores de girassol Helianthus annuus L. Ciencia e Agrotecnologia 26: 1167 1177.

Neff JL, Simpson BB, 1990. The roles of phenology and reward structure in the pollination biology of wild sunflower (Helianthus annuus L., Asteraceae). Israel Journal of Plant Sciences 39: 197-216.

Oksanen O, Blanchet FG, Kindt R, Legendre P, Minchin PR, O'Hara RB, Simpson GL, Solymos P, Stevens MHH, Wagner H, 2016. Vegan: Community Ecology Package. R Package.

Parker FD, 1981. Sunflower pollination: abundance, diversity and seasonality of bees and their effect on seed yields. Journal of Apicultural Research 20: 49-61.

Perrot T, Gaba S, Roncoroni M, Gautier J-L, Saintilan A, Bretagnolle V, 2019. Experimental quantification of insect pollination on sunflower yield, reconciling plant and field scale estimates. Basic and Applied Ecology 34: 75-84.

Pisanty G, Klein A-M, Mandelik Y, 2014. Do wild bees complement honeybee pollination of confection sunflowers in Israel? Apidologie 45: 235-247.

Potts SG, Imperatriz-Fonseca VL, Ngo HT, Aizen MA, Biesmeijer JC, Breeze TD, Dicks LV, Garibaldi LA, Hill R, Settele J, Vanbergen AJ, 2016. Safeguarding pollinators and their values to human well-being. Nature 540: 220-229.

Raß M, Schein C, Matthäus B, 2008. Virgin sunflower oil. European Journal of Lipid Science and Technology 110: 618-624.

Ricarte A, Marcos-García MÁ, Moreno CE, 2011. Assessing the effects of vegetation type on hoverfly (Diptera: Syrphidae) diversity in a Mediterranean landscape: implications for conservation. Journal of Insect Conservation 15: 865-877.

Ricketts TH, 2004. Tropical forest fragments enhance pollinator activity in nearby coffee crops. Conservation Biology 18: 1262-1271.

Ricketts TH, Regetz J, Steffan-Dewenter I, Cunningham SA, Kremen C, Bogdanski A, Gemmill-Herren B, Greenleaf SS, Klein AM, Mayfield MM, Morandin LA, Ochieng A, Viana BF, 2008. Landscape effects on crop pollination services: are there general patterns? Ecology Letters 11: 499-515.

Roubik DW, 1989. Ecology and natural history of tropical bees. Cambridge University Press, Cambridge. 
Saturni FT, Jaffé R, Metzger JP, 2016. Landscape structure influences bee community and coffee pollination at different spatial scales. Agriculture, Ecosystems \& Environment 235: $1-12$.

Shahidi F, Camargo A, 2016. Tocopherols and tocotrienols in common and emerging dietary sources: Occurrence, applications, and health benefits. International journal of molecular sciences 17: 1745 .

Silva CA, Godoy WA, Jacob CR, Thomas G, Câmara GM, Alves DA, 2018. Bee pollination highly improves oil quality in sunflower. Sociobiology 65: 583-590.

Steffan-Dewenter I, Munzenberg U, Burger C, Thies C, Tscharntke T, 2002. Scale-dependent effects of landscape context on three pollinator guilds. Ecology 83: 1421-1432.

Tscharntke T, Klein A, Kruess A, Steffan-Dewenter I, Thies C, 2005. Landscape perspectives on agricultural intensification and biodiversity-ecosystem service management. Ecology Letters 8: 857-874.

Whately M, Cunha P, 2007. Cantareira 2006: um olhar sobre o maior manancial de água da Região Metropolitana de São Paulo. São Paulo: Instituto Socioambiental. https://www.socioambiental.org/banco_imagens/pdfs/10289.pdf (accessed 23/04/2019).

Wickham H, 2009. Ggplot2: Elegant Graphics for Data Analysis. Springer, New York.

Winfree R, 2010. The conservation and restoration of wild bees. Annals of the New York Academy of Sciences 1195: 169-197.

Winfree R, Aguilar R, Vázquez D, LeBuhn G, Aizen M, 2009. A meta-analysis of bees' responses to anthropogenic disturbance. Ecology 90: 2068-2076.

Witter S, Nunes-Silva P, Lisboa BB, Tirelli FP, Sattler A, Hilgert-Moreira SB, Blochtein B, 2015. Stingless bees as alternative pollinators of canola. Journal of Economic Entomology 108: 880-886.

Wratten SD, Gillespie M, Decourtye A, Mader E, Desneux N, 2012. Pollinator habitat enhancement: benefits to other ecosystem services. Agriculture, Ecosystems \& Environment 159: 112-122.

Zou Y, Bianchi FJ, Jauker F, Xiao H, Chen J, Cresswell J, Luo S, Huang J, Deng X, Hou L, 2017. Landscape effects on pollinator communities and pollination services in small-holder agroecosystems. Agriculture, ecosystems \& environment 246: 109-116.

Zurbuchen A, Landert L, Klaiber J, Müller A, Hein S, Dorn S, 2010. Maximum foraging ranges in solitary bees: only few individuals have the capability to cover long foraging distances. Biological Conservation 143: 669-676. 


\section{CONSIDERAÇÕES FINAIS}

Este estudo mostra que a riqueza de visitantes florais no girassol aumentou em áreas com menor porcentagem de floresta. Assim, sugere-se que mesmo a Mata Atlântica sendo fortemente afetada pelo processo de fragmentação e desmatamento pode estar havendo uma adaptação na comunidade de visitantes florais em ambientes degradados, uma vez que as espécies mais amostradas (A. mellifera e $T$. spinipes) são generalistas e importantes polinizadores de plantas em paisagens mais simples e desfavoráveis a outras espécies. No entanto, é necessário ter cautela ao interpretar esses dados, visto que diversos fatores podem estar relacionados a esses resultados, como a qualidade dos habitats, traços comportamentais das espécies amostradas e quantidade de recursos alimentares ofertados aos visitantes florais neste estudo.

Foi confirmado a expressiva dependência da polinização cruzada provida pelos insetos na produtividade do girassol, até mesmo em cultivar híbrido. Ficou evidente que quanto maior a riqueza e abundância de insetos, maior também é à produção de aquênios, peso das sementes e quantidade do óleo. Além disso, a visitação de insetos aumentou a qualidade do óleo, em relação aos teores de vitamina $\mathrm{E}$ e ácidos graxos saturados. Contudo, para que a manutenção desse serviço de polinização continue acessível para essa cultura, o agricultor deverá realizar medidas de preservação e manejo que assegurem a sobrevivência dos polinizadores. Embora o objetivo principal das medidas de manejo seja aumentar a aptidão ecológica dos polinizadores, através do aumento de suas populações, tais estratégias também fornecem benefícios secundários para a propriedade rural e para paisagem do entorno. A conservação de habitats para polinizadores aumenta a biodiversidade global e seus serviços ecossistêmicos (incluindo o aumento de inimigos naturais de pragas), protege o solo contra erosão, a qualidade de corpos de água e melhora a estética da propriedade rural.

Neste sentido, é de alta relevância estudos como este, que apresentou dados inéditos e pioneiro no Brasil, pois forneceu informações sobre a provisão do serviço de polinização realizado por insetos em uma das oleaginosas mais cultivadas no mundo. Assim, espera-se que os resultados aqui apresentados contribuíam para desenvolvimento de políticas públicas que conservem e preservem a populações de polinizadores, especialmente na região tropical, uma vez que a polinização biótica influencia em $70 \%$ na produtividade de frutas e sementes nos trópicos. Além disso, o serviço de polinização provido por esses organismos é muito importante para a produção de alimento e a segurança alimentar dos humanos. 


\section{ANEXOS}

Anexo A. Áreas de estudo, porcentagem total de cobertura florestal da Mata Atlântica, heterogeneidade espacial (Shannon do uso e ocupação do solo).

\begin{tabular}{cccccc}
\hline Munícipios & Área & $\begin{array}{c}\text { Cobertura } \\
\text { florestal }(\%)\end{array}$ & $\begin{array}{c}\text { Heterogeneidade } \\
\text { (Shannon) }\end{array}$ & $\begin{array}{c}\text { Temperatura } \\
\text { (mín - máx) }\end{array}$ & $\begin{array}{c}\text { Umidade Relativa } \\
\text { (mín - máx) }\end{array}$ \\
\hline Piracaia & A1 & 13,27 & 2,03875 & $19,4-28,4$ & $68,5-95,2$ \\
Atibaia & A2 & 19,92 & 2,02848 & $21,0-35,8$ & $59,5-92,7$ \\
Santa Isabel & A3 & 35,84 & 2,05735 & $19,0-31,0$ & $62,4-97,3$ \\
Bom Jesus dos Perdões & A4 & 38,63 & 1,78777 & $17,5-34,3$ & $48,9-90,4$ \\
Bragança Paulista & A5 & 43,48 & 1,52256 & $16,5-35,6$ & $86,0-49,0$ \\
Santa Isabel & A6 & 45,30 & 1,73039 & $18,6-32,0$ & $61,5-96,3$ \\
Nazaré Paulista & A7 & 47,39 & 1,81912 & $19,0-23,6$ & $83,6-94,1$ \\
Nazaré Paulista & A8 & 48,66 & 1,27015 & $19,7-29,5$ & $69,0-98,3$ \\
Mairiporã & A9 & 49,17 & 2,13932 & $17,5-23,7$ & $66,9-89,6$ \\
Nazaré paulista & A10 & 56,52 & 1,82860 & $19,4-31,0$ & $61,9-96,4$ \\
Atibaia & A11 & 57,45 & 1,63092 & $23,1-35,7$ & $39,0-85,2$ \\
Jarinu & A12 & 60,67 & 2,35331 & $19,5-30,4$ & $30,4-92,3$ \\
\hline
\end{tabular}


Anexo B. Número de indivíduos, espécies, gêneros, famílias e ordens de insetos amostrados nas flores de girassol em 12 áreas do Corredor Cantareira-Mantiqueira, Estado de São Paulo, em 2017.

\begin{tabular}{|c|c|c|c|}
\hline Ordem & Família & Espécie/Gênero/Família & $\begin{array}{c}\mathrm{N}^{\mathbf{0}} \text { de } \\
\text { indivíduos }\end{array}$ \\
\hline \multirow[t]{42}{*}{ Hymenoptera } & Andrenidae & Acamptopoeum prinii (Holmberg, 1884) & 1 \\
\hline & & Rhophitulus sp. & 1 \\
\hline & Apidae & Apidae sp. & 1 \\
\hline & & Apis mellifera Linnaeus, 1758 & 1203 \\
\hline & & Bombus (Fervidobombus) brasiliensis Lepeletier, 1836 & 1 \\
\hline & & Bombus (Fervidobombus) pauloensis Friese, 1913 & 3 \\
\hline & & Ceratina sp. 1 & 1 \\
\hline & & Ceratina sp. 2 & 1 \\
\hline & & Melissodes (Ecplectica) nigroaenea (Smith, 1854) & 2 \\
\hline & & Melissoptila paraguayensis (Brèthes, 1909) & 2 \\
\hline & & Melissoptila paranaensis Urban, 1998 & 1 \\
\hline & & Melissoptila richardiae Bertoni \& Schrottky, 1910 & 5 \\
\hline & & Melissoptila similis Urban, 1988 & 1 \\
\hline & & Melissoptila sp. & 1 \\
\hline & & Euglossa (Glossura) annectans Dressler, 1982 & 3 \\
\hline & & Exomalopsis (Exomalopsis) auropilosa Spinola, 1853 & 6 \\
\hline & & Exomalopsis (Exomalopsis) fulvofasciata Smith, 1879 & 1 \\
\hline & & Geotrigona subterranea $($ Friese, 1901) & 5 \\
\hline & & Melipona (Eomelipona) marginata Lepeletier, 1836 & 1 \\
\hline & & Melipona (Melipona) quadrifasciata Lepeletier, 1836 & 10 \\
\hline & & Nannotrigona testaceicornis (Lepeletier, 1836) & 2 \\
\hline & & Paratrigona subnuda Moure, 1947 & 7 \\
\hline & & Plebeia droryana (Friese, 1900) & 28 \\
\hline & & Plebeia remota (Holmberg, 1903) & 3 \\
\hline & & Tetragona clavipes (Fabricius, 1804) & 11 \\
\hline & & Tetragonisca angustula (Latreille, 1811) & 2 \\
\hline & & Trigona braueri Friese, 1900 & 7 \\
\hline & & Trigona fuscipennis Friese, 1900 & 4 \\
\hline & & Trigona spinipes Fabricius, 1793 & 115 \\
\hline & & Xylocopa (Neoxylocopa) brasilianorum (Linnaeus, 1767) & 6 \\
\hline & & Xylocopa (Neoxylocopa) frontalis (Olivier, 1789) & 17 \\
\hline & & Xylocopa sp. & 1 \\
\hline & Halictidae & Augochlora (Augochlora) cf. amphitrite (Schrottky, 1909) & 9 \\
\hline & & Augochlora (Augochlora) esox (Vachal, 1911) & 12 \\
\hline & & Augochlora (Augochlora) foxiana Cockerell, 1900 & 2 \\
\hline & & Augochlora (Oxystoglossella) morrae Strand, 1910 & 91 \\
\hline & & Augochlora sp. 1 & 8 \\
\hline & & Augochlora sp. 2 & 1 \\
\hline & & Augochlora (Oxystoglossella) cf. thalia Smith, 1879 & 47 \\
\hline & & Augochloropsis electra (Smith, 1853) & 1 \\
\hline & & Neocorynura codion (Vachal, 1904) & 24 \\
\hline & & Dialictus creusa (Schrottky, 1910) & 11 \\
\hline
\end{tabular}


Dialictus picadensis (Strand, 1910) 6

Dialictus sp.

Megachilidae Megachile (Moureapis) cf. benigna Mitchell, 1930 13

Megachile (Grafella) crotalariae (Schwimmer, 1980) 2

Megachile (Austromegachile) cf. giraffa Schrottky, 1913

Megachile (Sayapis) sp. 2

Vespidae Polistes cavapyta Saussure, 1853

Polistes simillimus Zikán, 1951

Polistes versicolor (Olivier) 1

Polybia scutellaris (Write, 1841) 1

Polybia occidentalis (Olivier, 1791) 1

Chartergus sp. 2

Mischocyttarus sp. 1

Sphecidae $\quad$ Sphecidae sp. 1

Chalcididae Chalcididae spp. 2

$\begin{array}{ll}\text { Formicidae } & \text { Formicidae sp. }\end{array}$

Hoplocrates cephalotes $\quad 1$

Lepidoptera Arctiidae $\quad$ Philorus rubriceps (Walk., 1854) 1

Hesperiidae Callimormus corades 1

Hesperinae sp. 4

Hylephila phyleus (Drury, 1773) 1

Mimoniades versicolor (Latreille, [1824]) 1

Polites vibex (Geyer, 1832) 1

Nymphalidae Actinote sp. 1

Hypanartia bella (Fabricius, 1793) 1

Sesiidae Sesiidae sp. $\quad 1$

Sphingidae $\quad$ Protambulyx strigilis (Linnaeus, 1771) 1

Sphingidae sp. $\quad 4$

Orthoptera sp. 4

Acrididae Dichroplus elongatus 1

Aethalionidae Aethalion reticulatum (Linnaeus, 1767) 4

Cicadellidae Aulacizes conspersa Walker, 1851b:792 1

Cicadellinae sp.

Macugonalia leucomelas Walker, 1851b:764 1

Neocoelidia crenulata Osborn 1923

Oncometopia facialis 2

Oncometopia sp. 2

Teletusa limpida (Signoret, 1855) 2

Xerophloea viridis (Fabricius, 1794) 1

Membracidae Cyphonia sp. 1

Enchenopa monocera (Germ., 1821) 1

Entylia gemmata (Germar, 1818) 1

Hemikyptha punctata Fabricius 1775

Lygaeidae Lygaeidae sp. 1

Xyonisius major $\quad 65$

Reduviidae $\quad$ Reduviidae sp.

Zelus sp. 1

Pentatomidae $\quad$ Cyrtocoris gibbus (Fabricius, 1803) 1

Podisus sp. 


\begin{tabular}{|c|c|c|c|}
\hline & & Thyanta perditor (Fabricius, 1794) & 2 \\
\hline & Coreidae & Camptischium clavipes Fabricius, 1803 & 1 \\
\hline & & Leptoglossus zonatus Dallas, 1852 & 2 \\
\hline & Miridae & Dagbertus sp. & 1 \\
\hline & Geocoridae & Geocoris sp. & 2 \\
\hline & & Geocoridae sp. & 4 \\
\hline Diptera & & Diptera sp. & 11 \\
\hline & Syrphidae & Allograpta hastata Fluke, 1942 & 7 \\
\hline & & Palpada expicta & 7 \\
\hline & & Palpada sp. & 2 \\
\hline & & Salpingogaster nigra & 1 \\
\hline & & Syrphidae sp. & 4 \\
\hline & Calliphoridae & Lucilia eximia (Wiedemann, 1819) & 1 \\
\hline & Drosophilidae & Drosophilidae sp. & 39 \\
\hline & Sarcophagidae & Sarcophagidae sp. & 15 \\
\hline & Tachinidae & Tachinidae sp. & 4 \\
\hline & Bombyliidae & Bombyliidae sp. & 1 \\
\hline & Muscidae & Muscidae sp. & 8 \\
\hline & Asilidae & Asilidae spp. & 5 \\
\hline Coleoptera & Tenebrionidae & Lagria villosa (Fabricius 1783) & 1 \\
\hline & & Lystronychus coeruleus Solier, 1835 & 1 \\
\hline & & Strongylium haemorrhoidale (Fabricius, 1782) & 2 \\
\hline & Coccinellidae & Eriopis connexa (Germar, 1824) & 1 \\
\hline & & Harmonia axyridis (Pallas, 1773) & 1 \\
\hline & Chrysomelidae & Diabrotica rufolimbata (Baly, 1890) & 1 \\
\hline & & Diabrotica speciosa (Germar, 1824) & 136 \\
\hline & & Galerucinae sp. & 1 \\
\hline & & Maecolaspis occidentalis Linne, 1758 & 2 \\
\hline & & Chrysomelidae sp. & 24 \\
\hline & Cetoniidae & Euphoria lurida (Fabricius, 1775) & 10 \\
\hline & Scarabaeidae & Isonychus sp. & 4 \\
\hline & Elateridae & Conoderus fuscofasciatus (Eschscholtz, 1829) & 2 \\
\hline & & Conoderus malleatus (Germar, 1824) & 1 \\
\hline & & Conoderus spp. & 1 \\
\hline & & Conoderus spp. 2 & 1 \\
\hline & Curculionidae & Curculionidae sp. & 3 \\
\hline & Cantharidae & Paramaronius sp. & 1 \\
\hline & Lampyridae & Photinus sp. & 2 \\
\hline Total & & & 2.181 \\
\hline
\end{tabular}


Anexo C. Composição nutricional do óleo extraído de sementes de girassol amostrados em 12 áreas do Corredor Cantareira-Mantiqueira, Estado de São Paulo.

\begin{tabular}{|c|c|c|c|c|c|c|c|c|c|c|c|c|}
\hline \multirow{2}{*}{$\begin{array}{l}\text { Componentes } \\
\text { Tocoferóis }(\mathrm{mg} / \mathrm{lo0g})\end{array}$} & \multicolumn{12}{|c|}{ Unidades amostrais (vide detalhes no Anexo A) } \\
\hline & $A 1$ & $A 2$ & $A 3$ & $A 4$ & $A 5$ & A6 & A7 & $A 8$ & A9 & $A 10$ & $A 11$ & $A 12$ \\
\hline Alfa-tocoferol & 79,58 & 77,16 & 88,96 & 70,51 & 74,13 & 87,57 & 82,75 & 81,1 & 93,96 & 93,74 & 98,18 & 88,21 \\
\hline Beta-tocoferol & 1,15 & 1,3 & 0,53 & 1,01 & 1,04 & 1,06 & 0,59 & 1,09 & 2,56 & 2,38 & 1,17 & 1,32 \\
\hline Gama-tocoferol & 0,22 & 0,86 & 0,13 & 0,48 & 0.0 & 0,201 & 0,16 & 0,11 & 0,17 & 0,1 & 0,32 & 0,23 \\
\hline \multicolumn{13}{|l|}{ Ácidos graxos $(\mathrm{g} / 100 \mathrm{~g})$} \\
\hline Saturados & 12,17 & 10,68 & 12,64 & 10,64 & 11,08 & 12,3 & 12,3 & 12,05 & 11,56 & 11,63 & 11,83 & 10,99 \\
\hline Monoinsaturados & 40,6 & 32,56 & 38,03 & 33,39 & 49,86 & 41,14 & 39,74 & 36,56 & 36,64 & 32,4 & 30,74 & 32,56 \\
\hline Poli-insaturados & 41,84 & 51,56 & 43,99 & 51,19 & 34,16 & 41,12 & 42,69 & 46,39 & 46,63 & 50,77 & 52,76 & 50,9 \\
\hline \multicolumn{13}{|c|}{ Composição de ácidos graxos $(\mathrm{g} / \mathrm{l} 100 \mathrm{~g})$} \\
\hline Palmítico & 5,41 & 5,56 & 5,63 & 5,35 & 4,57 & 5,33 & 5,2 & 5,27 & 5,45 & 5,74 & 5,55 & 5,31 \\
\hline Palmitoleico (ômega-7) & 0,09 & 0,12 & 0,00 & 0,11 & 0,07 & 0,09 & 0,08 & 0,09 & 0,10 & 0,113 & 0,10 & 0,10 \\
\hline Esteárico & 4,47 & 3,42 & 4,78 & 3,59 & 4,50 & 4,82 & 4,82 & 4,62 & 4,18 & 3,90 & 4,18 & 3,80 \\
\hline Oleico (ômega-9) & 40,37 & 32,31 & 37,88 & 33,14 & 49,65 & 40,92 & 39,54 & 36,35 & 36,41 & 32,15 & 30,5 & 32,32 \\
\hline Linoleico (ômega-6) & 41,84 & 51,47 & 43,99 & 51,13 & 34,16 & 41,12 & 42,6 & 46,32 & 46,63 & 50,71 & 52,68 & 50,9 \\
\hline Linolênico (ômega-3) & 0,00 & 0,09 & 0,00 & 0,07 & 0,00 & 0,00 & 0,10 & 0,07 & 0,00 & 0,07 & 0,09 & 0,00 \\
\hline Araquídico & 0,44 & 0,32 & 0,50 & 0,34 & 0,38 & 0,44 & 0,50 & 0,45 & 0,39 & 0,39 & 0,43 & 0,35 \\
\hline Behênico & 1,20 & 0,83 & 1,24 & 0,94 & 1,14 & 1,19 & 1,16 & 1,21 & 1,06 & 0,98 & 1,14 & 0,98 \\
\hline Lignocérico & 0,57 & 0,46 & 0,49 & 0,34 & 0,49 & 0,53 & 0,55 & 0,43 & 0,41 & 0,55 & 0,53 & 0,55 \\
\hline
\end{tabular}

